\begin{abstract}
UNIVERSIDADE DE SÃO PAULO
ESCOLA DE ARTES, CIÊNCIAS E HUMANIDADES

PROGRAMA DE PÓS-GRADUAÇÃO EM TÊXTIL E MODA
\end{abstract}

CRISTINA SALETE VALENTIN

Projeto Com-test:

estudo de características dos tecidos relacionadas com o conforto térmico de vestimentas destinadas à proteção de riscos de origem térmica

São Paulo 


\section{Projeto Com-test: \\ estudo de características dos tecidos relacionadas com o conforto térmico de vestimentas destinadas à proteção de riscos de origem térmica}

Versão corrigida

Dissertação apresentada à Escola de Artes, Ciências e Humanidades da Universidade de São Paulo para obtenção do título de Mestre

Versão corrigida contendo as alterações solicitadas pela comissão julgadora no dia 17 de Novembro de 2015. A versão original encontra-se em acervo reservado da EACH/USP e na Biblioteca Digital de Teses e Dissertações da USP (BDTD), de acordo com a resolução CoPGr 6018, de 13 de Outubro de 2011.

Área de Concentração:

Têxtil e Moda

Orientador: Prof ${ }^{a}$. Dr ${ }^{a}$. Regina Aparecida Sanches

\section{São Paulo}


Autorizo a reprodução e divulgação total ou parcial deste trabalho, por qualquer meio convencional ou eletrônico, para fins de estudo e pesquisa, desde que citada a fonte.

CATALOGAÇÃO-NA-PUBLICAÇÃO

(Universidade de São Paulo. Escola de Artes, Ciências e Humanidades. Biblioteca)

Valentin, Cristina Salete

Projeto Com-test: estudo de características dos tecidos relacionadas com o conforto térmico de vestimentas destinadas à proteção de riscos de origem térmica / Cristina Salete Valentin ; orientadora, Regina Aparecida Sanches. - São Paulo, 2015

$113 \mathrm{f}$.

Dissertação (Mestrado em Ciências) - Programa de PósGraduação em Têxtil e Moda, Escola de Artes, Ciências e Humanidades, Universidade de São Paulo

Versão corrigida

1. Tecnologia têxtil. 2. Vestuário - Fabricação - Propriedades térmicas. 3. Conforto térmico. I. Sanches, Regina Aparecida, orient. II. Título.

CDD 22.ed. - 677 
Dissertação de autoria de Cristina Salete Valentin, sob o título "Projeto Com-test: estudo de características dos tecidos relacionadas com o conforto térmico de vestimentas destinadas à proteção de riscos de origem térmica", apresentada à Escola de Artes, Ciências e Humanidades da Universidade de São Paulo, para obtenção do título de Mestre pelo Programa de Pós-graduação em Têxtil e Moda, aprovada em 17 de Novembro de 2015 pela comissão julgadora constituída pelos doutores:

Prof. Dr(a).___ Regina Aparecida Sanches

Presidente

Instituição: Universidade de São Paulo - Escola de Artes, Ciências e Humanidades

Prof. Dr(a).__ João Paulo Pereira Marcicano

Instituição: Universidade de São Paulo - Escola de Artes, Ciências e Humanidades

Prof. Dr(a). __ Ana Cristina da Luz Broega

Instituição: __Universidade do Minho 
Dedico este trabalho a minha família. 


\section{Agradecimentos}

À minha orientadora, Prof. ${ }^{a}$ Dr. $^{a}$ Regina Aparecida Sanches, pela orientação e apoio no desenvolvimento deste trabalho.

Ao Carlos Martin Gutierrez, pelo incentivo e concessão de materiais utilizados neste trabalho.

Ao Sr. João Ferreira, pelo apoio na concessão de material experimental para a realização do trabalho.

Ao meu amigo Willian Alves, que me recomendou e através do qual tive a chance de conhecer essa oportunidade.

O meu agradecimento especial à minha mãe, por me aguentar tanto tempo isolada e somente dedicada a esse trabalho, bem como pelo incentivo, muito obrigada. 
VALENTIN, Cristina Salete. Projeto Com-test: estudo de características dos tecidos relacionadas com o conforto térmico de vestimentas destinadas á proteção de riscos de origem térmica. 2016. 113 f. Dissertação (Mestrado em Têxtil e Moda) - Escola de Artes, Ciências e Humanidades, Universidade de São Paulo, São Paulo, 2015. Versão corrigida.

\section{Resumo}

Em função de uma forte e crescente demanda do mercado consumidor de vestuário de proteção por maior conforto, considerando entre outros aspectos o fato que o conforto interfere no uso e proteção, aliado ao fato do Brasil ter clima predominantemente quente e úmido, e a inexistência de trabalhos e estudos referentes ao tema na área, este trabalho objetivou realizar um estudo das características relacionadas ao conforto, dos têxteis, (tecidos), utilizados nas vestimentas destinadas à proteção frente a riscos de origem térmica (calor e fogo) no mercado brasileiro. Após a seleção de onze produtos como objeto de estudo da pesquisa, realizou-se ensaios de transporte de umidade em tecidos, resistência ao vapor de água, ensaios de conforto físico e ergonômico (ensaio de massa laminar e Kawabata Evalution System (KES), e o Termo Labo II para avaliação da condutividade térmica e propriedades de retenção de calor.

Palavras-chave: conforto térmico, vestimentas de proteção, têxteis de proteção, riscos origem térmica 
VALENTIN, Cristina Salete. Com-test Project: study of fabric features related to thermal comfort of clothes designed to protect from termal hazards. 2016. $113 \mathrm{f}$. Dissertation

(Master's Degree in Mestradoem Textiles \& Fashion) - School of Arts, Sciences and Humanities, University of São Paulo, São Paulo, 2015. Corrected version.

\begin{abstract}
Consumers, while seeking for more comfort, have a strong and growing demand for protective clothing. Considering that comfort interferes on the use and protection, and also taking into account that Brazilian weather is predominantly hot and humid and there are no papers or studies about this subject, this work aimed to study the features related to the comfort of fabrics that are used to make clothes designed to protect from thermal hazards (heat and fire) in Brazilian market. After selecting eleven products as objects of the research, we performed tests of humidity transportation on fabrics, water vapor resistance, physical and ergonomic comfort (laminar mass test and Kawabata Evaluation System (KES) and Labo II Term for evaluation of thermal conductivity and heat retention properties.
\end{abstract}

Keywords: thermal comfort, protection clothing, protection fabric, thermal hazards 


\section{Lista de figuras}

Figura 1 - Representação esquemática da fisiologia humana e as trocas térmicas

Figura 2 - Percepção subjetiva do conforto 33

Figura 3 - Classificação dos têxteis técnicos 45

Figura 4 - Fotografias dos tecidos objeto de estudo 49

Figura 5 - Equipamento de transporte de umidade ............................................................50

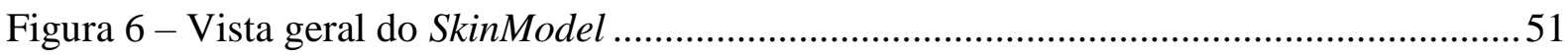

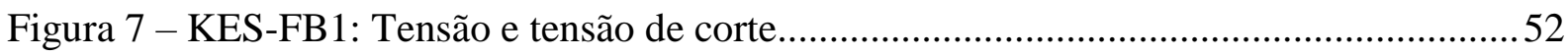

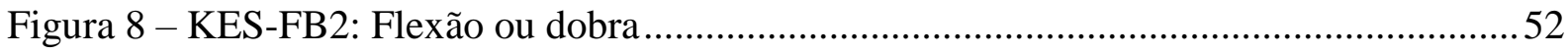

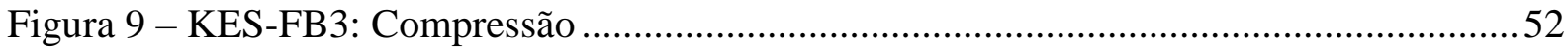

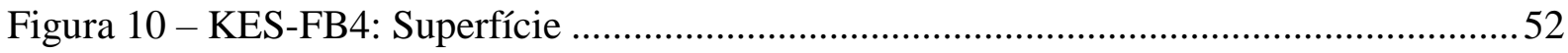

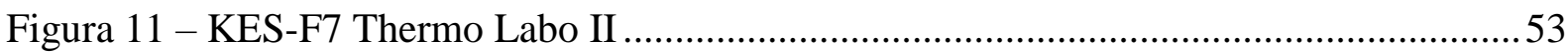

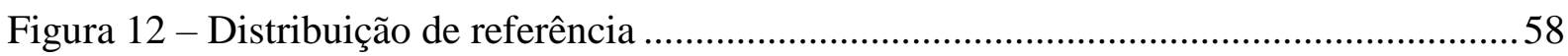

Figura 13 - Representação gráfica da distribuição de referência (Distr. F) .............................60

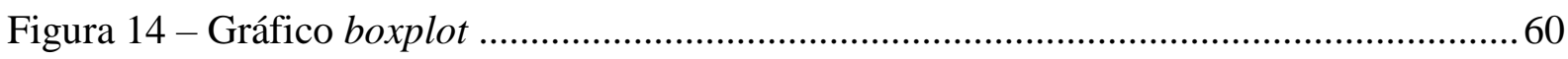

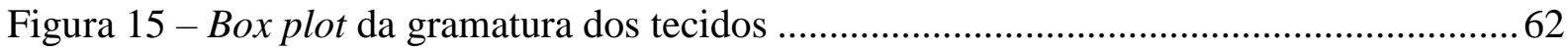

Figura 16 - Box plot do transporte de umidade dos tecidos ...................................................69

Figura 17 - Box plot da resistência ao vapor de água dos tecidos .......................................... 73

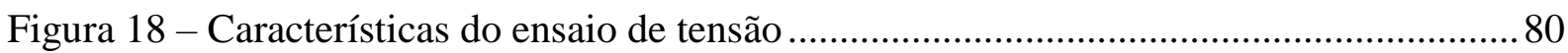

Figura 19 - Características do ensaio de tensão de corte ....................................................... 83

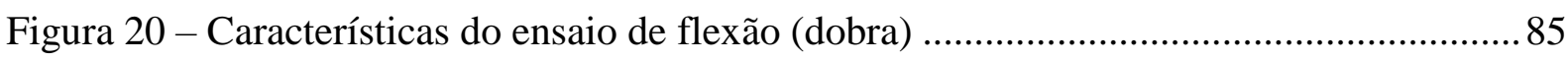

Figura 21 - Características do ensaio de compressão ............................................................ 87

Figura 22 - Fricção da superfície (esquerda) e rugosidade da superfície (direita)...................90

Figura 23 - Determinação do coeficiente de fricção ...............................................................91

Figura 24 - Determinação da rugosidade da superfície ..........................................................91

Figura 25 - Variação do fluxo de calor com o tempo ......................................................... 100

Figura 26 - Fluxograma do método de classificação ......................................................... 104 


\section{Lista de tabelas}

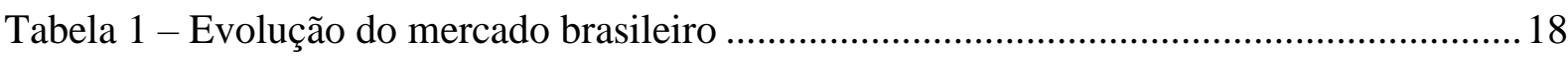

Tabela 2 - Mercado de vestimentas por tipo e risco (2013)................................................. 19

Tabela 3 - Representação genérica de um planejamento aleatorizado por níveis, utilizando n

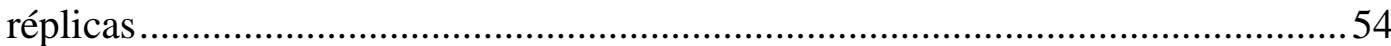

Tabela 4 - Resumo da tabela ANOVA para análise dos resultados .......................................56

Tabela 5 - Resultados dos ensaios de gramatura (g/m2) - ASTM D3776/96 ........................60

Tabela 6 - Resumo da tabela ANOVA para testar a hipótese $\mathrm{H}_{0}$ dos valores de gramatura dos

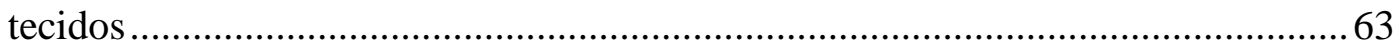

Tabela 7 - Resultados do ensaio de transporte de umidade .................................................65

Tabela 8 - Graus de classificação para o ensaio de transporte de umidade em tecidos ...........67

Tabela 9 - Resultados dos ensaios de capacidade de transporte de umidade - AATCC 195:2011

Tabela 10 - Resumo da tabela ANOVA para testar a hipótese $\mathrm{H}_{0}$ dos valores de transporte de

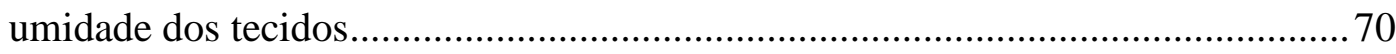

Tabela 11 - Resultados dos ensaios de resistência ao vapor de água $\left(\mathrm{m}^{2} \mathrm{~Pa} / \mathrm{W}\right)$ - EN 31092.73

Tabela 12 - Resumo da tabela ANOVA para testar a hipótese $\mathrm{H}_{0}$ dos valores de resistência ao

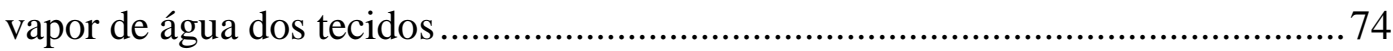

Tabela 13 - Resultados experimentais para análise do conforto tátil..................................... 76

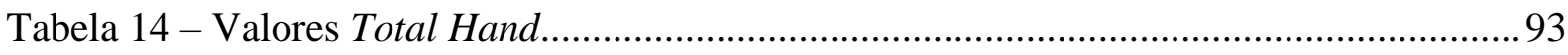

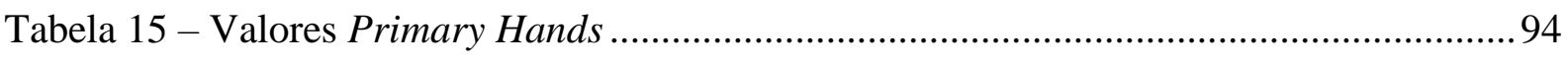

Tabela 16 - Resultados experimentais para análise térmica ................................................99 


\section{Lista de gráficos}

Gráfico 1 - Evolução do mercado brasileiro (em valores de US\$ milhões) ............................ 18

Gráfico 2 - Mercado de vestimentas por risco (2013), em valores (\%) .................................. 19

Gráfico 3 - Representação da porcentagem máxima de tensão ............................................ 81

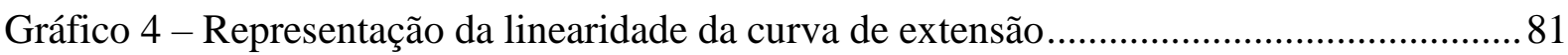

Gráfico 5 - Representação da energia de tensão por unidade de área .................................... 82

Gráfico 6 - Representação da porcentagem de recuperação .................................................. 82

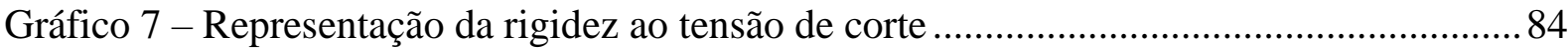

Gráfico 8 - Representação da histerese de tensão de corte em diferentes ângulos ...................84

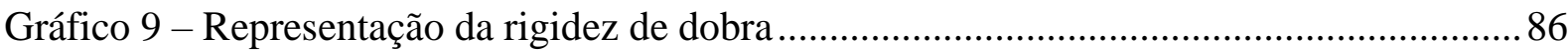

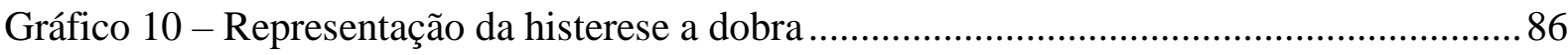

Gráfico 11 - Representação da linearidade da curva de compressão...................................... 88

Gráfico 12 - Representação de energia requerida para a compressão ..................................... 88

Gráfico 13 - Representação da porcentagem de resiliência da compressão ............................89

Gráfico 14 - Representação da espessura de cada amostra.................................................. 89

Gráfico 15 - Representação do valor médio do coeficiente de fricção ....................................92

Gráfico 16 - Representação do valor do desvio médio do coeficiente de fricção....................92

Gráfico 17 - Representação da rugosidade geométrica do tecido..........................................92

Gráfico 18 - Representação do peso dos tecidos ................................................................94

Gráfico 19 - Representação dos valores Primary Hands .................................................... 95

Gráfico 20 - Representação dos valores Total Hand Value .....................................................96

Gráfico 21 - Representação da classificação do tipo de tecido.............................................102

Gráfico 22 - Representação da capacidade de transporte de umidade dos tecidos com tratamento superficial

Gráfico 23 - Representação da capacidade de transporte de umidade dos tecidos sem tratamento superficial 


\section{Sumário}

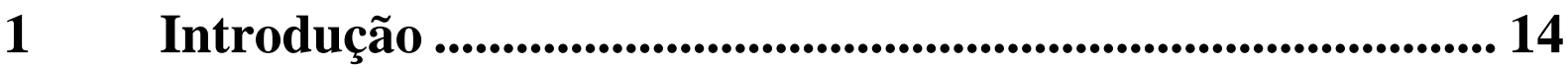

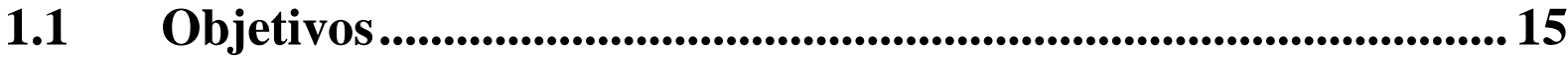

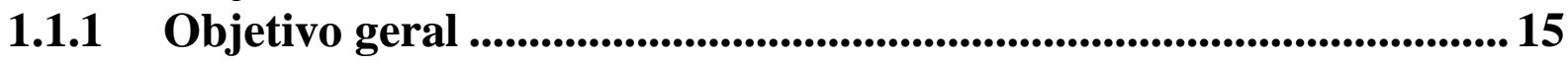

1.1.2 Objetivos específicos ........................................................................................ 16

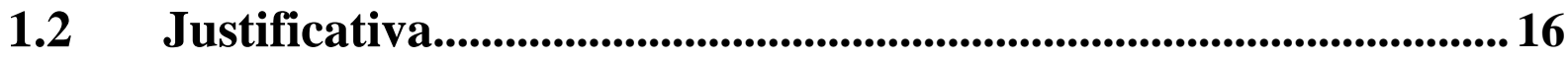

1.2.1 O mercado ........................................................................................... 17

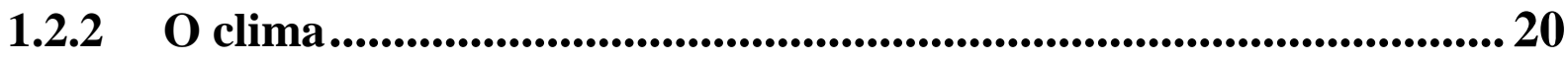

1.3 Metodologia ...........................................................................21

1.3.1 Etapas de desenvolvimento do trabalho ............................................ 21

1.3.2 Classificação da pesquisa ..................................................................... 21

1.4 Estrutura do trabalho ......................................................... 22

2 Referencial Teórico................................................................... 23

2.1 O conforto térmico............................................................ 24

2.2 O sistema de termorregulação humano ............................................ 26

2.3 Balanço térmico entre o homem e o ambiente ................................. 27

2.4 Variáveis envolvidas no conforto térmico.......................................30

2.4.1 Variáveis ambientais...............................................................30

2.4.2 Variáveis humanas.................................................................................. 31

2.5 A percepção do conforto .............................................................. 32

2.6 Aspectos do conforto de vestuário ............................................................... 33

2.6.1 Propriedades de conforto do tecido ....................................................... 34

2.7 A importância do conforto térmico........................................................... 38

2.8 Normas sobre conforto térmico .......................................................40 40

2.8.1 ISO 11399 (1995) - Ergonomia do ambiente térmico: príncipios e aplicações de normas internacionais relevantes .............................. 40

2.8.2 ISO 7726 (1998) - Ergonomia do ambiente térmico: instrumentos para medições das variáveis físicas..................................................... 40

2.8.3 ISO 7243 (1989) - Ambientes Quentes - Estimativa do estresse por calor sobre o trabalhador, baseado no IBUTG - (bulbo úmido e temperatura de globo)

2.8.4 ISO 7933 (2004) - Ergonomia do ambiente térmico - determinação analítica e interpretação de estresse por calor usando cálculo da taxa requerida de suor.

2.8.5 ISO 7730 (2005) - Ambientes térmicos moderados: determinação dos índices PMV e PPD e especificação das condições para conforto térmico 
2.8.6 ISO 8996 (2004) - Ergonomia: determinação da produção de calor metabólico

2.8.7 ISO 9920 (2007) - Ergonomia do ambiente térmico: estimativa do isolamento térmico e da resistência evaporativa de um conjunto de vestimentas

2.8.8 ISO 10551 (1995) - Ergonomia do ambiente térmico: avaliação da influência do ambiente térmico utilizando escalas de julgamento subjetivo

2.8.9 ASHARE Standard 55 (2013) ) - Condições ambientais térmicas para ocupação humana .................................................................. 43

2.8.10 NR 15 - Atividades e Operações Insalubres .................................43

2.8.11 NR 17 - Norma Regulamentadora de Ergonomia .........................43

2.8.12 ABNT NBR 16401-2:2008 Instalações centrais de ar condicionado para conforto: Parâmetros básicos de projeto ................................... 44

3 Têxteis Técnicos 45

3.1 Têxteis Técnicos na Proteção Pessoal contra riscos de origem térmica

4 Materiais e Métodos ............................................................... 48

4.1 Caracterização dos tecidos........................................................48

4.2 Ensaio de determinação da gramatura ...................................... 49

4.3 Ensaios de conforto térmico .....................................................50

4.3.1 Transporte de umidade em tecidos.........................................................50

4.3.2 Resistência ao vapor de água (Ret)..............................................................5 50

4.4 Ensaios de conforto físico e ergonômico.....................................5 51

4.4.1 Ensaio de determinação da gramatura para pequenas amostras ...51

4.4.2 Kawabata Evaluation System (KES), para conforto tátil .................... 52

4.4.3 Thermo Labo II .............................................................................................53

4.5 Estudo estatístico .............................................................................. 54

4.5.1 Planejamento aleatorizado por níveis ......................................................... 54

4.5.2 Teste de hipóteses ........................................................................................... 55

4.5.3 Análise de variância (ANOVA) ................................................................... 55

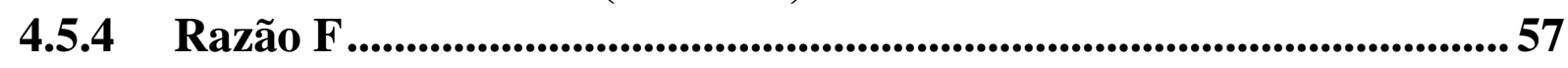

4.5.5 Comparação das médias individuais dos tratamentos ....................... 58

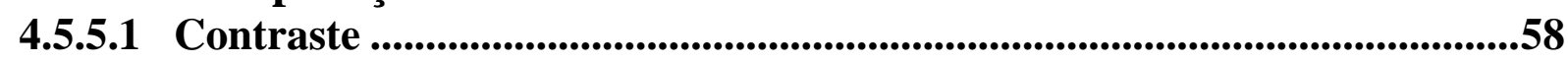

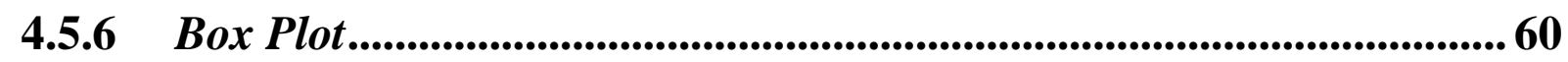

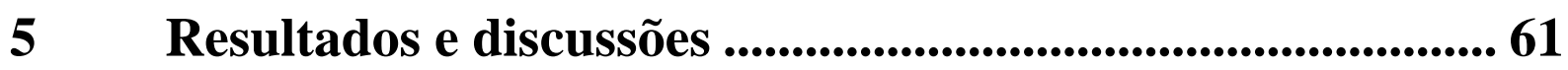


$5.1 \quad$ Ensaios de gramatura..............................................................61

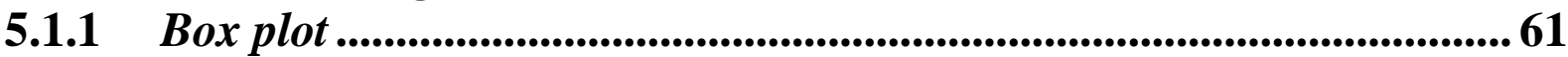

5.1.2 Planejamento aleatorizado por níveis .................................................62 62

5.2 Ensaios de conforto térmico ...................................................64 64

5.2.1 Transporte de umidade.................................................................64

5.2.1.1 Análise dos resultados ................................................................................................667

5.2.1.2 Box plot ...................................................................................................................69

5.2.1.3 Planejamento aleatorizado por níveis.................................................................69

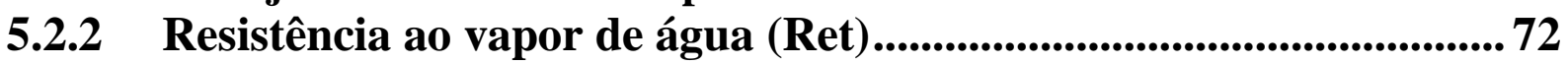

5.2.2.1 Box plot ........................................................................................................................73

5.2.2.2 Planejamento aleatorizado por níveis.....................................................................74

5.3 Ensaios de conforto físico e ergonômico........................................... 75

5.3.1 Ensaio de gramatura ............................................................................................ 75

5.3.2 KawabataEvaluation System (KES), para conforto tátil .....................80

5.3.3 Definição das medidas realizadas pelo sistema de medição KES.... 93

5.3.4 Primary Hand e THV (Total Hand Value) .......................................... 99

5.3.5 Ensaio térmico ....................................................................................99

6 Conclusão................................................................................. 102

6.1 Sugestões de trabalhos futuros .................................................. 105

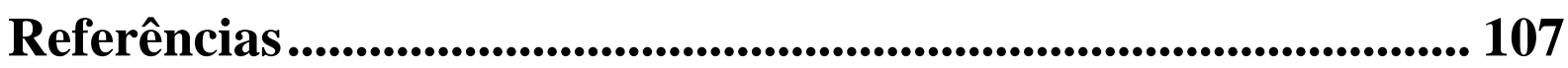

Anexo A -Tipos de tecidos ....................................................................... 112 


\section{Introdução}

O conforto é um dos mais importantes requisitos da qualidade de vida. O ser humano, consciente ou não está permanentemente procurando manter ou melhorar seu benéfico estado de conforto, físico ou psicológico.

O conforto pode ser entendido como um estado de harmonia física e mental com o meio ambiente, excluindo a ausência de qualquer sensação de incômodo (GASI; BITTENCOURT, 2010).

Quando se trata de satisfação com as condições térmicas de um ambiente, então se está tratando do conforto térmico (RUAS, 1999).

Ruas (1999), também define que o conforto térmico num determinado ambiente, é a sensação de bem-estar experimentada por uma pessoa, como resultado da combinação satisfatória, de diversas variáveis presentes nesse ambiente: a temperatura radiante média, a umidade relativa, a temperatura, a velocidade relativa do ar com a atividade lá desenvolvida e com a vestimenta utilizada pelas pessoas. Nesse contexto, o vestuário constitui uma resistência natural entre o corpo humano e o seu meio ambiente.

Desse modo e em seus vários aspectos, a roupa se caracteriza como isolante térmico. Nesse sentido, ela interfere na troca térmica do organismo, processo que ocorre entre o corpo e o ambiente. É uma característica que a coloca como uma das seis variáveis que interferem no conforto térmico (MOURA, 2012).

Por outro lado, quando se trata de vestuário de proteção, contra algum infortúnio, este possui antes de mais nada, e como primeira função, proteger o usuário em função do risco a que vai ser exposto, para o qual o vestuário se destina.

Nesse entendimento, consideram-se têxteis de proteção o vestuário e outros produtos confeccionados com tecidos concebidos para proteger o usuário de efeitos ambientais perigosos que possam resultar em danos ou morte (ARAÚJO, FANGUEIRO, HONG, 2000).

No ambiente de trabalho, o vestuário de proteção considerado Equipamento de Proteção Individual (EPI), é regulamentado na Legislação Brasileira pela Norma Regulamentadora NR 6 do Ministério do Trabalho e Emprego, publicada pela Portaria n. ${ }^{\circ}$ 3.214, de 8 de junho de 1978 .

De acordo com o item 6.1 dessa NR 6, "considera-se Equipamento de Proteção Individual - EPI, todo dispositivo ou produto, de uso individual utilizado pelo trabalhador, destinado à proteção de riscos suscetíveis de ameaçar a segurança e a saúde no trabalho". 
As características e funcionalidades do vestuário de proteção individual estão muito relacionadas com os têxteis utilizados na sua produção, dependendo eles por sua vez, das necessidades especificas de cada aplicação.

Uma das características fundamentais, que a maior parte dos têxteis de proteção deve ter, é resistir ao fogo e ao calor (ARAÚJO, FANGUEIRO, HONG, 2000). Por essa razão, as fibras utilizadas na sua produção são comumente fibras sintéticas, altamente resistentes ao fogo e ao calor; porém, também são amplamente conhecidas pelo desconforto térmico que causam em função, por exemplo, da incapacidade de absorver umidade devido à impermeabilidade do tecido.

Segundo Gasi e Bitencourt (2010),

[...] a permeabilidade ao vapor d'água é uma das propriedades mais importantes de um tecido no que tange ao conforto fisiológico. É muito importante, para o balanço térmico, permitir que a umidade gerada pelo suor da pele evapore e passe como vapor pela estrutura fibrosa, facilitando o processo de termorregulação e impedindo que o vapor da transpiração fique retido entre a pele e o artigo têxtil.

Dentro deste contexto, este trabalho desenvolve um estudo das características relacionadas com a perspectiva de conforto dos têxteis (tecidos), utilizados nas vestimentas destinadas a proteger riscos de origem térmica (calor e fogo) as quais estão presentes no mercado brasileiro.

\subsection{Objetivos}

\subsubsection{Objetivo geral}

Fornecer dados e informações concretas, especificamente de tecidos para vestimentas de trabalho para proteção térmica (calor e chamas), como subsídio para a real avaliação do conforto térmico em ambientes de trabalho no Brasil. 


\subsubsection{Objetivos específicos}

- Determinar as características técnicas relacionadas com o conforto de tecidos destinados à proteção individual frente a riscos de origem térmica (calor e chamas) e analisá-las comparativamente.

- Elaborar um ranking dos resultados e determinar aquele com maior capacidade de proporcionar conforto térmico em função dos testes e dos resultados apresentados.

\subsection{Justificativa}

Na perspectiva de Correia (2005), o estudo e a avaliação de ambientes térmicos têm sido um tema importante de investigação, sendo que hoje, existem na literatura vários métodos de análise de ambientes térmicos.

O fato é que, todas as pesquisas para avaliar conforto térmico, seja em ambientes abertos, seja em ambientes fechados, com avaliação dos aspectos ambientais e pessoais, utilizam-se valores estimados para determinar a interferência da vestimenta, representada pelo seu isolamento térmico; para tanto, usam-se tabelas desenvolvidas a partir de estudos de isolamento térmico de vestimentas, disponíveis em normas técnicas como a ISO 9920 ou ISO 7730, respectivamente Ergonomics of the thermal environment - Estimation of thermal insulation and water vapour resistance of a clothing ensemble, e Ergonomics of the thermal environment - Analytical determination and interpretation of thermal comfort using calculation of the PMV and PPD indices and local thermal comfort criteria.

Conforme Moura (2012), para a maioria dos estudiosos, os custos não compensam medir diretamente o isolamento das roupas e, por isso, os pesquisadores geralmente utilizam uma estimativa de valores usando tabelas desenvolvidas a partir de estudos de isolamento térmico. Entretanto, é difícil uma correta estimativa do isolamento térmico das vestimentas por meio dos valores tabelados nas normas ISO 7730 e ISO 9920; isso porque essas normas não contêm informações precisas sobre a influência no isolamento de certos fatores, tais como a velocidade do ar, a postura e o movimento do corpo.

Embora o conhecimento nessa área esteja em expansão, os valores atuais contidos na ISO 9920 são relativamente simples e não refletem totalmente os efeitos da postura, do material de corte, da transferência de calor dinâmico ou as variações de perda de calor por 
todo o corpo no vestuário (CHARLES, 2003). Ruas (2001) acrescenta que uma outra fonte de erros é a subjetividade de enquadrar as peças de uma vestimenta naquelas listadas nas tabelas.

Além disso, ainda segundo Ruas (2001), um outro aspecto a ser abordado é que, no Brasil, não se conhecem trabalhos sobre isolamento térmico das vestimentas e, assim, não se dispõem de parâmetros que permitam comparar as roupas aqui utilizadas com aquelas estudadas por Olesen conforme cita Ruas (2001) e que formam a base das tabelas da ISO 9920.

De forma que Ruas, sugere e destaca, pela sua imediata aplicabilidade, a realização de um estudo do isolamento térmico e da permeabilidade ao vapor de água das roupas brasileiras, em especial, aquelas usadas nos ambientes de trabalho.

Conforme Moura (2012), quanto ao conforto térmico e às vestimentas de trabalho, a Legislação precisa ser aprimorada, mas depende, dentre outros fatores, de estudos e desenvolvimento tecnológico voltado às roupas de proteção aos trabalhadores.

\subsubsection{O mercado}

Nos últimos anos, a evolução da economia brasileira tem aumentado substancialmente a sua atividade industrial. Nesse cenário, consequentemente, percebe-se um crescimento no setor de roupas de proteção individual devido à criação de novos postos de trabalho (ALBUQUERQUE et al., 2011).

Acrescente-se que esse fato gera a vinda de empresas internacionais, - sejam europeias sejam americanas, - para este segmento do mercado brasileiro. Tal dinâmica, a um só tempo aumenta a concorrência e estimula o desenvolvimento tecnológico nessa área. A Tabela e o Gráfico 1 mostram essa evolução. 
Tabela 1 - Evolução do mercado brasileiro

\begin{tabular}{|c|c|c|c|}
\hline Mercado Anual de EPI - Brasil & $\begin{array}{c}2009 \\
\text { Valor de Mercado } \\
\text { (US } \$)\end{array}$ & $\begin{array}{c}2011 \\
\text { Valor de Mercado } \\
\text { (US\$) }\end{array}$ & $\begin{array}{c}2013 \\
\text { Valor de Merc } \\
\text { (US\$) }\end{array}$ \\
\hline Calçados de Segurança & $552.946 .629,21$ & $667.906 .900,00$ & 838.306 .6 \\
\hline Luvas de Segurança & $402.981 .320,22$ & $542.815 .325,00$ & 548.107 .1 \\
\hline Vestimentas de Segurança & $307.467 .415,73$ & $320.249 .500,00$ & 388.557 .7 \\
\hline Proteção Respiratória & $102.776 .404,49$ & $107.693 .375,00$ & 123.631 .5 \\
\hline Face/Olhos & $50.252 .977,53$ & $60.565 .550,00$ & 117.048 .8 \\
\hline Equipamentos Contra Quedas & $51.827 .247,19$ & $53.272 .650,00$ & 76.708 .4 \\
\hline Capacetes de Segurança & $29.865 .168,54$ & $35.610 .000,00$ & 72.522 .2 \\
\hline Cremes Protetores & $9.420 .224,72$ & $51.479 .500,00$ & 52.265 .3 \\
\hline Proteção Auditiva & $20.616 .292,13$ & $21.989 .000,00$ & 23.893 .5 \\
\hline Outros & $12.775 .280,90$ & $12.538 .550,00$ & \\
\hline Total & $1.540 .928 .960,66$ & $1.874 .120 .350,00$ & 2.241 .041 .55 \\
\hline Variação percentual & & $22 \%$ & 20 \\
\hline Média anual & & $10 \%$ & \\
\hline
\end{tabular}

Fonte: ANIMASEG, 2014

Gráfico 1 - Evolução do mercado brasileiro (em valores de US\$ milhões)

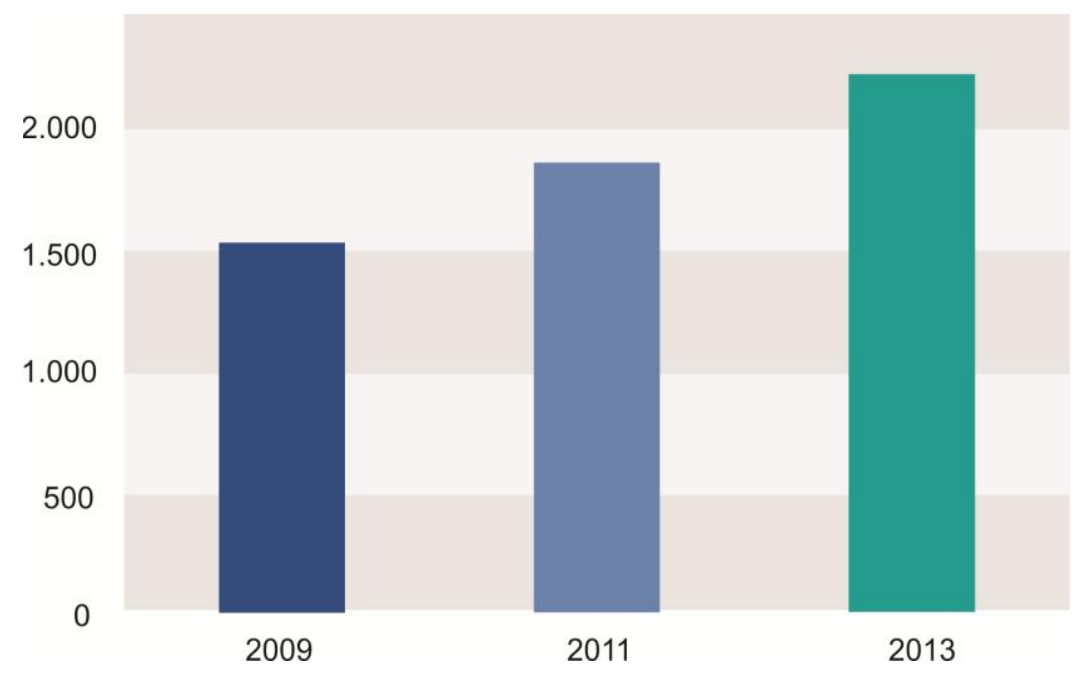

Fonte: ANIMASEG, 2014

A Tabela e o Gráfico 2, a seguir, mostram dentro do segmento de vestimentas de segurança, a representatividade daquelas destinadas a riscos térmicos/calor, ao apresentar os números por tipo de vestimenta e risco. 
Tabela 2 - Mercado de vestimentas por tipo e risco (2013)

\begin{tabular}{|c|c|c|c|c|}
\hline Vestimentas de Segurança & Quantidade & $\begin{array}{l}\text { Preço Médio } \\
\text { (R\$) }\end{array}$ & $\begin{array}{l}\text { Valor de Mercado } \\
(\mathrm{R} \$)\end{array}$ & $\begin{array}{l}\text { Valor de Mercado \% } \\
\text { (US\$) }\end{array}$ \\
\hline Térmicos/Calor & & & $273.378 .000,00$ & $121.501 .333,333$ \\
\hline Calor por Contato & 50.000 & 350,00 & $17.500 .000,00$ & 7.777.777,78 \\
\hline Calor Convectivo & 33.000 & 400,00 & $13.200 .000,00$ & $5.866 .666,67$ \\
\hline Calor Irradiado (Vestimenta) & 42.000 & $1.200,00$ & $50.400 .000,00$ & $22.400 .000,00$ \\
\hline Japona para Combate a Incêndio & 24.000 & $1.400,00$ & $33.600 .000,00$ & $14.933 .333,33$ \\
\hline Balaclava para Combate a Incêndio & 61.000 & 100,00 & $6.100 .000,00$ & $2.711 .111,11$ \\
\hline Calça para Combate a Incêndio & 15.000 & $1.300,00$ & $19.500 .000,00$ & $8.666 .666,67$ \\
\hline Arco Elétrico - Fogo Repentino & 526.000 & 253,00 & $133.078 .000,00$ & $59.145 .777,78$ \\
\hline Térmicos/Frio & & & $15.800 .000,00$ & $7.022 .222,22$ \\
\hline Pré (Roupa de Baixo) & 11.000 & 100,00 & $1.100 .000,00$ & $488.888,89$ \\
\hline Japona/Calça/Macacão & 98.000 & 150,00 & $14.700 .000,00$ & $6.533 .333,33$ \\
\hline Intempéries & & & $175.760 .000,00$ & $78.115 .555,5620,1$ \\
\hline Água e Umidade & 6.760 .000 & 26,00 & $175.760 .000,00$ & $78.115 .555,56$ \\
\hline Químicos & & & $228.080 .000,00$ & $101.368 .888,8926,1$ \\
\hline Agroindústria Descartável & 9.000 .000 & 18,00 & $162.000 .000,00$ & $72.000 .000,00$ \\
\hline Agroindústria Reaproveitável & 250.000 & 50,00 & $12.500 .000,00$ & $5.555 .555,56$ \\
\hline Industrial & 950.000 & 45,00 & $42.750 .000,00$ & $19.000 .000,00$ \\
\hline Gases & 5.700 & $1.900,00$ & $10.830 .000,00$ & $4.813 .333,33$ \\
\hline Mecânicos & & & $181.237 .000,00$ & $80.549 .777,7820,7$ \\
\hline Geral & 694.000 & 55,50 & $38.517 .000,00$ & $17.118 .666,67$ \\
\hline Motoserrista/Calça & 40.000 & 110,00 & $4.400 .000,00$ & $1.955 .555,56$ \\
\hline Motoserrista/Perneira & 1.280 .000 & 19,00 & $24.320 .000,00$ & $10.808 .888,89$ \\
\hline Vestimenta para Hidrojateamento & 60.000 & $1.900,00$ & $114.000 .000,00$ & $50.666 .666,67$ \\
\hline Outros & & & $540.000,00$ & $240.000,00$ \\
\hline Vestimenta para Apicultura & 6.000 & 90,00 & $540.000,00$ & $240.000,00$ \\
\hline Total & & & $874.255 .000,00$ & $388.557 .777,78$ \\
\hline
\end{tabular}

Fonte: ANIMASEG, 2014

Gráfico 2 - Mercado de vestimentas por risco (2013), em valores (\%)

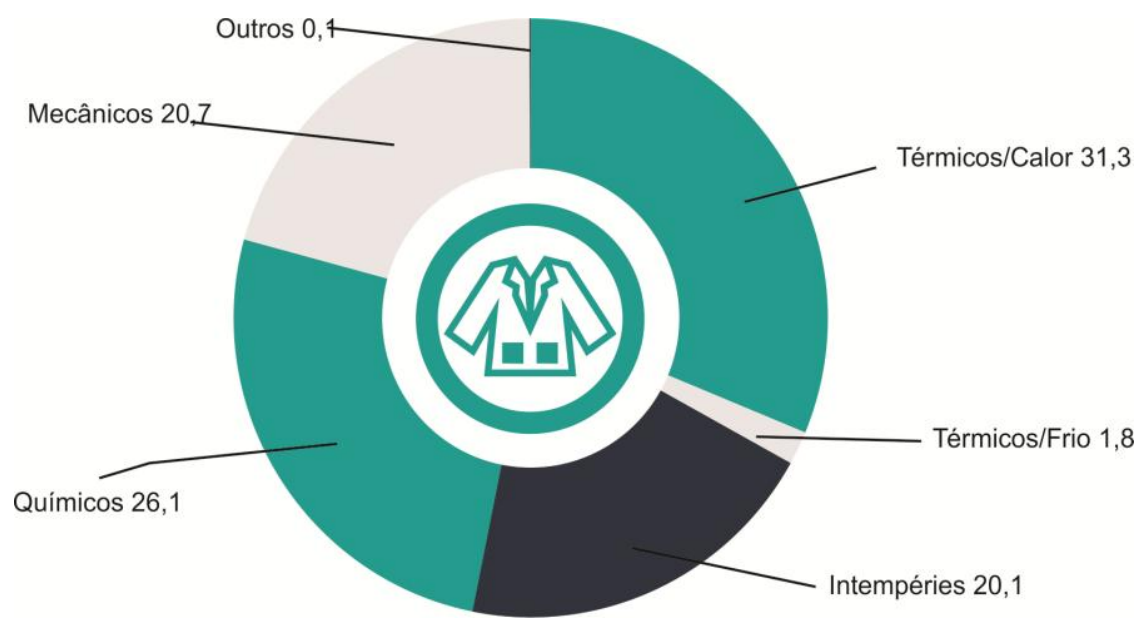

Fonte: ANIMASEG, 2014 


\subsubsection{O clima}

O Brasil possui uma grande extensão territorial e, assim, em função da diversidade de relevo, e de altitude, bem como a dinâmica das correntes e massas de ar, o país é dotado de uma grande diversidade de climas. Atravessado ao norte pela Linha do Equador e, ao sul, pelo Trópico de Capricórnio, o Brasil está situado, na maior parte do território, nas zonas de latitudes baixas, - chamadas de zona intertropical, - nas quais prevalecem os climas quentes e úmidos.

Com relação às temperaturas, observam-se nas Regiões Norte e Nordeste um clima quente com temperaturas elevadas e com pouca variabilidade durante o ano. O Sudeste e o Centro-Oeste, devido às suas localizações latitudinais, caracterizam-se por serem regiões de transição entre os climas quentes de latitudes baixas e os mesotérmicos de tipo temperado das latitudes medias. O Sul do país é a região com maior variabilidade térmica anual, embora a distribuição regional da temperatura seja bastante uniforme. No inverno, é frequente a penetração de massas de ar frio de altas latitudes, o que contribui para a predominância de baixas temperaturas.

A descrição desse panorama permite inferir que a temperatura e a umidade afetam os trabalhadores de várias maneiras, principalmente os que trabalham em indústrias, conforme atestam diversas pesquisas feitas em laboratórios ou indústrias, com as condições cuidadosamente controladas, conforme estudos de Iida e Wierzbichi, (1973).

Segundo Frota (1995), estudos da Comissão Americana de Ventilação, em 1916, visando principalmente ao trabalho físico do operário, - vieram mostrar que:

- $\quad$ para o trabalho físico, o aumento da temperatura ambiente de $20^{\circ} \mathrm{C}$ para $24^{\circ} \mathrm{C}$ diminui o rendimento em $15 \%$;

- $\quad$ a $30^{\circ} \mathrm{C}$ de temperatura ambiente, com umidade relativa de $80 \%$, o rendimento cai para $28 \%$.

À parte que, observações acerca do rendimento do trabalho em minas na Inglaterra, mostraram o seguinte: o mineiro rende $41 \%$ menos quando a temperatura efetiva é $27^{\circ} \mathrm{C}$, com relação à temperatura efetiva de $19^{\circ} \mathrm{C}$.

E ainda, que foram observadas também variações de produção em indústrias, segundo a mudança das estações do ano, havendo, do mesmo modo, estudos que correlacionam ambientes termicamente desconfortáveis com índices elevados de acidentes no trabalho e de doenças laborais. 
Sob esse aspecto, do ambiente de trabalho, convém ressaltar ainda que o conforto térmico depende, entre outros parâmetros, do calor produzido pelas atividades desenvolvidas e pelos equipamentos envolvidos nos processos.

Conforme Frota e Schiffer (1999), as condições de conforto térmico estão vinculadas àfunção da atividade desenvolvida pelo individuo, ao tipo da sua vestimenta e às variáveis ambientais que proporcionam as trocas de calor entre o corpo e o ambiente.

Dessa forma, e em virtude de haver predominância de climas quentes e úmidos, especial atenção deve ser dada à comprovada influência do desconforto térmico na disposição para o trabalho e no desempenho do trabalhador no exercício da função.

\subsection{Metodologia}

\subsubsection{Etapas de desenvolvimento do trabalho}

Para responder à demanda do mercado por vestimentas de segurança que proporcionassem maior conforto térmico, foram, primeiramente, selecionados no mercado tecidos utilizados na fabricação de vestimentas destinadas à proteção frente aos riscos de origem térmica e estudadas as características desses tecidos no que diziam respeito ao conforto térmico.

Em seguida foi feito levantamento bibliográfico tanto dos assuntos, e conceitos, quanto dos trabalhos já desenvolvidos e das normas de Conforto Térmico.

Uma vez definidos os ensaios de conforto térmico a serem realizados, procedeu-se à sua realização, bem como aqueles voltados à caracterização dos materiais, como, por exemplo, densidade de fios, construção e peso, entre outros.

Posteriormente, foi feita a análise dos resultados dos ensaios, inclusive estatisticamente, e realizadas as conclusões.

\subsubsection{Classificação da pesquisa}

Segundo os procedimentos técnicos adotados, no presente estudo a pesquisa é classificada como experimental. Gil (2002) ensina que pesquisa experimental consiste em determinar um objeto de estudo, selecionar as variáveis que seriam capazes de influenciá-lo, e definir as formas de controle e de observação dos efeitos que a variável produz no objeto. 
Conforme Cervo e Bervian (1996), enquanto a pesquisa descritiva procura classificar, explicar e interpretar os fenômenos que ocorrem, a pesquisa experimental pretende dizer de que modo ou por quais causas o fenômeno é produzido.

\subsection{Estrutura do trabalho}

O presente trabalho está dividido em cinco capítulos: neste primeiro capítulo, introduz-se o assunto a ser abordado, apresentando as diversas razões que tornam importante realizar a pesquisa; inclui ainda os objetivos da pesquisa. O Capítulo 2 traz o referencial teórico destacando a importância do conforto térmico. No Capítulo 3 encontram-se descritas as normas relativas a conforto térmico. No Capítulo 4 consta a metodologia de pesquisa empregada e a descrição dos objetos de pesquisa. No quinto capítulo estão as análises e a discussão dos resultados obtidos. O Capítulo 6 apresenta a conclusão final da pesquisa e sugestão de futuros trabalhos. Finalmente, a Bibliografia onde são listados os trabalhos e obras consultadas e referenciadas no desenvolvimento desta dissertação. 


\section{Referencial teórico}

A preocupação do homem com o conforto térmico é muito antiga. Um exemplo desse fato lemos na obra History and Art of Warming and Ventilation Rooms and Buildings, escrita pelo engenheiro civil Walter Bernan e publicada em 1845. Nela, Bernan prevê que a criação e o controle de ambientes climáticos artificiais assumirão a dimensão de uma ciência que contribuirá para o desenvolvimento da humanidade, e para a preservação da saúde e para a longevidade do ser humano (RUAS, 2001).

Entretanto, apesar dessa referência ao passado, até a Revolução Industrial, não foi dada a devida atenção aos estudos de conforto térmico. Porém, com o impulso da industrialização ocorrido no início do século XX, ocorre a visão de que melhores condições ambientais para o desenvolvimento do trabalho eram importantes. Desde então, o assunto começou a frutificar, tendo em vista, principalmente, a manutenção da saúde e da produtividade do trabalhador (XAVIER, 2000).

Conforme Fabris (2003), a partir de 1970, o professor dinamarquês Ole Fanger (19342006) realizou estudos em câmaras climatizadas na Dinamarca para verificar o balanço térmico entre o homem e o ambiente construído ao seu redor. Esses estudos sobre conforto térmico foram tão importantes que os modelos propostos por Fanger em suas pesquisas são utilizados até hoje; foram inclusive normalizados pela referida ISO 7730.

Além disso, os estudos de Fanger abriram caminho para que outras pesquisas fossem realizadas, agora não mais em câmaras climatizadas, mas também em ambientes reais; desses os mais notórios em nível mundial foram os realizados por Humpreys, Busch, Nicol, entre outros.

Segundo o supracitado Xavier (2000), os estudos de conforto térmico tradicionais e convencionais podem ser subdivididos em dois grupos distintos: (a) os efetuados em câmaras climatizadas ou com condições ambientais controladas, como os de Fanger, de Hayward, Frank, entre outros; (b) os efetuados mediante pesquisas de campo sem intervenção nas condições, como os de Humphreys, Busch, Nicol, entre outros. O primeiro grupo buscou analisar a situação de conforto térmico baseada em modelos físicos de troca de calor entre o homem e o ambiente; o segundo grupo baseou-se na verificação de parâmetros ambientais, mais notadamente a temperatura, - para a qual as pessoas pudessem sentir-se termicamente confortáveis, levando em consideração suas oportunidades de adaptação. 


\subsection{O conforto térmico}

Como descreve Xavier (2000), em estudos realizados em câmaras climatizadas, Fanger define conforto térmico como sendo "uma condição da mente que expressa satisfação com o ambiente térmico". E acrescenta que, com a posterior normalização dos estudos de conforto térmico, através da American Society of Heating, Refrigerating and AirConditioning Engineers - ASHARE 55 (1992) e ISO 7730, essa definição tornou-se clássica.

De acordo com a própria ASHARE, esta definição todavia deixa em aberto o conceito de conforto térmico em função do seu caráter subjetivo, psicológico no que diz respeito à “condição da mente". Por outro lado, enfatiza corretamente que o julgamento do conforto térmico é um processo cognitivo que envolve muitas entradas influenciadas pelo físico, fisiológico, psicológico, entre outros processos.

Xavier (2000), por sua vez, explica que o conforto térmico pode ser analisado sob dois aspectos distintos:

- (a) do ponto de vista pessoal: é aquele onde uma determinada pessoa que se encontre em um determinado ambiente esteja em estado confortável com relação à sua sensação térmica.

- (b) do ponto de vista ambiental: aquele onde a combinação das variáveis físicas inerentes a esse ambiente criem condições termo ambientais para que um menor número de pessoas esteja insatisfeita com esse ambiente. Uma vez que os estudos de conforto térmico envolvem aspectos pessoais e ambientais, é impossível que um grupo de pessoas sujeitas a um mesmo ambiente, ao mesmo tempo, esteja todo ele satisfeito com as suas condições térmicas. Assim sendo, diz-se que um ambiente é aceitável termicamente quando apresenta combinações variáveis físicas que o tornem desconfortável para o menor número de pessoas possível (ISO 7730, 1994).

Ruas (1999), neste sentido também definiu o conforto térmico como a sensação de bem-estar experimentada por uma pessoa, como resultado da combinação satisfatória, nesse ambiente, da temperatura radiante média (trm), umidade relativa (UR), temperatura do ambiente (ta) e velocidade relativa do ar (vr) com a atividade lá desenvolvida e com a vestimenta utilizada pelas pessoas.

Dessa forma, classifica como as variáveis que determinam o conforto térmico aquelas de natureza ambiental e aquelas de natureza pessoal. 
As de natureza ambiental:

- temperatura do ar (ta);

- temperatura radiante média (trm);

- velocidade relativa do ar (vr);

- $\quad$ umidade relativa do ar ambiente (UR).

As de natureza pessoal:

- tipo de vestimenta (representada pelo seu isolamento térmico);

- tipo de atividade física executada (representada pelo metabolismo).

Essas variáveis separadas por Ruas (1999) em dois grupos somente foram para efeito de classificação, tendo em vista que o efeito combinado de todas elas é que determina a sensação de conforto ou de desconforto térmico.

Segundo Frota e Schiffer (1999), as principais variáveis climáticas de temperatura, de umidade e velocidade do ar e a radiação solar incidente guardam estreitas relações com o regime de chuvas, com a vegetação, e a permeabilidade do solo, com as águas superficiais e subterrâneas, e com a topografia, entre outras características locais que podem ser alteradas pela presença humana em suas ações antrópicas.

Além do que, as exigências humanas de conforto térmico estariam relacionadas com o funcionamento de seu organismo, cujo mecanismo, complexo, pode ser, grosso modo, comparado a uma máquina térmica que produz calor segundo sua atividade. $\mathrm{O}$ homem precisa liberar calor em quantidade suficiente para que sua temperatura interna se mantenha da ordem de $37^{\circ} \mathrm{C}$ - designada homeotermia.

Quando as trocas de calor entre o corpo humano e o ambiente ocorrem sem maior esforço, a sensação do indivíduo é de conforto térmico, e sua capacidade de trabalho, desse ponto de vista, é máxima. Se as condições térmicas ambientais causam sensação de frio ou de calor, é porque o organismo está perdendo mais calor ou menos calor que o necessário para a manutenção da homeotermia; essa, então, passa a ser conseguida com um esforço adicional que sempre representa sobrecarga, com queda do rendimento no trabalho, até o limite; sob condições de rigor excepcionais, perda total de capacidade para realização de trabalho e/ou para problemas de saúde (FROTA; SCHIFFER, 1999). 


\subsection{O sistema de termorregulação humano}

O homem produz energia interna a partir da transformação dos alimentos mediante processo metabólico. Essa energia é consumida na manutenção das funções fisiológicas vitais, e na realização de trabalhos mecânicos externos (atividade muscular); e o restante é liberado na forma de calor (RUAS, 1999). Este calor, resultado dessa atividade metabólica do corpo, deve ser continuamente dissipado para regular e manter normal a temperatura do corpo. Perda de calor insuficiente leva ao superaquecimento (hipertemia), enquanto que a perda de calor excessiva leva ao resfriamento corporal (hipotermia).

Uma temperatura interna inferior a cerca de $82^{\circ} \mathrm{F}$ pode levar à arritmia cardíaca grave e à morte; a uma temperatura superior a $110^{\circ} \mathrm{F}$ pode causar irreversível dano cerebral. Fica evidente, portanto, que a regulação da temperatura do corpo é essencial para a saúde e para o conforto (ASHARE, 2013).

O hipotálamo, localizado no cérebro, é o órgão central de controle da temperatura corporal. Ele tem sensores de temperatura quente e fria e é banhado pelo sangue arterial. Dado que a taxa de recirculação sanguínea é rápida e o sangue é misturado no coração antes de voltar para o corpo, o sangue arterial é indicativo da temperatura média interna do corpo. $\mathrm{O}$ hipotálamo também recebe informação térmica a partir de sensores de temperatura na pele (ASHARE, 2013).

O hipotálamo controla vários processos fisiológicos para regular a temperatura corporal. Seu comportamento de controle é essencial e proporcional a desvios de temperatura. O mais importante e mais frequentemente utilizado é o processo fisiológico que regula o fluxo sanguíneo para a pele: quando a temperatura interna sobe acima de um ponto de ajuste, ocorre a vasodilatação, onde mais sangue é direcionado para a pele objetivando transportar o calor interno para a pele a fim de transferir para o meio ambiente (ASHARE, 2013). Quando a temperatura do corpo cai abaixo do ponto, ocorre a vasoconstrição, ou seja, o fluxo sanguíneo da pele é reduzido para conservar o calor.

Este processo também abaixa a temperatura da pele, diminuindo, assim, a troca de calor com o meio. Quando a vasoconstrição não consegue o equilíbrio térmico, o sistema termorregulador provoca o tremor muscular que aumenta o metabolismo nos músculos e, portanto, a produção de calor interno (RUAS, 2001).

Da mesma forma, no caso em que, em ambientes quentes, a vasodilatação e um possível aumento da frequência cardíaca para aumentar a vazão de sangue para a pele não 
sejam suficientes para manter o equilíbrio térmico, é iniciada a produção de suor para que o corpo possa perder calor com a sua evaporação (RUAS, 2001). As glândulas sudoríparas bombam suor para a superfície da pele para a evaporação. Esse mecanismo de defesa é uma maneira poderosa para esfriar a pele e aumentar a perda de calor (ASHARE, 2013).

\subsection{Balanço térmico entre o homem e o ambiente}

O homem é um animal homeotérmico, ou seja, seu organismo é mantido a uma temperatura interna sensivelmente constante. Essa temperatura é da ordem de $37^{\circ} \mathrm{C}$, com limites muito estreitos - entre 36,1 e $37,2^{\circ} \mathrm{C}$-, sendo $32^{\circ} \mathrm{C}$ o limite inferior e $42^{\circ} \mathrm{C}$, o limite superior para sobrevivência, em estado de enfermidade.

O organismo dos homeotérmicos pode ser comparado a uma máquina térmica - sua energia é conseguida através de fenômenos térmicos. A energia térmica produzida pelo organismo humano advém de reações químicas internas, sendo a mais importante a combinação do carbono, introduzido no organismo sob a forma de alimentos, com o oxigênio, extraído do ar pela respiração (FROTA; SCHIFFER, 1999).

A produção de calor através do metabolismo pode ser dividido em:

Metabolismo basal - Refere-se aos processos automáticos de produção de calor para a manutenção das atividades vitais;

Metabolismo muscular - Refere-se à produção de calor pelos músculos quando desenvolvem trabalho mecânico para realizar determinada tarefa (BALTAR, 2006).

Da energia obtida pelo metabolismo, cerca de $20 \%$ é transformada em potencialidade de trabalho, (pelo que se pode dizer que, termodinamicamente falando, a "máquina humana" tem um rendimento muito baixo); e o restante, $80 \%$, se transforma em calor que deve ser dissipado para o organismo manter-se em equilíbrio.

Esta constatação mostra a importância de se proporcionar ao corpo as mais favoráveis formas de ele dispersar enorme quantidade de energia sem lhe causar desconforto. Em clima frio, isso se torna fácil, pois calor é sinônimo de aconchego, conforto; entretanto, em clima quente, a tarefa é mais complexa (BALTAR, 2006).

Tanto o calor produzido como o dissipado dependem da atividade que o indivíduo desenvolve; e com isto, a depender da atividade, haverá maior ou menor necessidade de dissipação de calor produzido pelo metabolismo. Esse calor é dissipado por meio de mecanismos de trocas térmicas entre o corpo e o ambiente, envolvendo: 
- Trocas térmicas sensíveis - Envolvem variações de temperatura (convecção, radiação e condução).

- Trocas térmicas latentes - Provêm da mudança do estado líquido para vapor e do estado de vapor para líquido, sem variações de temperatura (evaporação).

O calor perdido para o ambiente mediante as trocas secas é denominado calor sensível, e é função das diferenças de temperatura entre o corpo e o ambiente. O calor perdido por meio das trocas úmidas é denominado calor latente, e envolve mudanças de fase; o suor (líquido) passa para o estado gasoso pela evaporação (BALTAR, 2006).

Tal dissipação do calor, função dessas trocas térmicas, no corpo ocorre por intermédio da:

- Pele $\left\{\begin{array}{l}\text {-Perda sensível de calor, por convecção e radiação; } \\ \text {-Perda latente de calor, por evaporação do suor e por difusão da } \\ \text { umidade da pele. }\end{array}\right.$ - Respiração $\left\{\begin{array}{l}\text {-Perda sensível de calor, por convecção; } \\ \text {-Perda latente de calor, por evaporação. }\end{array}\right.$

Na Figura 1 podemos ver uma representação esquemática da fisiologia humana e as trocas térmicas. 
Figura 1 - Representação esquemática da fisiologia humana e as trocas térmicas.
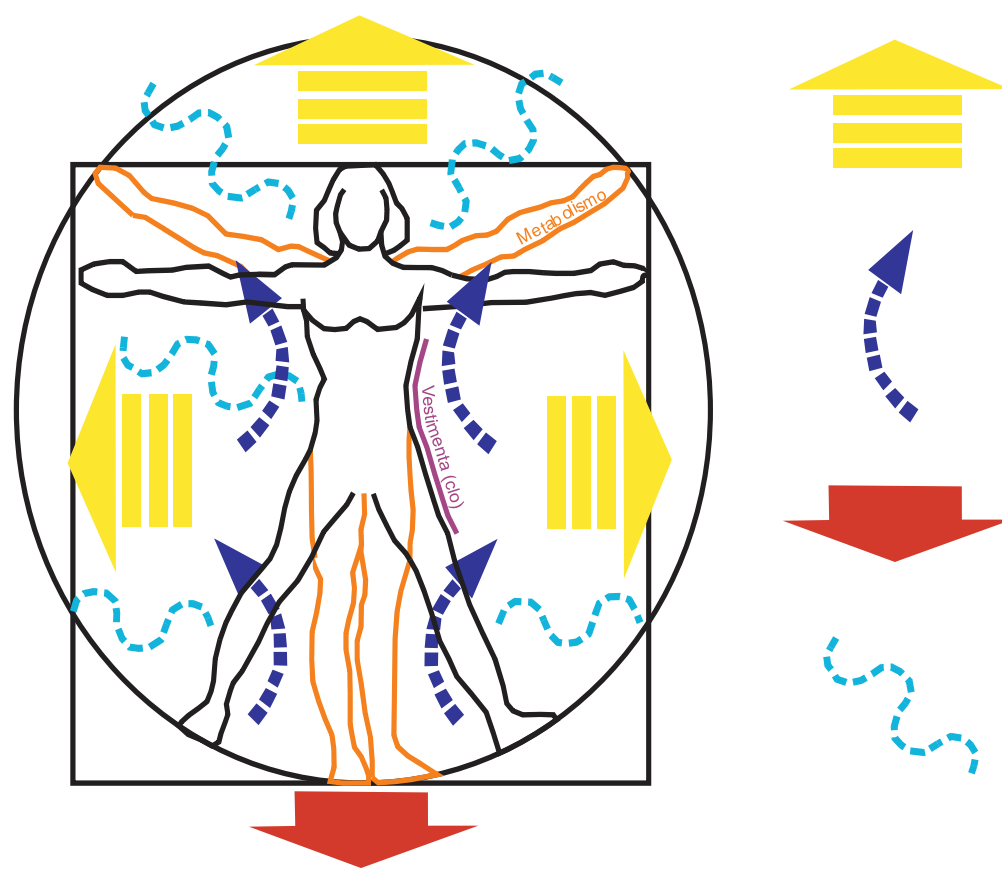

Radiação

Depende da temperatura das superfícies ao redor

Convecção

Depende da temperatura e da velocidade do ar

\section{Condução}

Depende da temperatura das superfícies onde existe um contato físico

\section{Evaporação}

Depende da atividade física, da temperatura das superfícies internas das paredes $\mathrm{e}$ velocidade do ar

Fonte: LabEEE UFSC, 2011

Para Fanger, a primeira condição para que uma pessoa se encontre em estado de conforto térmico é que ela se encontre em balanço térmico, ou que todo o calor gerado pelo organismo seja dissipado em igual proporção para o ambiente, mediante as trocas de calor por convecção, radiação, condução e evaporação (GRANDI, 2006).

De acordo com a ASHARE (2013), o balanço térmico pode ser representado pela equação abaixo, identificada como equação do balanço térmico (1):

$$
M-W=q s k+q r e s+S=(C+R+E s k)+(\text { Cres }+ \text { Eres })+(S s k+S c r)
$$

Onde:

$M=$ taxa de produção de calor metabólico $\left(\mathrm{W} / \mathrm{m}^{2}\right)$;

$W=$ taxa de trabalho mecânico realizado $\left(\mathrm{W} / \mathrm{m}^{2}\right)$;

$q s k=$ taxa total de perda de calor do corpo $\left(\mathrm{W} / \mathrm{m}^{2}\right)$;

qres $=$ taxa total de perda de calor pela respiração $\left(\mathrm{W} / \mathrm{m}^{2}\right)$;

$S=$ taxa total de calor armazenado no corpo $\left(\mathrm{W} / \mathrm{m}^{2}\right)$

$C+R=$ perda de calor sensível da pele $\left(\mathrm{W} / \mathrm{m}^{2}\right)$; 
$E s k=$ taxa total de perda de calor por evaporação a partir da pele $\left(\mathrm{W} / \mathrm{m}^{2}\right) ;$

Cres $=$ taxa de perda de calor por convecção da respiração $\left(\mathrm{W} / \mathrm{m}^{2}\right)$;

Eres $=$ taxa de perda de calor por evaporação da respiração $\left(\mathrm{W} / \mathrm{m}^{2}\right)$;

$S s k=$ taxa de armazenamento de calor na pele $\left(\mathrm{W} / \mathrm{m}^{2}\right)$;

$\mathrm{Scr}=$ taxa de armazenamento de calor no centro do corpo $\left(\mathrm{W} / \mathrm{m}^{2}\right)$.

Todos os termos da equação (1) são dados em forma de potência (watts) por unidade de área $\left(\mathrm{W} / \mathrm{m}^{2}\right)$, e referem-se à área da superfície do corpo nu. Uma expressão convencional para cálculo dessa área é dada pela equação da área de DuBois, equação (2):

$$
A_{D u}=0,202 m^{0,425} \cdot I^{0,725}
$$

Onde:

$\mathrm{A}_{\mathrm{Du}}=$ área superficial do corpo, ou área de DuBois $\left(\mathrm{m}^{2}\right)$;

$\mathrm{m}=$ massa do corpo $(\mathrm{kg})$;

$\mathrm{I}=$ altura do corpo $(\mathrm{m})$.

\subsection{Variáveis envolvidas no conforto térmico}

As principais variáveis que influenciam a avaliação do conforto térmico são: temperatura do ar (ta), temperatura radiante média (trm), velocidade relativa do ar (vr), umidade relativa do ar (UR), isolamento térmico das vestimentas e tipo de atividade física representada pelo metabolismo. As quatro primeiras variáveis são chamadas variáveis ambientais, e as duas últimas, variáveis pessoais, por não dependerem do ambiente (BALTAR, 2006). Estas são as variáveis utilizadas nos cálculos analíticos do conforto térmico, baseados em estudos realizados em câmaras climatizadas (LAMBERTS, 2011).

\subsubsection{Variáveis ambientais}

- Temperatura do ar (ta)

É a temperatura de bulbo seco que é temperatura do ar em torno de nós; é um dos fatores mais importantes. É definida em graus Celsius (SHAKIR, 2001).

- Temperatura radiante média (trm) 
A temperatura radiante é a temperatura de uma superfície exposta em um ambiente. As temperaturas de superfícies individuais são combinadas na temperatura radiante média, expressa em graus Celsius.

Também pode ser definida como a temperatura uniforme de um ambiente imaginário no qual a transferência de calor por radiação do corpo de um indivíduo é igual à transferência de calor radiante em um ambiente real não uniforme (BALTAR, 2006).

O dispositivo de medição mais frequentemente utilizado é o termômetro de globo, porque permite que a temperatura radiante média seja determinada a partir dos valores obtidos da temperatura de globo, da temperatura do ar e da velocidade do ar ao redor do globo.

- Velocidade relativa do ar (vrm)

É o movimento do ar provocado pelos ocupantes ou pelos sujeitos em um determinado ambiente. É expresso em $\mathrm{m} / \mathrm{s}$; e é necessário para determinar a transferência de calor por convecção e por evaporação. É uma variável geralmente difícil de se medir em função de suas rápidas flutuações em intensidade e direção num intervalo de tempo.

- Umidade relativa do ar (UR)

É a quantidade de vapor de água contida no ar. Esse vapor é formado pela evaporação da água, processo originado da mudança do estado líquido para o gasoso, sem modificação da sua temperatura (BALTAR, 2006).

\subsubsection{Variáveis humanas}

- Taxa Metabólica

A taxa metabólica $(\mathrm{M})$ corresponde à quantidade de energia liberada pelo corpo para realizar atividades físicas, ou, conforme a norma ISO 8996 (1990), é a conversão de energia química em energia mecânica e térmica, medindo o custo energético da carga muscular, resultando um índice numérico de atividade. Pode ser expressa por uma unidade met, onde 1 met é igual a 58,2 W/m². É necessário conhecer a energia gasta durante as atividades físicas, uma vez que a produção de energia metabólica aumenta proporcionalmente à intensidade do exercício. A taxa metabólica varia, dependendo da atividade, da pessoa e das condições nas quais a atividade é realizada.

A taxa metabólica pode ser determinada com base na medição do consumo de oxigênio do trabalhador, conforme ISO 8996 (1990), ou pela estimativa com base em 
tabelas normalizadas de referência, em função da atividade, tais como a da ISO 7730 (1994) e da ASHARE (2001).

- Resistência térmica das vestimentas

A vestimenta, quando em uso, se comporta como uma camada de isolamento entre o corpo e o ambiente a qual consequentemente, reduz a perda de calor. $\mathrm{O}$ isolamento térmico provocado pelas vestimentas é expresso dentro de unidades de clo, sendo que 1clo é igual a $0,155 \mathrm{~m}^{2}{ }^{\circ} \mathrm{C} / \mathrm{W}$. O cálculo para a obtenção desse isolamento térmico é feito pelo somatório dos isolamentos das peças que a compõem, conseguidos em tabelas como as da ISSO 7730 (1994) e ISSO 9920 (1995). Os valores listados nessas tabelas foram obtidos em medições realizadas em câmaras climatizadas com o uso de manequins térmicos, fixos na posição em pé. Por evidente, as condições dos testes não reproduzem as situações reais onde o isolamento sofre a influência de fatores como a velocidade do ar, a postura e o movimento do corpo (RUAS, 2001).

\subsection{A percepção do conforto}

A percepção humana do conforto de uma vestimenta é uma interação entre fatores físicos, psicológicos e fisiológicos com o meio ambiente quando vestindo uma peça de vestuário.

O conforto é um fenômeno multidimensional e complexo. A percepção subjetiva de conforto envolve processos complicados em que um grande número de estímulos de roupas e ambientes externos comunica ao cérebro através de multicanais de respostas sensoriais para formar percepções subjetivas.

Essas percepções envolvem um processo psicológico no qual todas as percepções sensoriais relevantes são formuladas, ponderadas, combinadas, e avaliadas contra experiências passadas e desejos presentes para formar uma avaliação global do estado de conforto.

Os processos físicos vão fornecer os sinais ou estímulos para os órgãos sensoriais do corpo humano, que irá recebê-los, produzir impulsos neurofisiológicos, enviá-los para o cérebro, e tomar medidas para ajustar a taxa de transpiração, o fluxo sanguíneo, e às vezes a produção de calor por tremor. O cérebro irá processar os sinais sensoriais para percepção subjetiva formulada de várias sensações individuais, e ainda avaliar e pesa-loscontra a 
experiência e desejos passados, o que é influenciado por muitos fatores, ambientais, sociais, culturais (CHOUDHURY; MAJUMDAR, 2011).

O fluxograma para a percepção subjetiva do conforto (Figura 2) ilustra o processo de como a percepção subjetiva geral de conforto é formulada.

Figura 2 - Percepção subjetiva do conforto

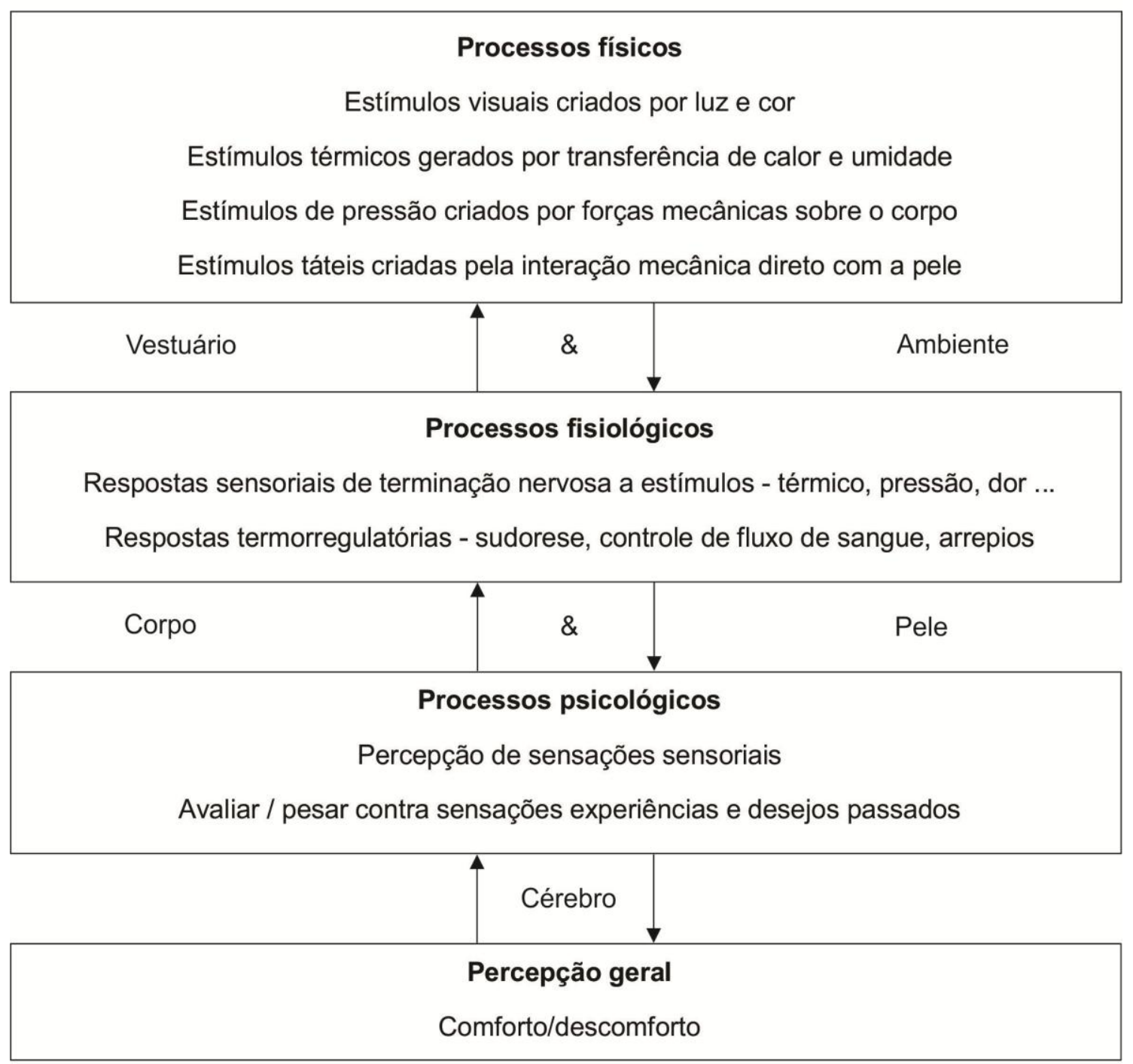

Fonte: A. K. Roy Choudhury, P. K. Majumdar, 2011

\subsection{Aspectos do conforto de vestuário}

Conforme Choudhury e Majumdar (2011), os três aspectos do conforto de vestuário são: 
1 - Conforto térmico: realização de um estado térmico e umidade confortável; que envolve o transporte de calor e umidade através do tecido.

O conforto térmico humano depende da taxa metabólica (produção de calor interno), a perda de calor do corpo e as condições climáticas. O vestuário interfere na perda de calor e na perda de umidade da superfície da pele, por isso desempenha um papel fundamental na manutenção do equilíbrio térmico.

2- Conforto sensorial: o desencadeamento de várias sensações quando um têxtil entra em contato com a pele.

O conforto sensorial é uma percepção do conforto do vestuário, que é a resposta sensorial de terminações nervosas a estímulos externos, incluindo térmico, pressão, dor, etc, que vai produzir os impulsos neurofisiológicos enviados para o cérebro. Estes sinais sensoriais são processados pelo cérebro para formular as percepções subjetivas de sensações e são adequadamente respondidas ajustando o fluxo de sangue, taxa de sudação ou produção de calor por tremores.

3- Conforto ergonômico: capacidade de um têxtil para permitir a liberdade de movimento, peso reduzido, e dar a forma do corpo, conforme necessário.

\subsubsection{Propriedades de conforto do tecido}

Segundo Ravandi e Valizadeh (2011), o comportamento do tecido é afetado pelas propriedades químicas e físicas de suas fibras constitutivas, pelas características físicas e mecânicas dos seus fios constitutivos, e os tratamentos de acabamento que são aplicados sobre ele. E que o tipo de fibra é o parâmetro mais eficaz em definir o conforto do produto final.

As propriedades do fio são por sua vez e em primeiro lugar, criadas pelas propriedades físicas e químicas de suas fibras constitutivas. No entanto, a técnica de fiação, densidade linear do fio, torção, são características que influenciam as propriedades dos fios tais como força, flexão, rigidez, regularidade, propriedades de atrito, isolamento térmico, permeabilidade ao vapor liquido, permeabilidade ao ar, e consequentemente as propriedades dos tecidos e vestuário. 
É pelo entrelaçamento dos fios que o tecido é feito. A partir do tipo de entrelaçamento dos fios para sua formação (ligamento ou construção), o tecido pode ser classificado em tecido plano ou tecido de malha.

Uma das características mais importantes do tecido que afeta as propriedades de conforto de um tecido é a especificação de construção. Parâmetros como espessura, peso por metro quadrado, tipo de ligamento e densidade de fios são os mais importantes. O tipo de construção do tecido cria suas propriedades de espessura e peso e, por outro lado, determina a permeabilidade do ar e do líquido e de isolamento térmico. Além disso, acrescente-se que o tipo de construção do tecido também tem valor estético para os clientes (RAVANDI, VALIZADEH, 2011).

Troynikov e Wardiningsih (2011) em sua pesquisa baseada em tecidos de malha de bambu, verificaram a influência do fator de cobertura na capacidade do tecido de gerenciar o transporte de umidade. Concluíram que, como o fator de cobertura aumenta, o tempo de molhagem também aumenta, e o raio máximo molhado diminui. Isso significa que, com o aumento do fator de cobertura, é preciso mais tempo para molhar um tecido, e a umidade se espalha em um raio menor em determinado tempo de teste. A absorção de líquidos nesses tecidos também é menor em comparação com tecidos de estrutura aberta com alta porosidade durante o mesmo tempo de teste.

Tashkandiet al. (2013), por sua vez, procedeu a um estudo das propriedades de conforto térmico de tecidos utilizados na "abaya", tradicional roupa exterior da mulher muçulmana. Os três tecidos utilizados no estudo foram $100 \%$ lã, 63/37 poliéster/lã e 50/50 poliéster/lã. Esses tecidos, depois de tingidos na cor preta, receberam um tratamento químico chamado Energy ReflectionChemical (ERC) para, em seguida, serem avaliados, sendo que as propriedades de conforto avaliadas foram permeabilidade ao ar, resistência térmica, resistência ao vapor de água e gerenciamento da umidade.

Os resultados mostraram que depois do tratamento ERC as propriedades de conforto térmico melhoraram marginalmente. As propriedades de permeabilidade ao ar e à resistência ao vapor de água não apresentaram estatisticamente diferenças significativas, dentro de um intervalo de confiança de $95 \%$, entre tecidos tingidos com e sem tratamento. Por outro lado, os tecidos 63/37 poliéster/lã e 50/50 poliéster/lã apresentaram melhora na performance de gerenciamento de umidade e resistência ao vapor de água. 
Wardiningsihet al. (2014) realizaram um estudo sobre a influência do uso de um vestuário de proteção de impacto nas propriedades de conforto termo fisiológicas do usuário. O estudo foi comparativo das propriedades de conforto térmico, nomeadamente isolamento térmico, resistência ao vapor de água e permeabilidade ao ar, entre um conjunto típico de desporte com o vestuário de proteção de impacto e um conjunto de desporte sem o vestuário de proteção. Foram utilizados, tanto o conjunto típico de desporte, como vestuário de proteção de impacto, ambos disponíveis comercialmente e reconhecidos por seu relevante desempenho nas propriedades de conforto do usuário. Os testes foram realizados em um manequim térmico.

O uso da peça de vestuário de proteção influenciou o isolamento térmico, e a resistência ao vapor de água, a inclusão do vestuário de proteção de impacto no quadril aumentou o isolamento térmico e a resistência à evaporação.

Troynikov e Ashayeri (2011) analisaram as propriedades de conforto fisiológico de vestuário esportivo utilizado em competições do tipo triathlon. Foram selecionados três tipos de uniforme: um de nível de base e os outros dois especializados; todos disponíveis comercialmente, do mesmo tamanho e semelhante forma. Os uniformes estavam construídos em tecidos de malha de urdume, com composição nylon/elastano, poliéster/elastano, sendo que dois dos três uniformes possuíam um tratamento térmico para ser ativado com a umidade e aumentar a condutividade térmica.

Os uniformes sofreram um pré-tratamento que consistiu num ciclo de lavagem suave numa máquina de lavar roupa doméstica, e secados ao ar antes de serem testados. Os testes foram realizados em um manequim térmico onde foram medidas as propriedades de resistência térmica e a resistência ao vapor de água. Os resultados demonstraram que, em termos de isolamento térmico, aquele que apresentou comparativamente um isolamento inferior aos outros dois uniformes, foi devido, principalmente, à espessura e à densidade do tecido em função de sua construção. Em termos de resistência ao vapor de água, aquele que apresentou uma resistência inferior aos outros dois uniformes, conforme Troynikov e Ashayeri (2011) possivelmente se deve à eficácia do tratamento térmico aplicado.

O estudo demonstrou que as propriedades de conforto fisiológico dos uniformes de triathlon são determinados tanto pelo tecido e materiais utilizados, quanto pela concepção e construção das peças. Alterando a concepção das peças e selecionando materiais com atributos de desempenho relevantes, é possível manipular o vestuário para um desempenho ótimo. 
Mccullough e Larry Kenney (2003) desenvolveram um estudo para avaliar as características de conforto térmico, - especificamente isolamento térmico e resistência ao vapor de água, - de cinco diferentes uniformes de futebol comumente utilizados para práticas de futebol americano. $\mathrm{O}$ valor do isolamento térmico foi realizado utilizando o método constante da norma ASTM F 1291, método de teste padrão para medição do isolamento térmico de roupa utilizando um manequim aquecido, que envolveu a medição da resistência térmica de cada sistema de vestuário usando o manequim aquecido eletricamente em equilíbrio com seu entorno. Para determinar a resistência por evaporação, o manequim foi coberto com uma malha de algodão e pulverizado com água destilada para simular a pele saturada de suor, de acordo com procedimentos publicados pelo próprio Mcculloughem um artigo da ASHRAE Trans. 95: 316-328, 1989.

Esse artigo apresentou dados quantitativos da troca de calor através de uniformes de futebol. Dados esses que podem ser utilizados para realizar com mais precisão o balanço de calor de jogadores de futebol durante jogos e treinamentos.

Ainda segundo Mccullough e Larry Kenney (2003), o isolamento térmico do vestuário aumenta em função da superfície do corpo coberto com vestimenta, e aumenta na medida em que a espessura das camadas de vestuário aumenta. A resistência à evaporação de um conjunto depende das características de permeabilidade à umidade e propriedades de capilaridade dos materiais componentes. O conteúdo de fibras tem pouco a ver com a permeabilidade à umidade de têxteis. A abertura da estrutura do tecido e o tipo de tratamento superficial têm mais impacto. Materiais sólidos e rígidos (usados em capacetes e ombreiras) e enchimento de espuma, com ou sem revestimento, particularmente impedem a evaporação do suor.

Nawaz, Troynikov e Watson (2011) realizaram um estudo cujo principal objetivo foi investigar as propriedades de conforto tátil de tecidos de malha utilizados em vestimentas para bombeiros, como primeira camada ou aquela em contato com a pele. Foram selecionados sete diferentes tipos de tecido de malha, comercialmente disponíveis, com composições e com construções distintas.

As malhas tinham composição de $100 \%$ lã, lã com fibra de bambu, 100\% algodão, lã com elastano, 100\% fibra de bambu, 100\% poliéster, e lã com fibra sintética. As construções variaram de uma malha do tipo jersey para uma malha interlock. Foram avaliadas as propriedades físicas de peso, densidade e espessura. 
As amostras foram avaliadas em estado seco e úmido, para determinar o efeito da umidade sobre as propriedades de superfície, avaliando o conforto do usuário que eventualmente tenha a vestimenta saturada de suor.

As propriedades de conforto tátil foram avaliadas pelo do sistema Kawabata (KES), especificamente coeficiente de atrito (MIU) e rugosidade superficial (SMD), que são os parâmetros que vão caracterizar a superfície do tecido, de forma que as amostras foram testadas do lado de contato com a pele.

Esse estudo revelou que o conteúdo de fibra e a estrutura do tecido eram os parâmetros mais críticos para influenciar as propriedades da superfície do tecido relevantes para o conforto sensorial; e, por outro lado, mostrou que as estruturas jersey simples eram o melhor para serem usadas em contato com a pele, e que $100 \%$ lã e lã misturada com fibra de bambu proporcionavam melhor conforto sensorial se comparados com $100 \%$ algodão ou $100 \%$ poliéster.

\subsection{A importância do conforto térmico}

No âmbito da melhoria das condições de trabalho, da qualidade de vida, da segurança e produtividade, o ambiente térmico desempenha um papel importante. A produtividade é condicionada pelo conforto/desconforto sentidos pela população, afetando, assim, diversas áreas ocupacionais (COSTA et al., 2011). Couto (1995), por sua vez, refere que a atividade intelectual fica claramente comprometida em ambientes quentes e úmidos. Ao lado disso, ocorre o comprometimento da produtividade, independente de qual seja o tipo de trabalho.

Entretanto, estabelecer uma relação entre conforto térmico e produtividade é uma tarefa complexa, uma vez que ambos dependem de vários fatores que, quando combinados, não geram necessariamente o mesmo efeito. Um outro complicador é a definição de critérios objetivos de medida de desempenho humano característico do tipo de atividade desenvolvida, como esclarece Grandi (2006).

Ainda segundo Couto (1995), entre temperaturas de $24^{\circ}$ a $40^{\circ} \mathrm{C}$, cada $1^{\circ}$ centígrado de aumento da temperatura ambiente (temperatura de bulbo seco ou temperatura de globo, se houver calor radiante), aumenta a sobrecarga fisiológica em 1\%. Assim, um trabalhador pode desenvolver de forma contínua 1/3 (33,33\%) de sua capacidade aeróbica num ambiente sem carga térmica (até $24^{\circ} \mathrm{C}$ ); se a temperatura de bulbo seco ou de globo for de $30^{\circ} \mathrm{C}$ (aumento de 
$6^{\circ} \mathrm{C}$ ), o máximo exigido durante a jornada cairá para $27 \%$ da capacidade aeróbica máxima (COUTO, 1995).

E Silva et al. (2010) alertaram: com o aumento da temperatura, o rendimento cai, a velocidade do trabalho e a concentração diminuem, as pausas tornam-se maiores e mais frequentes e os erros e os acidentes aumentam, sendo esse efeito claro a partir dos $30^{\circ} \mathrm{C}$.

Por outro lado, podem ocorrer diversos acometimentos de saúde em consequência do trabalho em altas temperaturas, sendo alguns mais graves e outros menos graves. Também algumas doenças que se encontravam em estado latente podem piorar na presença do calor, doenças estas que constituem contraindicação para o trabalho nesses ambientes. Conforme Couto (1995), as doenças ocasionadas pelo calor e que podem acometer até indivíduos sadios são: hipetermia ou intermação, tontura e desfalecimento devido à deficiência de sódio, tontura e desfalecimento causados pela deficiência relativa de volume líquido circulante, tontura e desfalecimento resultante da evaporação inadequada do suor, e também a desidratação, e distúrbios psíquicos.

Além do descrito, Costa et al. (2011) ainda acrescenta que a excessiva exposição ao calor está relacionada com o estresse por calor, sendo prejudicial para a saúde (COSTA et al., 2011).

Conforme Lamberts (2011), o estresse térmico pode ser considerado como o estado psicofisiológico a que está submetida uma pessoa, quando exposta a situações ambientais extremas de frio ou calor. E que o ser humano no desempenho de suas atividades, quando submetido a condições de estresse térmico, tem entre outros sintomas, a debilitação do estado geral de saúde, as alterações das reações psicossensoriais e a queda da capacidade de produção.

Chande (2009), por seu lado, frisa que, em ambientes industriais onde o calor é um fator primordial no processo produtivo e onde a presença de trabalhadores é requerida, a probabilidade de ocorrer fenômenos de estresse térmico é uma realidade; por esse motivo, o risco de acidentes associados ao calor excessivo constitui uma ameaça constante. Nessas condições, a concentração e a capacidade física dos trabalhadores são afetadas, o que, naturalmente, compromete a produtividade da empresa e, não menos importante, cria condições favoráveis à ocorrência de acidentes de trabalho ou o agravamento de patologias existentes, nomeadamente aquelas relacionadas com a exposição contínua ou intermitente a ambientes térmicos adversos.

Além dos acima citados, de acordo com Costa et al. (2011), como consequência da exposição a temperaturas elevadas (interiores ou exteriores), ocorrem frequentes variações de 
comportamento, humor, distração, fadiga, desmotivação e absenteísmo. Salientam ainda outros problemas como, por exemplo, diminuição da capacidade mental e da destreza, aumento do tempo de reação (no caso da desidratação), podendo ainda causar doenças crônicas e, em alguns casos, a morte. Aumentos da temperatura central do corpo e exposições crônicas a níveis elevados de estresse por calor estão também associados a doenças: estresse, infertilidade temporária (homens e mulheres), elevada frequência cardíaca, distúrbios de sono, cansaço e irritabilidade.

\subsection{Normas sobre conforto térmico}

As principais normas internacionais sobre conforto térmico foram desenvolvidas pela International Organization for Standardization (ISO) e pela American Society of Heating, Refrigerating and Air-conditioning Enginners (ASHARE), baseadas em estudos que envolvem as variáveis que influenciam o conforto térmico, seja em ambientes condicionados ou não.

\subsubsection{ISO 11399 (1995) - Ergonomia do ambiente térmico: princípios e aplicações de normas internacionais relevantes}

Nessa norma é especificado o uso correto, efetivo e prático dos padrões internacionais relacionados com a ergonomia do ambiente térmico; é descrito o uso complementar das normas na avaliação do ambiente. Apresenta princípios ergonômicos do ambiente térmico, conceitos e princípios básicos da resposta humana ao ambiente térmico. Descreve parâmetros do ambiente térmico, métodos de medição e conceitos. Recomenda, ainda, consultar normas específicas para cada tipo de ambiente para avaliar as suas condições.

\subsubsection{ISO 7726 (1998) - Ergonomia do ambiente térmico: instrumentos para medições das variáveis físicas}

O objetivo dessa norma internacional é definir padrões e orientar as medições dos parâmetros físicos de ambientes térmicos, tanto para ambientes moderados, análise de conforto térmico, como ambientes extremos e análises de estresse térmico. 


\subsubsection{ISO 7243 (1989) - Ambientes Quentes - Estimativa do estresse por calor sobre o trabalhador, baseado no IBUTG - (bulbo úmido e temperatura de globo)}

Método que pode ser facilmente utilizado num ambiente industrial para avaliar tensões sobre um indivíduo. Aplica-se à avaliação do efeito médio do calor sobre o homem durante um período representativo de sua atividade; mas não se aplica a períodos muito curtos, nem na avaliação próximo à zona de conforto.

\subsubsection{ISO 7933 (2004) - Ergonomia do ambiente térmico - determinação analítica e interpretação de estresse por calor usando cálculo da taxa requerida de suor}

A norma especifica um método para a avaliação analítica e a interpretação do estresse térmico de um indivíduo em um ambiente quente. Descreve um método para prever a taxa de suor e a temperatura do núcleo interno do corpo humano que irá desenvolver-se em resposta às condições de trabalho.

Os vários termos utilizados nesse modelo e, em particular, no equilíbrio de calor, mostram a influência dos diferentes parâmetros físicos do ambiente em relação ao estresse térmico experimentado pela pessoa. Dessa forma, essa norma internacional torna possível determinar qual o parâmetro ou o grupo de parâmetros que deve ser modificado, e em que medida, a fim de reduzir o risco de tensões fisiológicas.

\subsubsection{ISO 7730 (2005) - Ambientes térmicos moderados: determinação dos índices PMV e PPD e especificação das condições para conforto térmico}

Essa norma apresenta os métodos para prever a sensação térmica geral e o grau de desconforto (insatisfação térmica) das pessoas expostas a ambientes térmicos moderados. Permite determinar e interpretar conforto térmico utilizando o cálculo do PMV (PredictedMean Vote) e PPD (PercentageofDissatisfied), dando as condições ambientais 
consideradas aceitáveis para o conforto térmico geral, bem como aquelas que representam desconforto.

Nesta nova versão, foi adicionado um método para avaliar de períodos longos, como também informações sobre desconforto térmico localizado, condições em estado não estacionário e adaptação. Além disso, foi adicionado um anexo estipulando como os requisitos de conforto térmico podem ser expressos em diferentes categorias.

\subsubsection{ISO 8996 (2004) - Ergonomia: determinação da produção de calor metabólico}

Essa norma especifica diferentes métodos para determinar a taxa metabólica no contexto da ergonomia do ambiente de trabalho. Também pode ser usada para outras aplicações como, por exemplo, a avaliação das práticas de trabalho, o custo energético de trabalhos específicos ou atividades esportivas, o custo total de uma atividade, etc.

\subsubsection{ISO 9920 (2007) - Ergonomia do ambiente térmico: estimativa do isolamento térmico e da resistência evaporativa de um conjunto de vestimentas}

Essa norma estabelece os métodos para estimar as características térmicas (resistência à perda de calor sensível e à perda por evaporação), em condições de estado estacionário, de um conjunto de roupas com base em valores de vestuário conhecidos, trajes e tecidos.

\subsubsection{ISO 10551 (1995) - Ergonomia do ambiente térmico: avaliação da influência do ambiente térmico utilizando escalas de julgamento subjetivo}

Essa norma fornece um conjunto de escalas de julgamento de percepção, avaliação, preferência e tolerância do ambiente térmico, para ser utilizado na obtenção de dados confiáveis e comparativos sobre os aspectos subjetivos do conforto térmico. 


\subsubsection{ASHARE Standard 55 (2013) - Condições ambientais térmicas para ocupação humana}

O objetivo dessa norma é especificar a combinação de fatores ambientais térmicos dos espaços internos e os fatores pessoais que irão fornecer condições aceitáveis para a maioria dos ocupantes dentro de um espaço. Sendo que a "maioria" é definida em $80 \%$ de aceitabilidade global, enquanto limites de descontentamento específicos variam para fontes diferentes de desconforto local.

\subsubsection{NR 15 - Atividades e Operações Insalubres}

A Norma Regulamentadora - NR 15 fixa os limites máximos de tempo a que um trabalhador pode ficar exposto a uma condição de estresse por calor, no desempenho de sua atividade, utilizando o IBUTG. Relaciona o tipo de atividade desempenhada com os ciclos de trabalho/descanso em função dos valores máximos de referência do IBUTG tabelados.

\subsubsection{NR 17 - Norma Regulamentadora de Ergonomia}

Esta Norma Regulamentadora visa estabelecer os parâmetros que permitam a adaptação das condições de trabalho às características psicofisiológicas dos trabalhadores, de modo a proporcionar o máximo de conforto, segurança e desempenho eficiente.

As condições de trabalho incluem aspectos relacionados com o levantamento, transporte e descarga de materiais, ao mobiliário, aos equipamentos e às condições ambientais do posto de trabalho e à própria organização do trabalho.

Especificamente quanto às condições ambientais do posto de trabalho, essa norma estabelece que, nos locais de trabalho onde são executadas atividades que exijam solicitação intelectual e atenção constantes, tais como: salas de controle, laboratórios escritórios, salas de desenvolvimento ou análise de projetos, dentre outros, é recomendado um índice de temperatura efetiva entre $20^{\circ} \mathrm{C}$ e $23^{\circ} \mathrm{C}$, velocidade do ar não superiora $0,75 \mathrm{~m} / \mathrm{s}$, umidade relativa do ar não inferior a 40\%, níveis de ruído conforme NBR 10152. 
2.8.12 ABNT NBR 16401-2:2008 Instalações centrais de ar condicionado para conforto: Parâmetros básicos de projeto

Essa norma determina as bases fundamentais para elaborar de projetos de instalações de unidades com capacidade individual a partir de $9000 \mathrm{kcal} / \mathrm{h}$. 


\section{Têxteis Técnicos}

Têxteis técnicos são definidos de acordo com o uso ou aplicação final do produto, e não de acordo com a composição ou estrutura do material (IPT, Instituto de Pesquisas Tecnológicas).

Os têxteis técnicos são estruturas especificamente projetadas e desenvolvidas para utilização em produtos, processos ou serviços de quase todas as áreas industriais. Por outras palavras, são produtos que pretendem satisfazer requisitos funcionais bem determinados, distinguindo-se, nesse aspecto, dos têxteis convencionais, nos quais as necessidades estéticas de conforto assumem importância primordial (COSTA, 2014). Na Figura 3 podemos ver a quantidade e diversidade de segmentos industriais onde os têxteis técnicos podem ser utilizados.

Figura 3 - Classificação dos têxteis técnicos

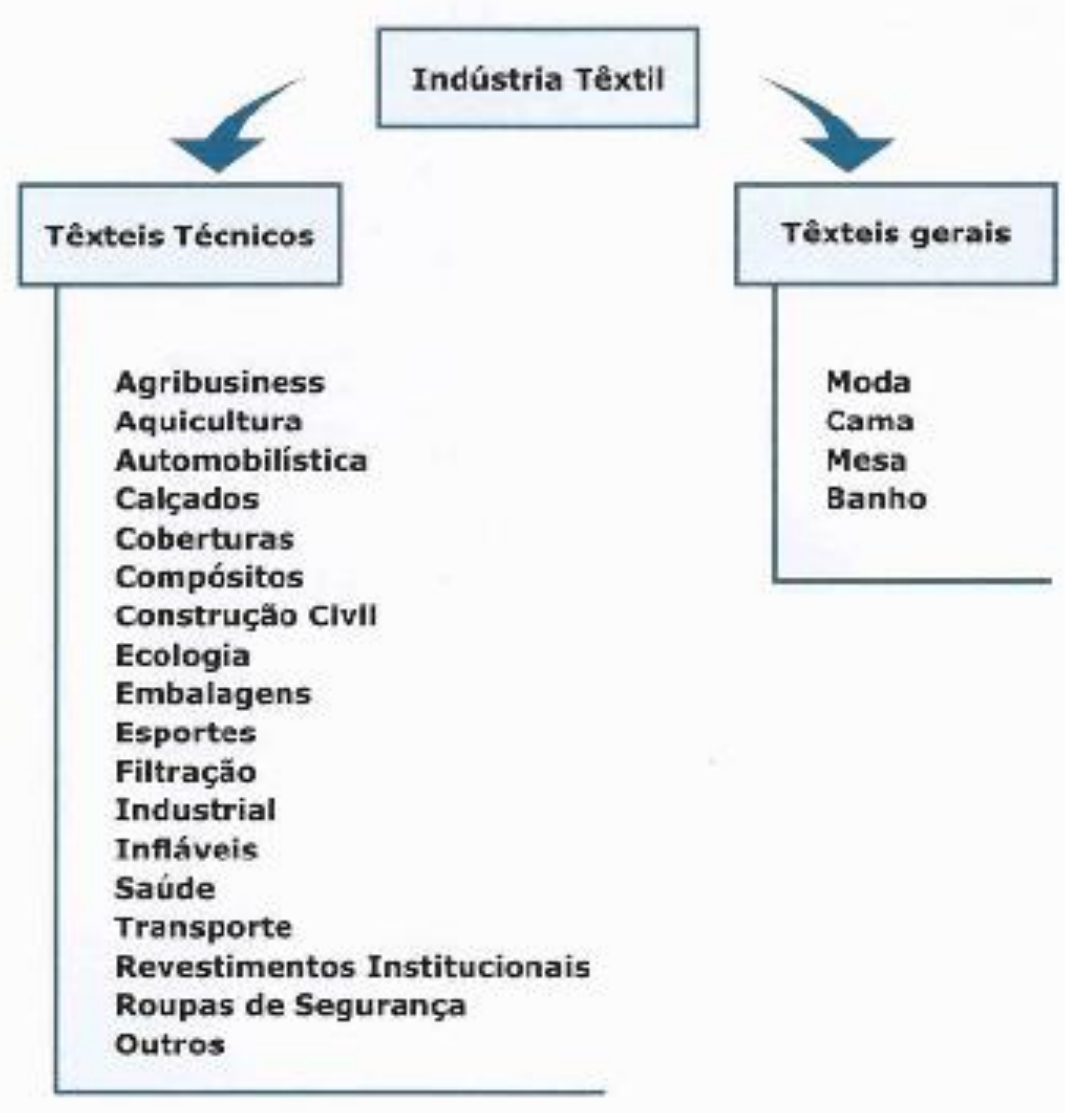

Fonte: Manual de Têxteis Técnicos, ABINT, 2005 


\subsection{Têxteis Técnicos na Proteção Pessoal contra riscos de origem térmica}

Consideram têxteis de proteção, o vestuário e outros produtos produzidos com tecidos, concebidos para proteger o utilizador de efeitos ambientais perigosos que possam resultar em danos ou morte (ARAÚJO, FANGUEIRO, HONG, 2000).

As condições ambientais são determinantes (em função dos riscos) do tipo e necessidade de proteção especifica, a qual deverá ser equacionada em conformidade com o nível de proteção desejado, o nível de conforto pretendido, o tempo de vida dos artigos, etc, e ainda os aspectos sociológicos, estéticos e legislativos/regulamentares (ARAÚJO, FANGUEIRO, HONG, 2000).

Uma das principais funções do vestuário e têxteis de proteção é proteger o usuário contra o calor extremo e o fogo. As necessidades de proteção contra o calor extremo, chamas, respingo de metais fundidos, fontes de radiação, etc., são das condições mais evidentes que requerem a utilização de vestuário com características especiais (ARAÚJO, FANGUEIRO, HONG, 2000).

As características e funcionalidades do vestuário de proteção por sua vez estão muito relacionadas com os têxteis utilizados na sua produção, dependendo estes das necessidades específicas de cada aplicação.

Conforme Holmes (2000), as propriedades ideais de um tecido destinado à proteção contra o calor e a chama são:

1- Alto nível de retardamento da chama e não contribuição para lesões do portador da vestimenta;

2- Integridade do tecido, mantendo uma barreira e evitando a exposição direta ao risco;

3- Baixo encolhimento, mantendo uma camada de isolamento de ar;

4-Bom isolamento térmico: reduz a transferência de calor de modo a dar tempo de o usuário escapar antes de o calor e/ou fogo causar danos à sua saúde;

5-Facilidade de limpeza, sem que se reduzam ou percam as suas características de retardante de chama;

6-Leve e confortável;

7-Repelência ao óleo, protegendo contra contaminantes inflamáveis, como óleos e solventes. 
Por outro lado, o comportamento das fibras frente ao fogo é influenciado - e muitas vezes determinado - por uma série de temperaturas de transição térmica e parâmetros termodinâmicos. O índice limite de oxigênio (LOI) é uma medida inerente à queima do material. Produtos com valores de LOI acima de $21 \%$ inflamam e queimam mais lentamente. Em geral, fibras e produtos têxteis com valores de LOI de, aproximadamente, $26 \%$ - 28\% podem ser considerados como retardante de chama (HORROCKS; PRICE, 2001 apud ALBUQUERQUE, 2013). 


\section{Materiais e Métodos}

Foram selecionados no mercado onze tecidos utilizados na fabricação de vestimentas destinadas à proteção frente aos riscos de origem térmica (calor e chamas). As vestimentas são fabricadas sob várias formas: camisa, calça, macacão, blusão, jaqueta, capa, entre outros. Tais vestimentas estão destinadas à proteção dos trabalhadores em diferentes Setores da Indústria: Setor Elétrico, Setor Petroquímico, Setor Siderúrgico e de Fundição, Mineração, entre outros setores ou nos quais se podem apresentar riscos de origem térmica (calor e chamas).

\subsection{Caracterização dos tecidos}

Foram determinados os ligamentos (NBR 12546) e a densidades de fios (NBR 10588), a composição da matéria-prima foi indicada pelos fabricantes dos tecidos:

a) Tecido 1: ligação sarja, com densidade de 26 fios/cm e 19 batidas/cm e composição $93 \%$ meta-aramida $5 \%$ para aramida $2 \%$ fibra de carbono

b) Tecido 2: ligação sarja, com densidade de 27 fios/cm e 20 batidas $/ \mathrm{cm}$ e composição $54 \%$ modacrilico $44 \%$ algodão $2 \%$ fibra de carbono

c) Tecido 3: ligação sarja, com densidade de 26 fios/cm e 14 batidas/cm e composição $54 \%$ modacrilico $44 \%$ algodão $2 \%$ fibra de carbono

d) Tecido 4: ligação sarja, com densidade de 28 fios/cm e 18 batidas $/ \mathrm{cm}$ e composição $60 \%$ modacrilico, $35 \%$ algodão, $4,5 \%$ poliamida, $0,5 \%$ fibra de carbono

e) Tecido 5: ligação sarja, com densidade de 27 fios $/ \mathrm{cm}$ e 20 batidas $/ \mathrm{cm}$ e composição $48 \%$ modacrilico, $37 \%$ liocel, $15 \%$ para aramida

f) Tecido 6: ligação sarja, com densidade de 30 fios/cm e 17 batidas $/ \mathrm{cm}$ e composição $100 \%$ algodão FR

g) Tecido 7: ligação sarja, com densidade de 30 fios/cm e 24 batidas/cm e composição $50 \%$ aramida e $50 \%$ viscose

h) Tecido 8: ligação sarja, com densidade de 32 fios/cm e 19 batidas/cm e composição $88 \%$ algodão FR, $12 \%$ poliamida de alta tenacidade 
i) Tecido 9: ligação tela, com densidade de 26 fios/cm e 18 batidas/cm e composição $93 \%$ meta aramida $5 \%$ para aramida $2 \%$ fibra de carbono

j) Tecido 10: ligação sarja, com densidade de 30 fios $/ \mathrm{cm}$ e 20 batidas $/ \mathrm{cm}$ e composição $93 \%$ meta aramida $5 \%$ para aramida $2 \%$ fibra de carbono

k) Tecido 11: ligação sarja, com densidade de 28 fios $/ \mathrm{cm}$ e 20 batidas $/ \mathrm{cm}$ e composição $54 \%$ modacrilico $44 \%$ algodão $2 \%$ fibra de carbono

A Figura 4 mostra os tecidos estudados.

Figura 4 - Fotografias dos tecidos objeto de estudo

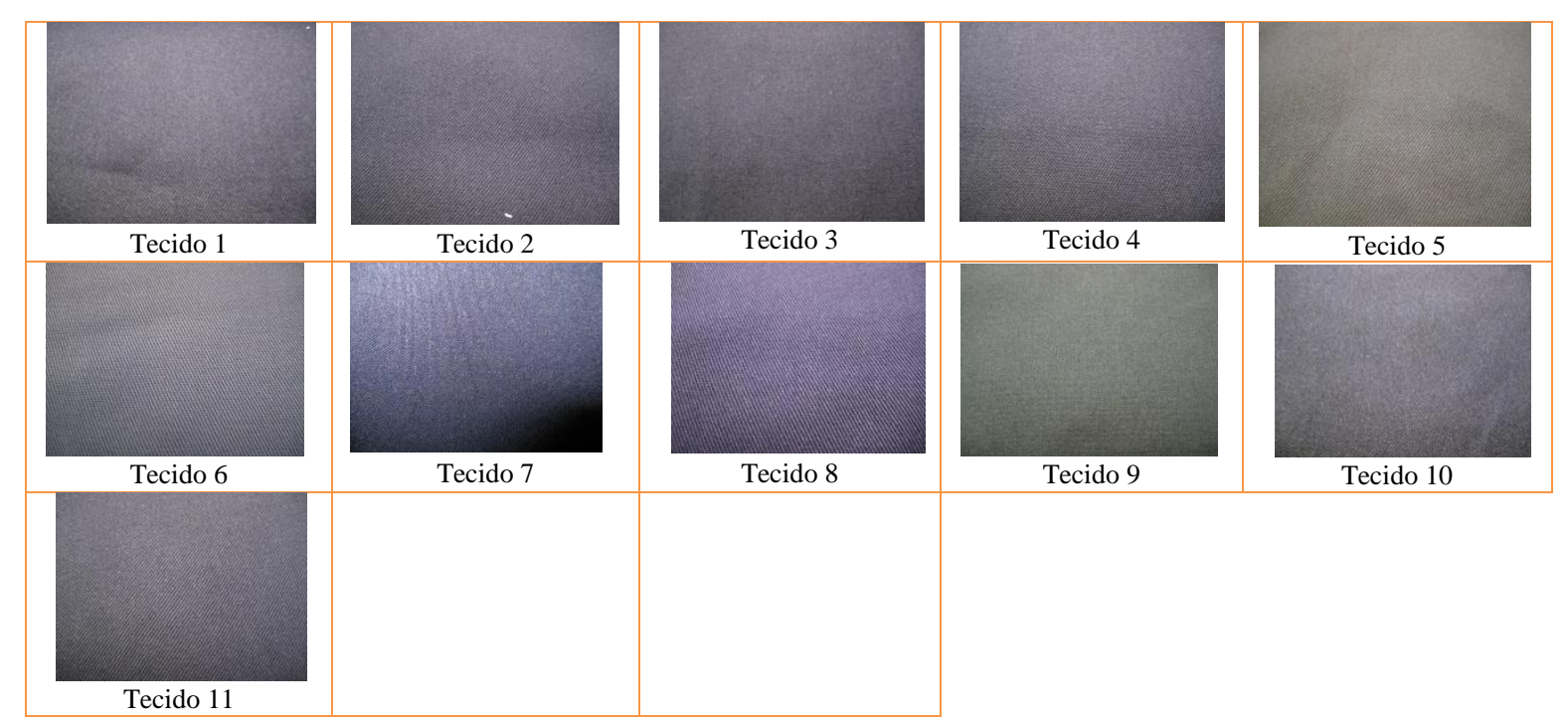

Fonte: Cristina Salete Valentin, 2014

\subsection{Ensaio de determinação da gramatura}

De acordo com a norma ASTM D3776 - 96, para realizar o ensaio devem ser preparados, utilizando-se gabarito com $100 \mathrm{~cm}^{2}$ de área cada um, cinco corpos de prova. $\mathrm{Na}$ sequência, os corpos de prova devem ser pesados em uma balança analítica; a partir do peso obtido, pode-se efetuar o cálculo da obtenção da gramatura do artigo em gramas por metro quadrado. 


\subsection{Ensaios de conforto térmico}

\subsubsection{Transporte de umidade em tecidos}

O ensaio de transporte de umidade nos tecidos foi desenvolvido conforme a Norma AATCC 195:2011; o equipamento utilizado foi o de transporte de umidade 12016I12, apresentado na Figura 5.

Figura 5 - Equipamento de transporte de umidade

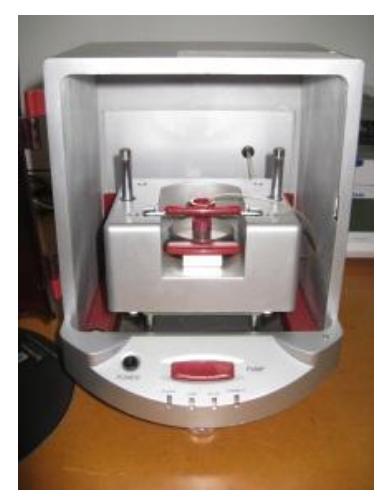

Fonte: Cristina Salete Valentin, 2014

Antes de realizar o ensaio, as amostras sofreram um pré-tratamento que consistiu em uma lavagem mediante ultrassom.

Descrição do ensaio: Sobre a face interior do tecido incide-se um volume determinado de uma dissolução salina de condutividade de $16 \mu \mathrm{S}$. A forma com que a dissolução se expande pela face de incidência e no seu inverso, é registrada com ajuda de uma disposição circular e concêntrica de sensores.

Toda a informação que se armazena durante esse ensaio se traduz em uma série de variáveis que determinarão o comportamento do tecido.

\subsubsection{Resistência ao vapor de água (Ret)}

Segundo a norma EN 31092, para determinar a resistência ao vapor de água, se recobre uma placa porosa aquecida eletricamente com uma membrana impermeável a água líquida, mas permeável ao vapor de água. A água fornecida à placa aquecida se evapora e 
passa através da membrana em forma de vapor, de modo que a água líquida não entre em contato com a amostra de teste.

Com a amostra de teste colocada sobre a membrana, o fluxo de calor necessário para manter a placa a uma temperatura constante, é uma medida do grau de evaporação da água e dele se determina a resistência ao vapor de água da amostra de teste.

Nesse caso se ajusta tanto a superfície de medida como o ambiente a $35^{\circ} \mathrm{C}$, e a umidade relativa a $40 \%$. Utilizam-se condições isotérmicas para evitar a condensação de vapor de água dentro da amostra de ensaio; a velocidade do ar é mantida em $1 \mathrm{~m} / \mathrm{s}$. A Figura 6 mostra o equipamento utilizado na realização desse ensaio.

Figura 6 - Vista geral do Skin Model

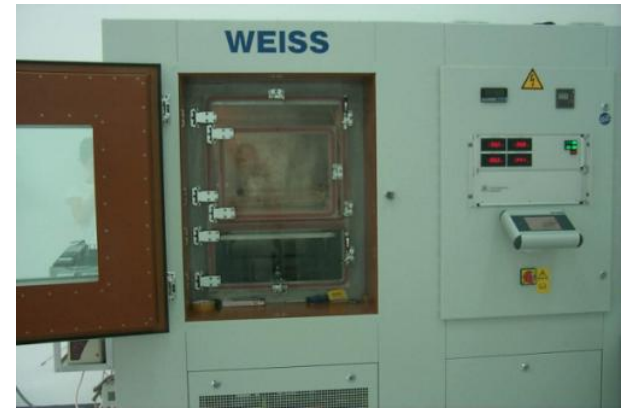

Fonte: Cristina Salete Valentin, 2014

Um tecido com baixo Ret não opõe resistência à difusão de vapor de água (suor), ou seja, a transpirabilidade desse tecido é elevada.

Para esse ensaio foram selecionados quatro tecidos: os dois tecidos com melhores resultados no ensaio de transporte de umidade e os dois tecidos com piores resultados.

\subsection{Ensaios de conforto físico e ergonômico}

\subsubsection{Ensaio de determinação da gramatura para pequenas amostras}

Para realizar os ensaios de conforto físico e ergonômico foi necessário determinar a gramatura das diferentes amostras. Utilizou-se como referência a norma UNE-EM 12127:1998. 


\subsubsection{Kawabata Evaluation System (KES), para conforto tátil}

Segundo a Associação de Investigação da Indústria Têxtil (AITEX), o KES é um sistema de medida que permite detectar quantitativamente e de modo objetivo o toque de um tecido a partir da análise de um conjunto de propriedades mecânicas, propriedades medidas por meio de uma série de módulos que compõem o sistema de experimentação.

Mediante as medidas das propriedades mecânicas realizadas pelos distintos módulos, se pode obter uma série de variáveis físicas quantitativas que, posteriormente, se utilizam para determinar as variáveis qualitativas que vão caracterizar o toque dos tecidos. As Figuras 7, 8, 9 e 10 mostram os equipamentos utilizados na determinação dessas propriedades.

Figura 7 - KES-FB1: Tensão e tensão de corte

Figura 8 - KES-FB2: Flexão ou dobra

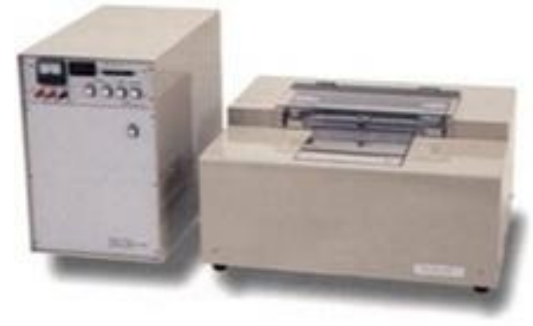

Fonte: Cristina Salete Valentin, 2014

Figura 9 - KES-FB3: Compressão

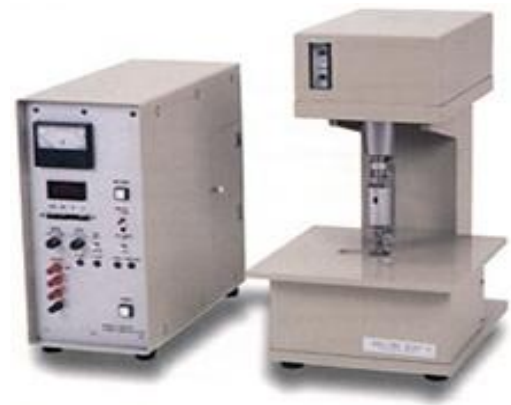

Fonte: Cristina Salete Valentin, 2014

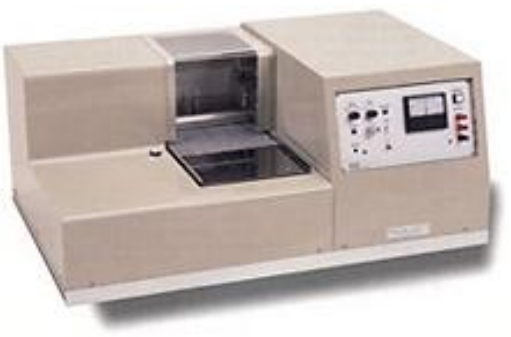

Fonte: Cristina Salete Valentin, 2014

Figura 10 - KES-FB4: Superfície

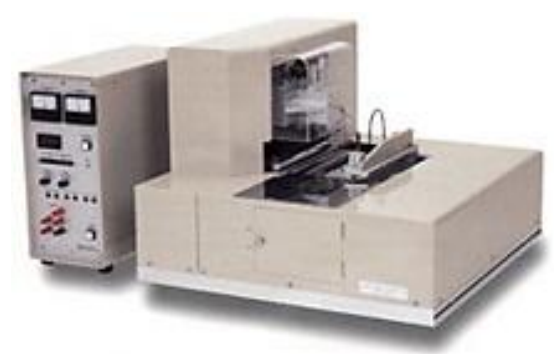

Fonte: Cristina Salete Valentin, 2014 


\subsubsection{Thermo Labo II}

O equipamento Thermo Labo II avalia a sensação frio/calor ao medir a condutividade térmica e as propriedades de retenção de calor de uma forma rápida e precisa. A sensação frio/calor é a sensação que se experimenta quando a pele humana toca um objeto; neste caso, um artigo têxtil.

Essa sensação afeta fortemente a seleção feita pelas pessoas quando compram tecidos ou roupas. A avaliação objetiva dessa sensação se tornou em muito importante desde a última década. Yoneda e Kawabata, professores da Universidade de Kyoto, foram os primeiros pesquisadores a expressarem a sensação frio/calor de forma objetiva utilizando o Thermo Labo. Eles projetaram o Thermo Labo II e introduziram o máximo nível do fluxo de calor por contato qmáx (W/m2 K) como a medida das características térmicas transitoriais (OGLAKCIOGLU; MARMARALI, 2010). Esse parâmetro caracteriza perfeitamente a sensação térmica transitória que se obtém no momento do toque.

O equipamento KES-F7 Thermo Labo II (Figura 11) pode medir basicamente três aspectos:

$1^{\circ}$ - Medida da sensação frio/calor mediante avaliação do valor qmáx. Essa propriedade esta relacionada com a propriedade de absorção de calor do tecido. Este valor de qmáx é medido como a quantidade relacionada com a sensação de frio/calor do tecido.

$2^{\circ}$ - Medida da condutividade térmica $(\mathrm{k})$.

$3^{\circ}$ - Medida da propriedade de retenção do calor.

Figura 11 - KES-F7 Thermo Labo II

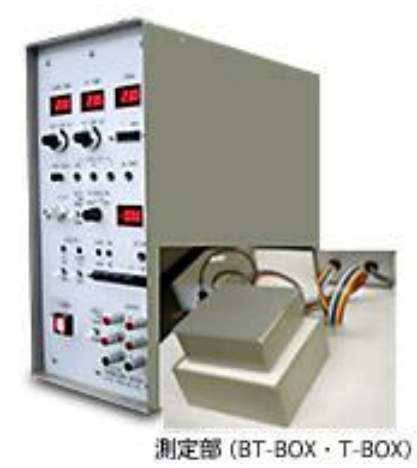

Fonte: Cristina Salete Valentin, 2014 
Tais parâmetros se incluem no THV (Total Hand Value), ou valor total do toque, para tecidos em contato direto com a pele (Modelo de gênero de malha ou roupa interior). Entretanto, eles podem ser medidos para todo tipo de tecido.

Para esse ensaio foram selecionados quatro tecidos: os dois tecidos com melhores resultados no ensaio de transporte de umidade e os dois tecidos com piores resultados; ou seja, os mesmos tecidos que foram utilizados no ensaio de resistência ao vapor de água (Ret).

\subsection{Estudo estatístico}

Para verificar a significância dos valores experimentais foi escolhido o modelo estatístico "planejamento aleatorizado por níveis".

\subsubsection{Planejamento aleatorizado por níveis}

Esse tipo de planejamento é recomendado quando se deseja estudar ensaios de diferentes tratamentos (a) de uma única variável de influência, com réplicas (n) para cada nível. Segundo Montgomery (2009), seu objetivo é, mediante teste de hipóteses apropriadas, avaliar os efeitos dos tratamentos e estimá-los. A Tabela 2 mostra a matriz para a execução dos ensaios.

Tabela 3 - Representação genérica de um planejamento aleatorizado por níveis, utilizando n réplicas

\begin{tabular}{|c|c|c|c|c|c|c|}
\hline Tratamentos & & erva & & & Totais & Médias \\
\hline 1 & $Y_{11}$ & $Y_{21}$ & $\ldots$ & $Y_{1 n}$ & $Y_{1 .}$ & $\bar{y}_{1 .}$ \\
\hline 2 & $Y_{21}$ & $Y_{22}$ & $\ldots$ & $Y_{2 n}$ & $Y_{2}$ & $\bar{y}_{2 .}$ \\
\hline . & . & . & $\ldots$ & . & . & . \\
\hline . & . & . & $\ldots$ & . & . & . \\
\hline . & . & . & $\ldots$ & . & . & . \\
\hline$a$ & $Y_{a 1}$ & $Y_{a 2}$ & $\ldots$ & $y_{a n}$ & $Y_{a}$ & $\bar{y}_{a .}$ \\
\hline
\end{tabular}

O modelo estatístico linear é definido na equação 3, onde: yij é o j-ésimo elemento obtido no tratamento i; $\mu$ é a média; ti é um parâmetro que define o efeito de cada tratamento; e eij é um componente devido a erros aleatórios. 


$$
\text { Yij }=\mu+t i+e i j, \text { com } i=1,2, \ldots, \text { a e } j=1,2, \ldots, n
$$

O modelo apresentado é denominado análise de variância de um fator único. A análise será objetiva se o planejamento experimental for completamente aleatorizado (MONTGOMERY, 2009).

A análise dos resultados pode ser feita por meio de um modelo de efeitos fixos ou de um modelo de efeitos aleatórios (modelo de componentes de variância). Na análise do modelo de efeitos fixos, os tratamentos são escolhidos de forma específica; o teste de hipóteses referese às médias dos tratamentos; e as conclusões extraídas são aplicáveis somente aos níveis considerados na análise (RODRIGUES; IEMMA, 2009).

No modelo de efeitos aleatórios, o teste de hipóteses verifica a variância dos efeitos dos tratamentos; e as conclusões da análise podem ser estendidas para todos os outros tratamentos da população, pois os tratamentos analisados representam uma amostra aleatória de uma população de tratamentos (FREUND, 2006).

\subsubsection{Teste de hipóteses}

O teste de hipótese é utilizado para comparar as médias dos tratamentos. A verificação do teste é feita pela da análise de variância. Caso $\mathrm{H}_{0}$ seja verdadeira, conclui-se que todos os tratamentos têm média igual a $\mu$.

$$
\begin{aligned}
& \mathrm{H}_{0}: \mu_{1}=\mu_{2}=\ldots=\mu_{\mathrm{a}} \\
& \mathrm{H}_{1}: \mu_{\mathrm{i}} \neq \mu_{\mathrm{j}} \text { (pelo menos para um par } \mathrm{i}, \mathrm{j} \text { ) }
\end{aligned}
$$

\subsubsection{Análise de variância (ANOVA)}

A análise de variância é utilizada para aceitar ou rejeitar as hipóteses investigadas com os experimentos. Seu objetivo é analisar os valores e identificar os fatores principais e interações que produzem efeitos significativos nas respostas (SANCHES, 2006).

Os resultados da ANOVA são normalmente apresentados em uma tabela, conforme mostra a Tabela 4. 
Tabela 4 - Resumo da tabela ANOVA para análise dos resultados

\begin{tabular}{|c|c|c|c|c|}
\hline $\begin{array}{c}\text { Fonte de } \\
\text { variação }\end{array}$ & $\begin{array}{c}\text { Soma de } \\
\text { quadrados }\end{array}$ & $\begin{array}{c}\text { Graus de } \\
\text { liberdade }\end{array}$ & $\begin{array}{c}\text { Quadrados } \\
\text { médios }\end{array}$ & $\mathrm{F}_{0}$ \\
\hline $\begin{array}{c}\text { Entre } \\
\text { tratamentos }\end{array}$ & $\mathrm{SS}_{\text {Trat }}$ & $(\mathrm{a}-1)$ & $\mathrm{SS}_{\text {Trat }} /(\mathrm{a}-1)$ & \multirow{2}{*}{$F_{0}=\frac{S S_{\text {Trat. }} /(a-1)}{S S_{E} /(N-a)}$} \\
\hline $\begin{array}{c}\text { Erro } \\
\text { dentro dos } \\
\text { tratamentos) }\end{array}$ & $\mathrm{SS}_{\mathrm{E}}$ & $(\mathrm{N}-\mathrm{a})$ & $\mathrm{SS} /(\mathrm{N}-\mathrm{a})$ & \\
\hline Total & $\mathrm{SS}_{\mathrm{T}}$ & $(\mathrm{N}-1)$ & & \\
\hline
\end{tabular}

Fonte: Montgomery, 2009

a) Soma de quadrados total (SST)

O termo análise de variância deriva da divisão da variabilidade total em seus componentes, que, dividida pelo número de graus de liberdade $(\mathrm{N}-1)$, fornece a variância da amostra e pode ser determinada pela expressão 4:

$$
S S_{T}=\sum_{i=1}^{a} \sum_{j=1}^{n}\left(y_{i j}-\bar{y} . .\right)^{2}
$$

b) Soma de quadrados entre tratamentos (SSTrat.)

A soma dos quadrados devidos aos tratamentos (dentro dos tratamentos) tem (a-1) graus de liberdade e pode ser determinada pela expressão 5:

$$
S S_{\text {Trat }}=n \sum_{i=1}^{a}\left(\bar{y}_{i} \cdot-\bar{y}_{\cdot .}\right)^{2}
$$

c) Soma de quadrados dentro dos tratamentos (SSE)

A soma dos quadrados devidos ao erro (dentro dos tratamentos) tem ( $\mathrm{N}-\mathrm{a})$ graus de liberdade e pode ser determinada pela expressão 6: 
d) Quadrado médio entre tratamentos (QMTrat.)

É a estimativa da variância entre os tratamentos, e pode ser determinado pela expressão 7:

$$
Q M_{\text {Trat. }}=\frac{S S_{\text {Trat. }}}{(a-1)}
$$

e) Quadrado médio dentro dos tratamentos (QMDentrotrat.)

É uma estimativa da variância dentro de cada um dos tratamentos, e pode ser determinada pela expressão 8:

$$
Q M_{\text {Dentrotrat. }}=\frac{S S_{E}}{(N-a)}
$$

\subsubsection{Razão F}

Para a análise estatística das hipóteses apresentadas, tem-se que SST é uma soma de quadrados de variáveis aleatórias normalmente distribuídas; SST $/ \sigma^{2}, \mathrm{SSE} / \sigma^{2}$ e SSTrat. $/ \sigma^{2}$ são distribuídas como chi-quadrado, respectivamente, com $(\mathrm{N}-1),(\mathrm{N}-\mathrm{a})$ e (a-1) graus de liberdade, se a hipótese nula $\mathrm{H}_{0}: \tau_{\mathrm{i}}=0$ for verdadeira. Nesse caso, aplicando-se o teorema de Cochran $(\mathrm{N}-1=\mathrm{N}-\mathrm{a}+\mathrm{a}-1)$, tem-se que SSE/ $\sigma^{2}$ e SSTrat. $/ \sigma^{2}$ são variáveis aleatórias chi-quadrado independentes.

Se a hipótese nula for verdadeira, ou seja, se não há diferença entre as médias dos tratamentos, a razão $\mathrm{F}_{0}$ é uma distribuição $\mathrm{F}$ com (a-1) e (N-a) graus de liberdade. A razão $\mathrm{F}$ pode ser calculada pela expressão 9:

$$
F_{0}=\frac{S S_{\text {Trat }} /(a-1)}{S S_{E} /(N-a)}
$$

Caso a hipótese nula seja verdadeira, tanto o numerador quanto o denominador da expressão são estimadores confiáveis de $\sigma^{2}$. Assim, se o valor esperado para o numerador é maior que o valor esperado para o denominador, deve-se rejeitar $\mathrm{H}_{0}$ para valores muito grandes do teste de hipóteses, ou seja, a hipótese nula será rejeitada se $\mathrm{F}_{0}>\mathrm{F}_{\alpha,(\mathrm{a}-1),(\mathrm{N}-\mathrm{a})}$. 
A Figura 12 mostra a representação gráfica da distribuição F de Snedecor para testar o critério $\mathrm{F}_{0}$.

Figura 12 - Distribuição de referência

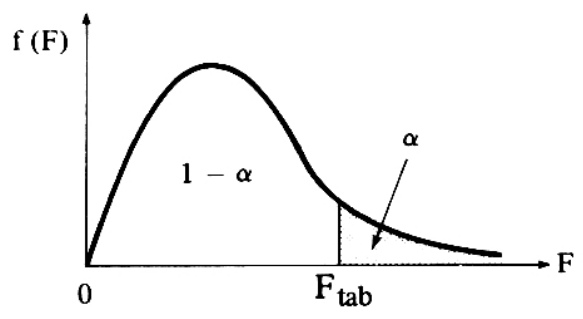

Fonte: Montgomery, 2009

\subsubsection{Comparação das médias individuais dos tratamentos}

O método do modelo de efeitos fixos permite verificar se as médias de diversos tratamentos são diferentes ou não; mas não é possível determinar quais delas divergem. Para a análise das médias individuais dos tratamentos devem-se comparar os somatórios das observações de cada tratamento ou de suas médias. Tais comparações são feitas pelos métodos de comparação múltipla (MONTGOMERY, 2009).

\subsubsection{Contraste}

a) Muitos métodos de comparação múltipla usam o conceito de contraste. Um contraste $\mathrm{C}$ é uma combinação linear dos totais $\mathrm{y}_{\mathrm{i} . q u e}$ permite comparar médias dos tratamentos e pode ser calculado pela expressão 10 :

$$
C=\sum_{i=1}^{a} c_{i} y_{i}
$$


Para tratamentos com o mesmo número de observações, utiliza-se a equação 11.

$$
\sum_{i=1}^{a} c_{i}=0
$$

b) Para o cálculo da soma dos quadrados de qualquer contraste, com os tratamentos tendo o mesmo número de observações, utiliza-se a expressão 12.

$$
S S c=\frac{\left(\sum_{i=1}^{a} c_{i} y_{i .}\right)^{2}}{n \sum_{i=1}^{a} c_{i}^{2}}
$$

c) Teste de hipótese de um contraste

$\mathrm{H}_{0}: \mathrm{C}=0$

$\mathrm{H}_{1}: \mathrm{C} \neq 0$

d) Análise dos resultados

Para testar as hipóteses, calcula-se a razão $\mathrm{F}_{0}$, utilizando-se a expressão 13 , que deve

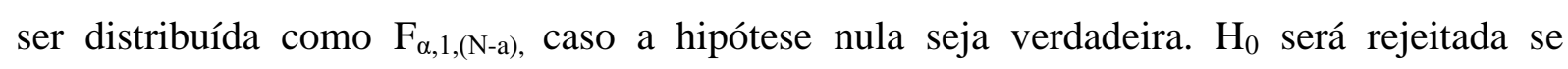
$\mathrm{F}_{0}>\mathrm{F}_{\alpha, 1,(\mathrm{~N}-\mathrm{a})}$.

$$
F_{0}=\frac{S S c}{S S_{E} /(N-a)}
$$

A Figura 13 mostra a representação gráfica da distribuição de referência para testar o critério $\mathrm{F}_{0}$. 
Figura 13 - Representação gráfica da distribuição de referência (Distr. F)

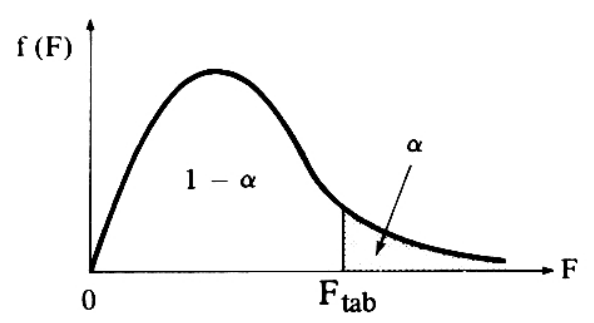

Fonte: Montgomery, 2009

\subsubsection{Box Plot}

O boxplot é uma ferramenta gráfica que fornece informações sobre a localização, a dispersão, a simetria, e o comprimento da cauda (bigode); e ajuda a identificar a existência de valores discrepantes (outliers) em um conjunto de dados. Esses valores atípicos podem afetar de forma adversa as decisões a serem tomadas a partir da análise dos dados se não forem devidamente considerados.

Segundo Triola (2008), o boxplot é um retângulo alinhado verticalmente com duas semirretas, uma em cada um dos lados opostos do retângulo. A altura do retângulo é definida pelos quartis Q1 (25\% dos dados) e Q3 (75\% dos dados). Uma linha secciona o retângulo na altura da mediana Q2 (50\% dos dados). Os valores anômalos (outliers) são normalmente apresentados por asteriscos. A Figura 14 mostra um gráfico boxplot.

Figura 14 - Gráfico boxplot

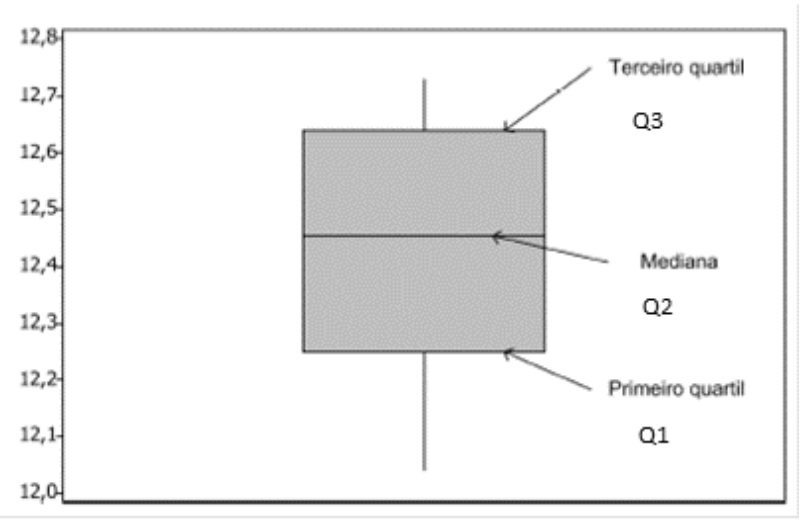

Fonte: Triola, 2008 


\section{Resultados e discussões}

Foram adquiridos no mercado onze tecidos: tecido 1 ligação sarja, composição $93 \%$ meta-aramida 5\% para aramida 2\% fibra de carbono; tecido 2 ligação 54\% modacrilico $44 \%$ algodão 2\% fibra de carbono; tecido 3 ligação sarja 54\% modacrilico $44 \%$ algodão $2 \%$ fibra de carbono; tecido 4 ligação sarja, com $60 \%$ modacrilico, $35 \%$ algodão, 4,5\% poliamida, 0,5\% fibra de carbono; tecido 5 ligação sarja, $48 \%$ modacrilico, 37\% liocel, $15 \%$ para aramida; tecido 6 ligação sarja composição $100 \%$ algodão FR; tecido 7 ligação sarja, com $50 \%$ aramida e 50\% viscose; tecido 8 ligação sarja com $88 \%$ algodão FR, $12 \%$ poliamida de alta tenacidade; tecido 9 ligação tela, com $93 \%$ meta-aramida 5\% para aramida $2 \%$ fibra de carbono; tecido 10: ligação sarja 93\% meta aramida 5\% para aramida $2 \%$ fibra de carbono; tecido 11 ligação sarja, 54\% modacrilico $44 \%$ algodão $2 \%$ fibra de carbono. Mediante os ensaios de gramatura, de conforto térmico, de conforto físico e de conforto ergonômico, foi possível comparar as propriedades dos tecidos estudados.

\subsection{Ensaios de gramatura}

Foram realizados ensaios de gramatura nos tecidos para verificar se possuem gramaturas médias estatisticamente iguais. A Tabela 5 mostra os resultados experimentais.

Tabela 5 - Resultados dos ensaios de gramatura (g/m2) - ASTM D3776/96

\begin{tabular}{|c|c|c|c|c|c|c|c|c|c|c|c|}
\hline Amostras & Tecido 1 & Tecido 2 & Tecido 3 & Tecido 4 & Tecido 5 & Tecido 6 & Tecido 7 & Tecido 8 & Tecido 9 & Tecido 10 & Tecido 11 \\
\hline 1 & 249,7 & 257,9 & 231,6 & 269,4 & 254,5 & 296,5 & 219,9 & 344,1 & 159,2 & 215,9 & 346,3 \\
\hline 2 & 248,4 & 255,7 & 230,8 & 271,7 & 253,8 & 295,0 & 219,1 & 346,6 & 158,3 & 217,1 & 344,5 \\
\hline 3 & 251,9 & 256,3 & 230,2 & 269,8 & 253,1 & 294,0 & 217,7 & 347,2 & 152,2 & 216,7 & 345,1 \\
\hline 4 & 251,2 & 256,6 & 232,4 & 270,2 & 254,3 & 302,5 & 219,7 & 350,4 & 151,1 & 215,8 & 345,8 \\
\hline 5 & 250,3 & 255,5 & 230,6 & 268,3 & 253,2 & 299,7 & 220,3 & 349,5 & 151,9 & 217,4 & 344,4 \\
\hline Média & 250,3 & 256,4 & 231,1 & 269,9 & 253,8 & 297,5 & 219,3 & 347,6 & 154,5 & 216,6 & 345,2 \\
\hline Desv. Padrão & 1,35 & 0,95 & 0,88 & 1,24 & 0,63 & 3,51 & 1,01 & 2,49 & 3,88 & 0,71 & 0,82 \\
\hline
\end{tabular}

Fonte: Cristina Salete Valentin, 2014

\subsubsection{Box plot}

A Figura 15 mostra informações sobre a média, a dispersão e a simetria dos valores de gramatura dos tecidos analisados. 
Figura 15 - Box plot da gramatura dos tecidos

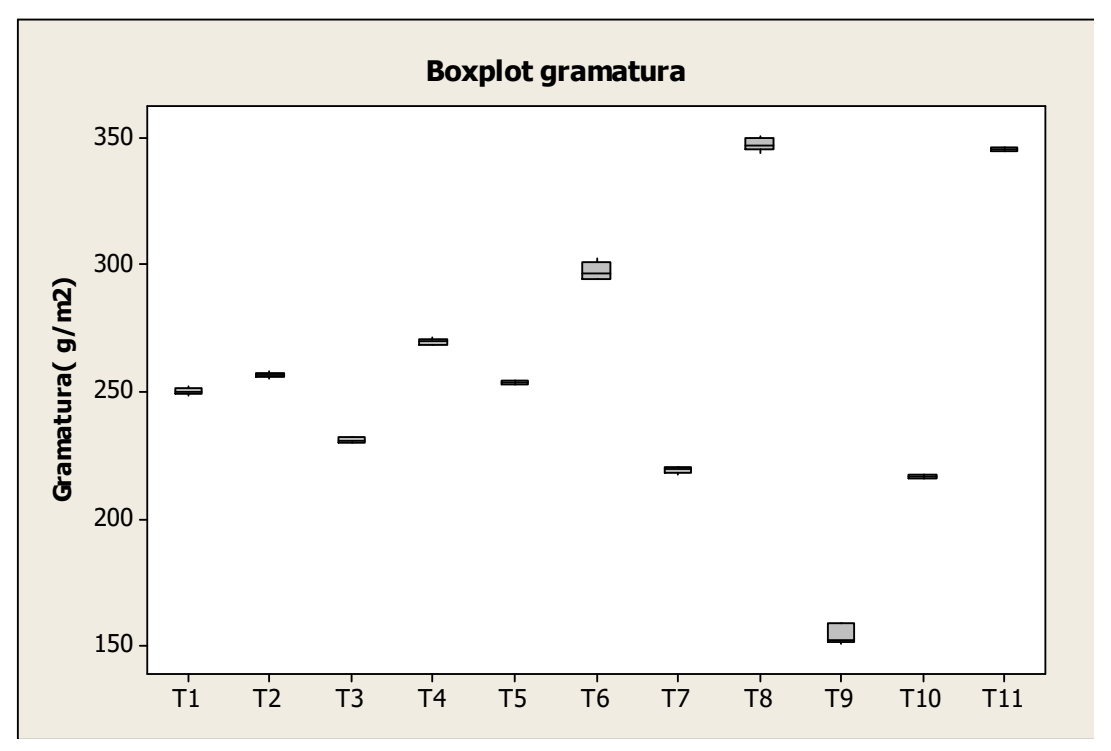

Fonte: Cristina Salete Valentin, 2014

Essa figura mostra que existe maior probabilidade das gramaturas médias dos tecidos 1,2 e 5 serem estatisticamente iguais; a mesma análise pode ser feita para os tecidos 7 e 10 e para os tecidos 8 e 11. Os demais tecidos possuem gramaturas médias diferentes.

\subsubsection{Planejamento aleatorizado por níveis}

Foi feita a análise de variância (ANOVA) para verificar se os valores de gramatura dos tecidos são estatisticamente iguais. Para a análise dos resultados foi utilizado um intervalo de confiança de $95 \%(\mathrm{p}=0,05)$.

a) Teste de hipóteses

$\mathrm{H}_{0}: \mu_{1}=\mu_{2}=\mu_{3}=\mu_{4}=\mu_{5}=\mu_{6}=\mu_{7}=\mu_{8}=\mu_{9}=\mu_{10}=\mu_{11}$

$\mathrm{H}_{1}: \mu_{\mathrm{i}} \neq \mu_{\mathrm{j}}$, para qualquer par $\mathrm{i}, \mathrm{j}$

b) Análise de variância (ANOVA) 
Tabela 6 - Resumo da tabela ANOVA para testar a hipótese $\mathrm{H}_{0}$ dos valores de gramatura dos tecidos

\begin{tabular}{|c|c|c|c|c|}
\hline $\begin{array}{c}\text { Fonte } \\
\text { variação }\end{array}$ & $\begin{array}{c}\text { Soma } \\
\text { Quadrados }\end{array}$ & $\begin{array}{c}\text { Graus de } \\
\text { Liberdade }\end{array}$ & $\begin{array}{c}\text { Quadrados } \\
\text { Médios }\end{array}$ & F0 \\
\hline $\begin{array}{c}\text { Entre } \\
\text { tratamento }\end{array}$ & 160238,0 & 10 & 16023,8 & 4274,88 \\
\hline $\begin{array}{c}\text { Erro (dentro } \\
\text { tratamento) }\end{array}$ & 164,9 & 44 & 3,7 & \\
\hline Total & 160402,9 & 54 & & \\
\hline
\end{tabular}

Fonte: Cristina Salete Valentin, 2014

c) Análise dos resultados

Da distribuição $F$ Snedecor tem-se que $F_{0,05,10,44}$ é igual a 2,08. Como $F_{0}>F_{0,05,10,44}$, pode-se dizer que há uma evidência muito forte de que $\mathrm{H}_{0}$ seja falsa e que pelo menos dois tecidos possuem gramaturas diferentes. O método do modelo de efeitos fixos permite verificar se as médias de diversos tratamentos são diferentes ou não. Portanto, neste caso, há necessidade de realizar uma comparação individual das médias para determinar quais delas divergem.

d) Comparação das médias individuais dos tratamentos

Para comparar os valores médios de gramatura foram verificadas as seguintes hipóteses nulas:

1) $\mathrm{H} 0: \mu 1=\mu 2 \Rightarrow \mathrm{C} 1=1 . \mathrm{y} 1 .-1 . \mathrm{y} 2 .+0 . \mathrm{y} 3 .+0 . \mathrm{y} 4 .+0 . \mathrm{y} 5 .+0 . \mathrm{y} 6 .+0 . \mathrm{y} 7 .++0 . \mathrm{y} 8 .+0 . \mathrm{y} 9 .+$ $0 . \mathrm{y} 10 .+0 . \mathrm{y} 11$.

2) $\mathrm{H} 0: \mu 1=\mu 5 \Rightarrow \mathrm{C} 2=1 . \mathrm{y} 1 .+0 . \mathrm{y} 2 .+0 . \mathrm{y} 3 .+0 . \mathrm{y} 4 .-1 . \mathrm{y} 5 .+0 . \mathrm{y} 6 .+0 . \mathrm{y} 7 .++0 . \mathrm{y} 8 .+0 . \mathrm{y} 9 .+$ $0 . \mathrm{y} 10 .+0 . \mathrm{y} 11$.

3) $\mathrm{H} 0: \mu 3=\mu 7 \Rightarrow \mathrm{C} 3=0 . \mathrm{y} 1 .+0 . \mathrm{y} 2 .+1 . y 3 .+0 . y 4 .+0 . y 5 .+0 . y 6 .-1 . y 7 .++0 . y 8 .+0 . y 9 .+$ $0 . \mathrm{y} 10 .+0 . \mathrm{y} 11$.

4) $\mathrm{H} 0: \mu 4=\mu 5 \Rightarrow \mathrm{C} 4=0 . \mathrm{y} 1 .+0 . \mathrm{y} 2 .+0 . \mathrm{y} 3 .+1 . \mathrm{y} 4 .-1 . \mathrm{y} 5 .+0 . \mathrm{y} 6 .+0 . \mathrm{y} 7 .++0 . \mathrm{y} 8 .+0 . \mathrm{y} 9 .+$ $0 . \mathrm{y} 10 .+0 . \mathrm{y} 11$.

5) $\mathrm{H} 0: \mu 7=\mu 10 \Rightarrow \mathrm{C} 5=0 . \mathrm{y} 1 .+0 . \mathrm{y} 2 .+0 . \mathrm{y} 3 .+0 . \mathrm{y} 4 .+0 . \mathrm{y} 5 .+0 \cdot \mathrm{y} 6 .+1 . \mathrm{y} 7 .++0 \cdot \mathrm{y} 8 .+0 \cdot \mathrm{y} 9$. $-1 . y 10 .+0 . y 11$.

6) $\mathrm{H} 0: \mu 8=\mu 11 \Rightarrow \mathrm{C} 6=0 . \mathrm{y} 1 .+0 . \mathrm{y} 2 .+0 . \mathrm{y} 3 .+0 . \mathrm{y} 4 .+0 . \mathrm{y} 5 .+0 . \mathrm{y} 6 .+0 . \mathrm{y} 7 .++1 . \mathrm{y} 8 .+$ 0.y9.+ 0.y10.- 1.y11. 
e) Verificação da restrição (experimentos com o mesmo número de amostras)

C1, tem-se: $1-1+0+0+0+0+0+0+0+0+0=0$

C2, tem-se: $1+0+0+0-1+0+0+0+0+0+0=0$

$\mathrm{C} 3$, tem-se: $0+0+1+0+0+0-1+0+0+0+0=0$

C4, tem-se: $0+0+0+1-1+0+0+0+0+0+0=0$

C5, tem-se: $0+0+0+0+0+0+1+0+0-1+0=0$

C6, tem-se: $0+0+0+0+0+0+0+1+0+0-1=0$

Portanto, todos os contrastes propostos satisfazem o critério.

f) Teste de hipótese

$1^{\mathrm{a}}$ hipótese - H0: $\mu 1=\mu 2$, tem-se que SSc1 = 93,02 e F01 = 25,14

$2^{\mathrm{a}}$ hipótese $-\mathrm{H} 0: \mu 1=\mu 5$, tem-se que SSc2 $=30,28$ e F02 = 8,18

$3^{\mathrm{a}}$ hipótese $-\mathrm{H} 0: \mu 3=\mu 7$, tem-se que SSc3 = 346,92 e F03 = 93,76

$4^{\mathrm{a}}$ hipótese $-\mathrm{H} 0: \mu 4=\mu 5$, tem-se que SSc4 = 648,02 e F04 = 175, 14

$5^{\mathrm{a}}$ hipótese $-\mathrm{H} 0: \mu 7=\mu 10$, tem-se que SSc5 = 19,04 e F05 = 5,14

$6^{\mathrm{a}}$ hipótese $-\mathrm{H} 0: \mu 8=\mu 11$, tem-se que SSc6 = 13,69 e F06 = 3,70

g) Análise dos resultados

Da distribuição F Snedecor tem-se que $\mathrm{F}_{0,05,1,44}$ é igual a 4,08. Portanto, a hipótese 6 deve ser aceita $\left(\mathrm{F}_{0,05,1,44}>\mathrm{F}_{06}\right)$. Dessa forma, conclui-se que somente as gramaturas média dos tecidos 8 e 11 são estatisticamente iguais; os demais tecidos possuem gramaturas diferentes.

\subsection{Ensaios de conforto térmico}

Foram avaliadas as propriedades de transporte de umidade e resistência ao vapor de água.

\subsubsection{Transporte de umidade}

Foram medidos os seguintes parâmetros: 
-Tempo de molhado: é o tempo em segundos em que as faces interna (WTT) e externa (WTB) da amostra começam a molhar após o início do ensaio.

-Índice de absorção: é a velocidade média de absorção de umidade das faces interna (ART) e externa (ARB) da amostra durante a mudança inicial de conteúdo de água no ensaio.

-Área máxima molhada: é a maior área medida nas faces interna (MWRT) e externa (MWRB).

-Velocidade de propagação: é o índice de umidade acumulado da superfície molhada do centro da amostra onde a dissolução do ensaio se deixa cair até a área máxima molhada (MWR). SST é a velocidade de propagação da face interna, e SSB da face externa.

-Capacidade de transporte unidirecional (R): é a diferença entre as áreas do conteúdo de umidade da face interna e externa da amostra com respeito ao tempo.

-Capacidade de transporte de umidade (OMMC): o índice de capacidade de transporte de umidade de um tecido é calculado mediante a combinação de três atribuições: índice de absorção da face externa (ARB), capacidade de transporte unidirecional (R), e máxima velocidade de propagação na face externa (SSB).

A Tabela 7 apresenta os resultados obtidos no ensaio de transporte de umidade.

Tabela 7 - Resultados do ensaio de transporte de umidade.

\begin{tabular}{|c|c|c|c|c|c|c|c|c|c|c|}
\hline \multicolumn{11}{|c|}{ TECIDO 1} \\
\hline & $\begin{array}{c}\text { WTT } \\
\text { (s) }\end{array}$ & $\begin{array}{c}\text { WTB } \\
(\mathbf{s})\end{array}$ & $\begin{array}{l}\text { ART } \\
(\% / s)\end{array}$ & $\begin{array}{l}\text { ARB } \\
(\% / s)\end{array}$ & $\begin{array}{c}\text { MWR } \\
\text { T } \\
(\% / \mathbf{s})\end{array}$ & $\begin{array}{c}\text { MWRB } \\
(\% / s)\end{array}$ & $\begin{array}{c}\text { SST } \\
(\mathbf{m m} / \mathbf{s})\end{array}$ & $\begin{array}{c}\text { SSB } \\
(\mathrm{mm} / \mathbf{s})\end{array}$ & $\begin{array}{c}\mathbf{R} \\
(\%)\end{array}$ & OMMC \\
\hline Média & 9.44 & 10.25 & 53.67 & 57.70 & 25 & 25 & 2.80 & 3.44 & 192.37 & 0.63 \\
\hline Desv. padrão & 2.87 & 3.82 & 24.35 & 23.01 & 0 & 0 & 0.54 & 0.57 & 407.14 & 0.25 \\
\hline Grau & 3 & 3.25 & 3.25 & 3.75 & 5 & 5 & 3.5 & 3.75 & 3.75 & 4 \\
\hline Resultado & M & $\mathrm{M}$ & $\mathrm{M}$ & $\mathrm{R}$ & MG & MG & $\mathrm{R}$ & $\mathrm{R}$ & MB & MB \\
\hline \multicolumn{11}{|c|}{ TECIDO 2} \\
\hline & $\begin{array}{l}\text { WTT } \\
\text { (s) }\end{array}$ & $\begin{array}{c}\text { WTB } \\
\text { (s) }\end{array}$ & $\begin{array}{l}\text { ART } \\
(\% / s)\end{array}$ & $\begin{array}{l}\text { ARB } \\
(\% / s)\end{array}$ & $\begin{array}{c}\text { MWR } \\
\text { T } \\
(\% / s)\end{array}$ & $\begin{array}{c}\text { MWRB } \\
(\% / s)\end{array}$ & $\begin{array}{c}\text { SST } \\
(\mathrm{mm} / \mathbf{s})\end{array}$ & $\begin{array}{c}\text { SSB } \\
(\mathbf{m m} / \mathbf{s})\end{array}$ & $\begin{array}{c}\mathbf{R} \\
(\%)\end{array}$ & OMMC \\
\hline Média & 8.00 & 119.95 & 217.04 & 0 & 5 & 0 & 0.63 & 0.00 & -1163.24 & 8 \\
\hline Desv. padrão & 1.70 & 0.00 & 212.81 & 0 & 0 & 0 & 0.11 & 0.00 & 82.66 & 1.70 \\
\hline Grau & 3.5 & 1 & 4.5 & 1 & 1 & 1 & 1 & 1 & 1 & 1 \\
\hline Resultado & $\mathrm{R}$ & SM & MR & ML & SM & SM & ML & ML & MP & MP \\
\hline \multicolumn{11}{|c|}{ TECIDO 3} \\
\hline & $\begin{array}{c}\text { WTT } \\
\text { (s) }\end{array}$ & $\begin{array}{l}\text { WTB } \\
\text { (s) }\end{array}$ & $\begin{array}{l}\text { ART } \\
(\% / s)\end{array}$ & $\begin{array}{l}\text { ARB } \\
(\% / s)\end{array}$ & $\begin{array}{c}\text { MWR } \\
\text { T } \\
(\% / s)\end{array}$ & $\begin{array}{c}\text { MWRB } \\
(\% / s)\end{array}$ & $\begin{array}{c}\text { SST } \\
(\mathbf{m m} / \mathbf{s})\end{array}$ & $\begin{array}{c}\text { SSB } \\
(\mathbf{m m} / \mathbf{s})\end{array}$ & $\begin{array}{c}\mathbf{R} \\
(\%)\end{array}$ & OMMC \\
\hline Média & 3.00 & 3.00 & 77.89 & 61.66 & 30 & 30 & 7.36 & 6.90 & -42.05 & 0.40 \\
\hline Desv. padrão & 3.25 & 3.29 & 69.77 & 58.17 & 29.29 & 29.29 & 6.22 & 6.63 & -6.18 & 0.43 \\
\hline Grau & 5 & 4.5 & 4 & 3.5 & 5 & 5 & 5 & 5 & 1.5 & 2.5 \\
\hline Resultado & MR & MR & $\mathrm{R}$ & $\mathrm{R}$ & MG & MG & MR & MR & $\mathrm{P}$ & $\mathrm{B}$ \\
\hline
\end{tabular}




\begin{tabular}{|c|c|c|c|c|c|c|c|c|c|c|}
\hline & $\begin{array}{c}\text { WTT } \\
\text { (s) }\end{array}$ & $\begin{array}{c}\text { WTB } \\
\text { (s) }\end{array}$ & $\begin{array}{l}\text { ART } \\
(\% / s)\end{array}$ & $\begin{array}{l}\text { ARB } \\
(\% / s)\end{array}$ & $\begin{array}{c}\text { MWR } \\
\text { T } \\
(\% / \mathbf{s})\end{array}$ & $\begin{array}{c}\text { MWRB } \\
(\% / s)\end{array}$ & $\begin{array}{c}\text { SST } \\
(\mathbf{m m} / \mathbf{s})\end{array}$ & $\begin{array}{c}\text { SSB } \\
(\mathbf{m m} / \mathbf{s})\end{array}$ & $\begin{array}{c}\mathbf{R} \\
(\%)\end{array}$ & OMMC \\
\hline Média & 7.47 & 119.95 & 126.64 & 0 & 5 & 0 & 0.67 & 0 & -1002.55 & 7.47 \\
\hline Desv. padrão & 1.49 & 0.00 & 148.67 & 0 & 0 & 0 & 0.10 & 0 & 52.50 & 1.49 \\
\hline Grau & 3.5 & 1 & 4 & 1 & 1 & 1 & 1 & 1 & 1 & 1 \\
\hline Resultado & $\mathrm{R}$ & SM & $\mathrm{R}$ & ML & SM & SM & ML & ML & MP & MP \\
\hline \multicolumn{11}{|c|}{ TECIDO 5} \\
\hline & $\begin{array}{c}\text { WTT } \\
\text { (s) }\end{array}$ & $\begin{array}{c}\text { WTB } \\
\text { (s) }\end{array}$ & $\begin{array}{l}\text { ART } \\
(\% / s)\end{array}$ & $\begin{array}{l}\text { ARB } \\
(\% / s)\end{array}$ & $\begin{array}{c}\text { MWR } \\
\text { T } \\
(\% / s)\end{array}$ & $\begin{array}{c}\text { MWRB } \\
(\% / \mathbf{s})\end{array}$ & $\begin{array}{c}\text { SST } \\
(\mathbf{m m} / \mathbf{s})\end{array}$ & $\begin{array}{c}\text { SSB } \\
(\mathbf{m m} / \mathbf{s})\end{array}$ & $\begin{array}{c}\mathrm{R} \\
(\%)\end{array}$ & OMMC \\
\hline Média & 3.22 & 3.42 & 60.37 & 55.25 & 25 & 25 & 5.03 & 4.80 & -28.26 & 0.40 \\
\hline $\begin{array}{c}\text { Desviação } \\
\text { standard }\end{array}$ & 0.10 & 0.21 & 2.83 & 2.35 & 0 & 0 & 0.16 & 0.13 & 7.00 & 0.01 \\
\hline Grau & 4.5 & 4.5 & 3.5 & 3.5 & 5 & 5 & 5 & 5 & 1.5 & 2.5 \\
\hline Resultado & MR & MR & $\mathrm{R}$ & $\mathrm{R}$ & MG & MG & MR & MR & $\mathrm{P}$ & B \\
\hline \multicolumn{11}{|c|}{ TECIDO 6} \\
\hline & $\begin{array}{c}\text { WTT } \\
\text { (s) }\end{array}$ & $\begin{array}{c}\text { WTB } \\
\text { (s) }\end{array}$ & $\begin{array}{l}\text { ART } \\
(\% / s)\end{array}$ & $\begin{array}{l}\text { ARB } \\
(\% / s)\end{array}$ & $\begin{array}{c}\text { MWR } \\
\text { T } \\
(\% / s)\end{array}$ & $\begin{array}{c}\text { MWRB } \\
(\% / \mathbf{s})\end{array}$ & $\begin{array}{c}\text { SST } \\
(\mathbf{m m} / \mathbf{s})\end{array}$ & $\begin{array}{c}\text { SSB } \\
(\mathbf{m m} / \mathbf{s})\end{array}$ & $\begin{array}{c}\mathbf{R} \\
(\%)\end{array}$ & OMMC \\
\hline Média & 3.17 & 3.64 & 62.22 & 57.65 & 25 & 24.17 & 4.30 & 4.07 & -19.04 & 0.41 \\
\hline Desv. padrão & 0.09 & 0.11 & 3.32 & 3.69 & 0 & 2.04 & 0.14 & 0.22 & 10.43 & 0.01 \\
\hline Grau & 4.5 & 4 & 3.75 & 3.5 & 5 & 5 & 5 & 4.75 & 1.5 & 2.5 \\
\hline Resultado & MR & $\mathrm{R}$ & $\mathrm{R}$ & $\mathrm{R}$ & MG & MG & MR & MR & $\mathrm{P}$ & $\mathrm{B}$ \\
\hline \multicolumn{11}{|c|}{ TECIDO 7} \\
\hline & $\begin{array}{c}\text { WTT } \\
\text { (s) }\end{array}$ & $\begin{array}{c}\text { WTB } \\
\text { (s) }\end{array}$ & $\begin{array}{l}\text { ART } \\
(\% / s)\end{array}$ & $\begin{array}{l}\text { ARB } \\
(\% / s)\end{array}$ & $\begin{array}{c}\text { MWR } \\
\text { T } \\
(\% / s)\end{array}$ & $\begin{array}{c}\text { MWRB } \\
(\% / \mathbf{s})\end{array}$ & $\begin{array}{c}\text { SST } \\
(\mathbf{m m} / \mathbf{s})\end{array}$ & $\begin{array}{c}\text { SSB } \\
(\mathbf{m m} / \mathbf{s})\end{array}$ & $\begin{array}{c}\mathbf{R} \\
(\%)\end{array}$ & OMMC \\
\hline Média & 7.47 & 119.95 & 126.64 & 0 & 5 & 0 & 0.67 & 0 & -1002.55 & 0 \\
\hline Desv. padrão & 1.49 & 0.00 & 148.67 & 0 & 0 & 0 & 0.10 & 0 & 52.50 & 0 \\
\hline Grau & 3.5 & 1 & 4 & 1 & 1 & 1 & 1 & 1 & 1 & 1 \\
\hline Resultado & $\mathrm{R}$ & SM & $\mathrm{R}$ & ML & SM & SM & ML & ML & MP & MP \\
\hline \multicolumn{11}{|c|}{ TECIDO 8} \\
\hline & $\begin{array}{c}\text { WTT } \\
\text { (s) }\end{array}$ & $\begin{array}{c}\text { WTB } \\
\text { (s) }\end{array}$ & $\begin{array}{l}\text { ART } \\
(\% / s)\end{array}$ & $\begin{array}{l}\text { ARB } \\
(\% / s)\end{array}$ & $\begin{array}{c}\text { MWR } \\
\text { T } \\
(\% / s)\end{array}$ & $\begin{array}{c}\text { MWRB } \\
(\% / s)\end{array}$ & $\begin{array}{c}\text { SST } \\
(\mathbf{m m} / \mathbf{s})\end{array}$ & $\begin{array}{c}\text { SSB } \\
(\mathbf{m m} / \mathbf{s})\end{array}$ & $\begin{array}{c}\mathbf{R} \\
(\%)\end{array}$ & OMMC \\
\hline Média & 6.82 & 11.65 & 69.24 & 61.41 & 27.50 & 27.50 & 2.87 & 3.32 & -129.49 & 0.33 \\
\hline Desv. padrão & 0.25 & 1.29 & 20.75 & 11.88 & 2.74 & 2.74 & 0.50 & 0.77 & 95.39 & 0.06 \\
\hline Grau & 3.5 & 3 & 3.75 & 3.5 & 5 & 5 & 3.5 & 3.75 & 1 & 2.25 \\
\hline Resultado & $\mathrm{R}$ & M & $\mathrm{R}$ & $\mathrm{R}$ & MG & MG & $\mathrm{R}$ & $\mathrm{R}$ & MP & $\mathrm{P}$ \\
\hline \multicolumn{11}{|c|}{ TECIDO 9} \\
\hline & $\begin{array}{c}\text { WTT } \\
\text { (s) }\end{array}$ & $\begin{array}{c}\text { WTB } \\
\text { (s) }\end{array}$ & $\begin{array}{l}\text { ART } \\
(\% / s)\end{array}$ & $\begin{array}{l}\text { ARB } \\
(\% / s)\end{array}$ & $\begin{array}{c}\text { MWR } \\
\text { T } \\
(\% / s)\end{array}$ & $\begin{array}{c}\text { MWRB } \\
(\% / s)\end{array}$ & $\begin{array}{c}\text { SST } \\
(\mathbf{m m} / \mathbf{s})\end{array}$ & $\begin{array}{c}\text { SSB } \\
(\mathbf{m m} / \mathbf{s})\end{array}$ & $\begin{array}{c}\mathrm{R} \\
(\%)\end{array}$ & OMMC \\
\hline Média & 7.48 & 35.17 & 48.24 & 27.73 & 16.67 & 16.67 & 0.92 & 0.66 & -688.75 & 0.07 \\
\hline Desv. padrão & 0.76 & 7.22 & 38.53 & 25.66 & 4.08 & 2.58 & 0.16 & 0.29 & 439.98 & 0.10 \\
\hline Grau & 3.5 & 2.5 & 2.5 & 1.75 & 3.5 & 3 & 1 & 1 & 1 & 1 \\
\hline Resultado & $\mathrm{R}$ & M & M & $\mathrm{L}$ & G & M & ML & ML & MP & MP \\
\hline \multicolumn{11}{|c|}{ TECIDO 10} \\
\hline & $\begin{array}{c}\text { WTT } \\
\text { (s) }\end{array}$ & $\begin{array}{c}\text { WTB } \\
\text { (s) }\end{array}$ & $\begin{array}{l}\text { ART } \\
(\% / s)\end{array}$ & $\begin{array}{l}\text { ARB } \\
(\% / s)\end{array}$ & $\begin{array}{c}\text { MWR } \\
\text { T } \\
(\% / s)\end{array}$ & $\begin{array}{c}\text { MWRB } \\
(\% / s)\end{array}$ & $\begin{array}{c}\text { SST } \\
(\mathbf{m m} / \mathbf{s})\end{array}$ & $\begin{array}{c}\text { SSB } \\
(\mathbf{m m} / \mathbf{s})\end{array}$ & $\begin{array}{c}\mathrm{R} \\
(\%)\end{array}$ & OMMC \\
\hline Média & 9.43 & 119.95 & 312.31 & 0 & 5 & 0 & 0.54 & 0 & -1216.13 & 9.43 \\
\hline Desv. padrão & 1.94 & 0.00 & 236.25 & 0 & 0 & 0 & 0.13 & 0 & 106.60 & 1.94 \\
\hline Grau & 3 & 1 & 5 & 1 & 1 & 1 & 1 & 1 & 1 & 1 \\
\hline Resultado & M & SM & MR & ML & SM & SM & ML & ML & MP & MP \\
\hline \multicolumn{11}{|c|}{ TECIDO 11} \\
\hline
\end{tabular}




$\begin{array}{ccccccccccc} & (\mathbf{s}) & (\mathbf{s}) & \mathbf{( \% / s )} & \mathbf{( \% / s )} & \mathbf{T} & \boldsymbol{( \% / s )} & (\mathbf{m m} / \mathbf{s}) & (\mathbf{m m} / \mathbf{s}) & (\boldsymbol{\%}) & \\ \text { Média } & 3.25 & 3.83 & 55.37 & 49.16 & 20 & 20 & 4.09 & 3.68 & -24.67 & 0.36 \\ \text { Desv. padrão } & 0.23 & 0.31 & 1.92 & 0.69 & 0 & 0 & 0.09 & 0.13 & 11.79 & 0.02 \\ \text { Grau } & 4.5 & 4 & 3.5 & 3.5 & 4 & 4 & 5 & 4 & 1.5 & 2.5 \\ \text { Resultado } & \mathrm{MR} & \mathrm{R} & \mathrm{R} & \mathrm{R} & \mathrm{G} & \mathrm{G} & \mathrm{MR} & \mathrm{R} & \mathrm{P} & \mathrm{B}\end{array}$

Fonte: Cristina Salete Valentin, 2014

onde:

$\mathrm{SM}=$ sem molhado, $\mathrm{L}=$ lento, $\mathrm{ML}=$ muito lento, $\mathrm{M}=$ médio, $\mathrm{MG}=$ muito grande, $\mathrm{R}=$ rápido, $\mathrm{MR}=$ muito rápido, $\mathrm{MP}=$ muito pobre, $\mathrm{P}=$ pobre, $\mathrm{B}=$ bom, $\mathrm{MB}=$ muito bom, $\mathrm{E}=$ excelente, $\mathrm{G}=$ grande.

A Tabela 8 mostra os graus de classificação para os resultados obtidos no ensaio.

Tabela 8 - Graus de classificação para o ensaio de transporte de umidade em tecidos.

\begin{tabular}{|c|c|c|c|c|c|c|}
\hline \multicolumn{2}{|l|}{ ÍNDICE } & 1 & 2 & 3 & 4 & 5 \\
\hline \multirow{4}{*}{$\begin{array}{c}\text { Tiempo de } \\
\text { mojado (seg.) }\end{array}$} & \multirow{2}{*}{ Interior } & $\geq 120$ & $20-119$ & $5 \sim 19$ & $3 \sim 5$ & $<3$ \\
\hline & & Sin Mojado & Lento & Medio & Rápido & Muy rápido \\
\hline & \multirow{2}{*}{ Exterior } & $\geq 120$ & $20-119$ & $5 \sim 19$ & $3 \sim 5$ & $<3$ \\
\hline & & Sin Mojado & Lento & Medio & Rápido & Muy rápido \\
\hline \multirow{4}{*}{$\begin{array}{c}\text { Índice de } \\
\text { Absorción } \\
\text { (\%/seg.) }\end{array}$} & \multirow{2}{*}{ Interior } & $0 \sim 10$ & $10 \sim 30$ & $30 \sim 50$ & $50 \sim 100$ & $>100$ \\
\hline & & Muy Lento & Lento & Medio & Rápido & Muy rápido \\
\hline & \multirow{2}{*}{ Exterior } & $0 \sim 10$ & $10 \sim 30$ & $30 \sim 50$ & $50 \sim 100$ & $>100$ \\
\hline & & Muy Lento & Lento & Medio & Rápido & Muy rápido \\
\hline \multirow{4}{*}{$\begin{array}{l}\text { Máximo radio } \\
\text { mojado }(\mathrm{mm})\end{array}$} & \multirow{2}{*}{ Interior } & $0 \sim 7$ & $7 \sim 12$ & $12 \sim 17$ & $17 \sim 22$ & $>22$ \\
\hline & & Sin Mojado & Pequeño & Medio & Grande & Muy Grande \\
\hline & \multirow{2}{*}{ Exterior } & $0 \sim 7$ & $7 \sim 12$ & $12 \sim 17$ & 17 22 & $>22$ \\
\hline & & Sin Mojado & Pequeño & Medio & Grande & Muy Grande \\
\hline \multirow{4}{*}{$\begin{array}{c}\text { Velocidad de } \\
\text { propagación } \\
\text { (mm/seg.) }\end{array}$} & \multirow{2}{*}{ Interior } & $0 \sim 1$ & $1 \sim 2$ & $2 \sim 3$ & $3 \sim 4$ & $>4$ \\
\hline & & Muy Lento & Lento & Medio & Rápido & Muy Rápido \\
\hline & \multirow{2}{*}{ Exterior } & $0 \sim 1$ & $1 \sim 2$ & $2 \sim 3$ & $3 \sim 4$ & $>4$ \\
\hline & & Muy Lento & Lento & Medio & Rápido & Muy Rápido \\
\hline \multirow{2}{*}{\multicolumn{2}{|c|}{$\begin{array}{c}\text { Capacidad de transporte } \\
\text { unidireccional }\end{array}$}} & $<-50$ & $-50 \sim 100$ & $100 \sim 200$ & $200 \sim 400$ & $>400$ \\
\hline & & Muy pobre & Pobre & Bueno & Muy bueno & Excelente \\
\hline \multirow{2}{*}{\multicolumn{2}{|c|}{ OMMC }} & $0 \sim 0.2$ & $0.2 \sim 0.4$ & $0.4 \sim 0.6$ & $0.6 \sim 0.8$ & $>0.8$ \\
\hline & & Muy pobre & Pobre & Bueno & Muy bueno & Excelente \\
\hline
\end{tabular}

Fonte: Norma AATCC:2011

\subsubsection{Análise dos resultados}

Segundo a norma AATCC 195:2011 e a comparação dos resultados obtidos nos ensaios com os padrões do Anexo A desta dissertação, pode-se concluir que:

1) Tecido 1: a amostra ensaiada transporta a umidade. Conforme a classificação do Anexo A, o tecido ensaiado é do tipo 7. 
2) Tecido 2: a amostra ensaiada é impermeável. Conforme a classificação do Anexo A, o tecido ensaiado é do tipo 1.

3) Tecido 3: a amostra ensaiada apresenta rápida absorção de umidade e rápida secagem. Conforme a classificação do Anexo A, o tecido ensaiado é do tipo 5.

4) Tecido 4: a amostra ensaiada é impermeável. Conforme a classificação do Anexo A, o tecido ensaiado é do tipo 1.

5) Tecido 5: a amostra ensaiada apresenta rápida absorção de umidade e rápida secagem. Conforme a classificação do Anexo A, o tecido ensaiado é do tipo 5.

6) Tecido 6: a amostra ensaiada apresenta rápida absorção de umidade e rápida secagem. Conforme a classificação do Anexo A, o tecido ensaiado é do tipo 5.

7) Tecido 7: a amostra ensaiada é impermeável. Conforme a classificação do Anexo A, o tecido ensaiado é do tipo 1.

8) Tecido 8: a amostra ensaiada apresenta rápida absorção de umidade e rápida secagem. Conforme a classificação do Anexo A, o tecido ensaiado é do tipo 5.

9) Tecido 9: a amostra ensaiada apresenta lenta absorção de umidade e lenta secagem. Conforme a classificação do Anexo A, o tecido ensaiado é do tipo 3.

10) Tecido 10: a amostra ensaiada é impermeável. Conforme a classificação do Anexo A, o tecido ensaiado é do tipo 1.

11) Tecido 11: a amostra ensaiada apresenta rápida absorção de umidade e rápida secagem. Conforme a classificação do Anexo A, o tecido ensaiado é do tipo 5.

A Tabela 9 mostra os valores individuais de capacidade de transporte de umidade para os tecidos estudados.

Tabela 9 - Resultados dos ensaios de capacidade de transporte de umidade - AATCC 195:2011

\begin{tabular}{|c|c|c|c|c|c|c|c|c|c|c|c|}
\hline Amostras & Tecido 1 & Tecido 2 & Tecido 3 & Tecido 4 & Tecido 5 & Tecido 6 & Tecido 7 & Tecido 8 & Tecido 9 & Tecido 10 & Tecido 11 \\
\hline 1 & 0,28 & 6,77 & 0,43 & 6,44 & 0,40 & 0,40 & 0,00 & 0,36 & 0,25 & \begin{tabular}{|l|}
6,67 \\
\end{tabular} & 0,37 \\
\hline 2 & 0,69 & 7,16 & 0,45 & 6,84 & 0,38 & 0,41 & 0,00 & 0,30 & 0,00 & 7,23 & 0,34 \\
\hline 3 & 0,95 & 7,00 & 0,55 & 6,77 & 0,39 & 0,41 & 0,00 & 0,41 & 0,00 & 10,84 & 0,35 \\
\hline 4 & 0,40 & 6,84 & 0,39 & 8,44 & 0,40 & 0,42 & 0,00 & 0,37 & 0,03 & 10,13 & 0,38 \\
\hline 5 & 0,79 & 9,48 & 0,40 & 6,92 & 0,42 & 0,41 & 0,00 & 0,26 & 0,12 & 10,84 & 0,36 \\
\hline 6 & 0,69 & 10,77 & 0,39 & 7,41 & 0,41 & 0,41 & 0,00 & 0,28 & 0,00 & 10,84 & 0,38 \\
\hline Média & 0,63 & 8,00 & 0,44 & 7,14 & 0,40 & 0,41 & 0,00 & 0,33 & 0,07 & 9,43 & 0,36 \\
\hline Desv. Padrão & 0,25 & 1,70 & 0,06 & 0,71 & 0,01 & 0,01 & 0,00 & 0,06 & 0,10 & 1,94 & 0,02 \\
\hline
\end{tabular}

Fonte: Cristina Salete Valentin, 2014 


\subsubsection{Box plot}

A Figura 16 mostra informações sobre a média, a dispersão e a simetria dos valores de capacidade de transporte de umidade dos tecidos analisados.

Figura 16 - Box plot do transporte de umidade dos tecidos

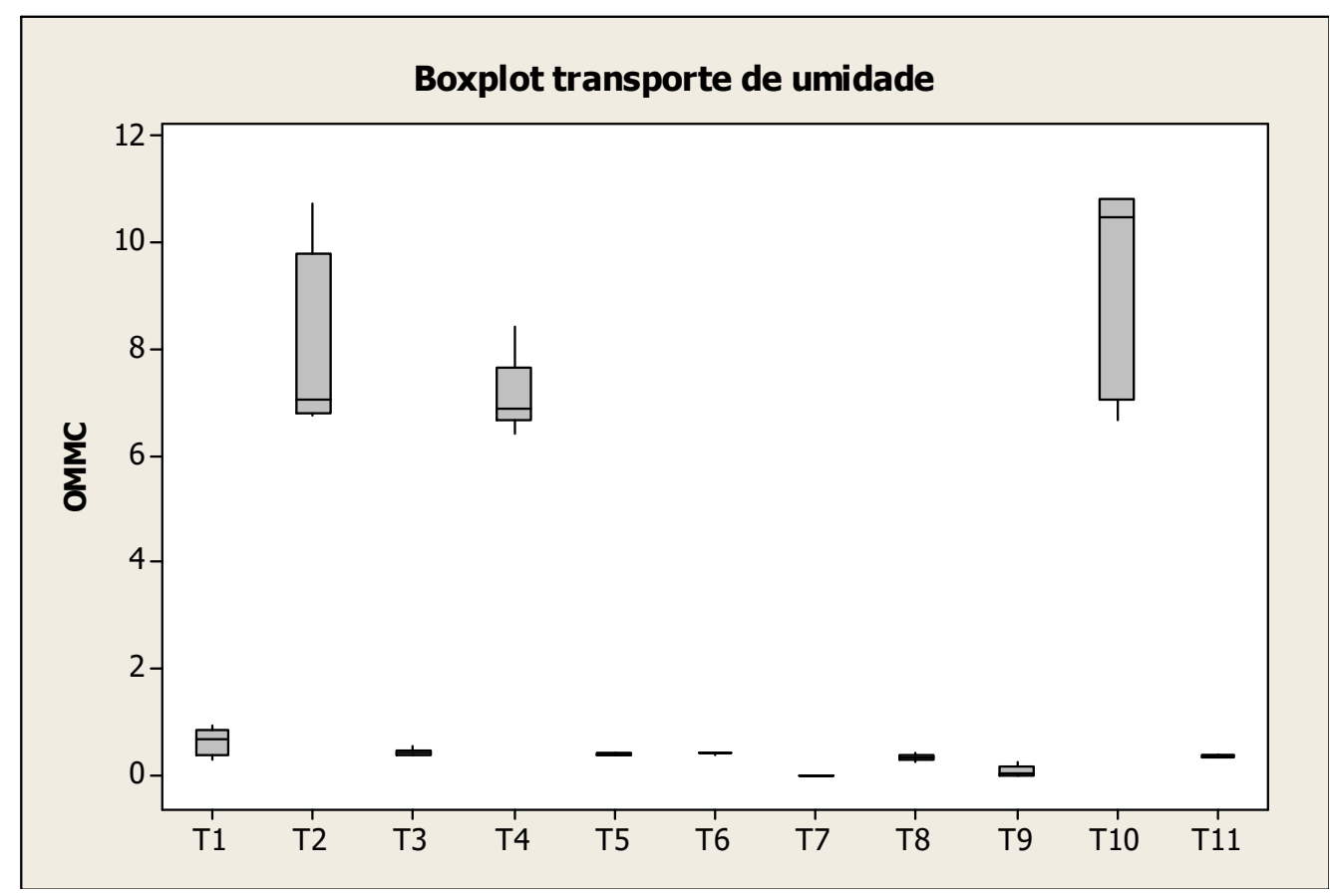

Fonte: Cristina Salete Valentin, 2014

A figura mostra que existe maior probabilidade da capacidade de transporte de umidade de os tecidos $1,3,5,6,7,8,9$ e 11 serem estatisticamente iguais; a mesma análise pode ser feita para os tecidos 2, 4 e 10. Entretanto, os valores médios de transporte de umidade dos tecidos do $1^{\circ}$ grupo são diferentes dos valores médios do $2^{\circ}$ grupo.

\subsubsection{Planejamento aleatorizado por níveis}

Foi utilizada a análise de variância (ANOVA) para verificar se os valores de transporte de umidade dos tecidos são estatisticamente iguais. Para a análise dos resultados foi utilizado um intervalo de confiança de $95 \%(\mathrm{p}=0,05)$.

a) Teste de hipóteses 
$\mathrm{H}_{0}: \mu_{1}=\mu_{2}=\mu_{3}=\mu_{4}=\mu_{5}=\mu_{6}=\mu_{7}=\mu_{8}=\mu_{9}=\mu_{10}=\mu_{11}$

$\mathrm{H}_{1}: \mu_{\mathrm{i}} \neq \mu_{\mathrm{j}}$, para qualquer par $\mathrm{i}, \mathrm{j}$

b) Análise de variância (ANOVA)

Tabela 10 - Resumo da tabela ANOVA para testar a hipótese $\mathrm{H}_{0}$ dos valores de transporte de umidade dos tecidos

\begin{tabular}{|l|c|c|c|c|}
\hline \multicolumn{1}{|c|}{$\begin{array}{c}\text { Fonte } \\
\text { variação }\end{array}$} & $\begin{array}{c}\text { Soma } \\
\text { Quadrados }\end{array}$ & $\begin{array}{c}\text { Graus de } \\
\text { Liberdade }\end{array}$ & $\begin{array}{c}\text { Quadrados } \\
\text { Médios }\end{array}$ & F0 \\
\hline $\begin{array}{l}\text { Entre } \\
\text { tratamento }\end{array}$ & 826,23 & 10 & 82,62 & 125,3 \\
\hline $\begin{array}{l}\text { Erro (dentro } \\
\text { tratamento) }\end{array}$ & 36,27 & 55 & 0,65 & \\
\hline Total & 862,5 & 65 & & \\
\hline
\end{tabular}

Fonte: Cristina Salete Valentin, 2014

c) Análise dos resultados

Da distribuição $F$ Snedecor, tem-se que $F_{0,05,10,55}$ é igual a 1,99. Como $F_{0}>F_{0,05,10,55}$, pode-se dizer que há uma evidência muito forte de que $\mathrm{H}_{0}$ seja falsa e que pelo menos dois tecidos possuem capacidade de transporte de umidade diferentes. O método do modelo de efeitos fixos permite verificar se as médias de diversos tratamentos são diferentes ou não. Portanto, nesse caso, há necessidade de realizar uma comparação individual das médias para determinar quais delas divergem.

d) Comparação das médias individuais dos tratamentos

Para comparar os valores médios de transporte de umidade foram verificadas as seguintes hipóteses nulas:

1) $\mathrm{H} 0: \mu 1=\mu 3 \Rightarrow \mathrm{C} 1=1 . \mathrm{y} 1 .+0 . \mathrm{y} 2 .-1 . \mathrm{y3} .+0 . \mathrm{y} 4 .+0 . \mathrm{y} 5 .+0 . \mathrm{y} 6 .+0 . \mathrm{y} 7 .++0 . \mathrm{y} 8 .+0 . \mathrm{y} 9 .+$ $0 . \mathrm{y} 10 .+0 . \mathrm{y} 11$.

2) $\mathrm{H} 0: \mu 1=\mu 6 \Rightarrow \mathrm{C} 2=1 . \mathrm{y} 1 .+0 . \mathrm{y} 2 .+0 . \mathrm{y} 3 .+0 . \mathrm{y} 4 .+0 . \mathrm{y} 5 .-1 . \mathrm{y} 6 .+0 . \mathrm{y} 7 .++0 . \mathrm{y} 8 .+0 . \mathrm{y} 9 .+$ $0 . \mathrm{y} 10 .+0 . \mathrm{y} 11$.

3) $\mathrm{H} 0: \mu 1=\mu 5 \Rightarrow \mathrm{C} 3=1 . \mathrm{y} 1 .+0 . \mathrm{y} 2 .+0 . \mathrm{y3} .+0 . \mathrm{y} 4 .-1 . \mathrm{y} 5 .+0 . \mathrm{y} 6 .+0 . \mathrm{y} 7 .++0 . \mathrm{y} 8 .+0 . \mathrm{y} 9 .+$ $0 . \mathrm{y} 10 .+0 . \mathrm{y} 11$. 
4) $\mathrm{H} 0: \mu 1=\mu 11 \Rightarrow \mathrm{C} 4=1 . \mathrm{y} 1 .+0 . \mathrm{y} 2 .+0 . \mathrm{y} 3 .+0 . \mathrm{y} 4 .+0 . y 5 .+0 . y 6 .+0 . y 7 .++0 . y 8 .+0 . y 9$. $+0 . y 10 .-1 . y 11$.

5) $\mathrm{H} 0: \mu 1=\mu 8 \Rightarrow \mathrm{C} 5=1 . \mathrm{y} 1 .+0 . \mathrm{y} 2 .+0 . \mathrm{y} 3 .+0 . \mathrm{y} 4 .+0 . \mathrm{y} 5 .+0 . \mathrm{y} 6 .+0 . \mathrm{y} 7 .-\quad-1 . \mathrm{y} 8 .+$ $0 . y 9 .+0 . y 10 .+0 . y 11$.

6) $\mathrm{H} 0: \mu 1=\mu 9 \Rightarrow \mathrm{C} 6=1 . \mathrm{y} 1 .+0 . \mathrm{y} 2 .+0 . \mathrm{y} 3 .+0 . \mathrm{y} 4 .+0 . \mathrm{y} 5 .+0 . \mathrm{y} 6 .+0 . \mathrm{y} 7 .+\quad+0 . \mathrm{y} 8 .-$ 1.y9. + 0.y10. + 0.y11.

7) $\mathrm{H} 0: \mu 7=\mu 9 \Rightarrow \mathrm{C} 7=0 . \mathrm{y} 1 .+0 . \mathrm{y} 2 .+0 . \mathrm{y} 3 .+0 . \mathrm{y} 4 .+0 . \mathrm{y} 5 .+0 . \mathrm{y} 6 .+1 . \mathrm{y} 7 .+\quad$ +0.y8. 1.y9. + 0.y10. + 0.y11.

8) $\mathrm{H} 0: \mu 2=\mu 4 \Rightarrow \mathrm{C} 8=0 . \mathrm{y} 1 .+1 . \mathrm{y} 2 .+0 . \mathrm{y} 3 .-1 . \mathrm{y} 4 .+0 . \mathrm{y} 5 .+0 . \mathrm{y} 6 .+0 . \mathrm{y} 7 .+\quad+0 . \mathrm{y} 8 .+$ $0 . \mathrm{y} 9 .+0 . \mathrm{y} 10 .+0 . \mathrm{y} 11$.

9) $\mathrm{H} 0: \mu 1=\mu 9 \Rightarrow \mathrm{C} 9=0 . \mathrm{y} 1 .+1 . \mathrm{y} 2 .+0 . \mathrm{y} 3 .+0 . \mathrm{y} 4 .+0 . \mathrm{y} 5 .+0 . \mathrm{y} 6 .+0 . \mathrm{y} 7 .+\quad+0 . \mathrm{y} 8 .+$ 0.y9. - 1.y10. + 0.y11

10) $\mathrm{H} 0: \mu 3=\mu 9 \Rightarrow \mathrm{C} 9=0 . \mathrm{y} 1 .+0 . \mathrm{y} 2 .+1 . \mathrm{y} 3 .+0 . \mathrm{y} 4 .+0 . \mathrm{y} 5 .+0 . \mathrm{y} 6 .+0 . \mathrm{y} 7 .+\quad+0 . \mathrm{y} 8 .-$ 1.y9. + 0.y10. + 0.y11.

e)Verificação da restrição (experimentos com o mesmo número de amostras)

$\mathrm{C} 1$, tem-se: $1+0-1+0+0+0+0+0+0+0+0=0$

C2, tem-se: $1+0+0+0+0-1+0+0+0+0+0=0$

$\mathrm{C} 3$, tem-se: $1+0+0+0-1+0+0+0+0+0+0=0$

C4, tem-se: $1+0+0+0+0+0+0+0+0+0-1=0$

C5, tem-se: $1+0+0+0+0+0+0-1+0+0+0=0$

C6, tem-se: $1+0+0+0+0+0+0+0-1+0+0=0$

C7, tem-se: $0+0+0+0+0+0+1+0-1+0+0=0$

C8, tem-se: $0+1+0-1+0+0+0+0+0+0+0=0$

C9, tem-se: $0+1+0+0+0+0+0+0+0-1+0=0$

C10, tem-se: $0+0+1+0+0+0+0+0-1+0+0=0$

Portanto, todos os contrastes propostos satisfazem o critério.

f) Teste de hipótese

$1^{\mathrm{a}}$ hipótese $-\mathrm{H} 0: \mu 1=\mu 3$, tem-se que SSc1 = 0,12 e F01 =0,18

$2^{\mathrm{a}}$ hipótese $-\mathrm{H} 0: \mu 1=\mu 6$, tem-se que SSc $2=0,15$ e F02 $=0,23$ 
$3^{\mathrm{a}}$ hipótese $-\mathrm{H} 0: \mu 1=\mu 5$, tem-se que SSc3 = 0,16 e F03 = 0,25

$4^{\mathrm{a}}$ hipótese $-\mathrm{H} 0: \mu 1=\mu 11$, tem-se que SSc4 = 0,22 e F04 = 0,34

$5^{\mathrm{a}}$ hipótese $-\mathrm{H} 0: \mu 1=\mu 8$, tem-se que SSc5 = 0,27 e F05 = 0,41

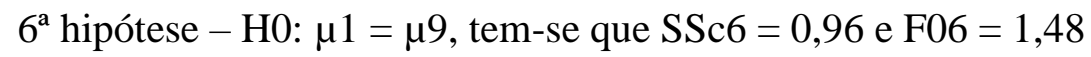

$7^{\mathrm{a}}$ hipótese $-\mathrm{H} 0: \mu 7=\mu 9$, tem-se que SSc7 = 1,20 e F07 = 1,85

$8^{\text {a }}$ hipótese $-\mathrm{H} 0: \mu 2=\mu 4$, tem-se que SSc $8=0,85$ e F08 = 1,31

$9^{\mathrm{a}}$ hipótese $-\mathrm{H} 0: \mu 2=\mu 10$, tem-se que SSc9 = 6,06 e F09 = 9,32

$10^{\mathrm{a}}$ hipótese $-\mathrm{H} 0: \mu 3=\mu 9$, tem-se que $\mathrm{SSc} 10=0,41$ e F010 = 0,63

g) Análise dos resultados

Da distribuição $F$ Snedecor tem-se que $F_{0,05,1,55}$ é igual a 1,35. Portanto, há uma evidência muito forte de que as hipóteses 7 e $9\left(\mathrm{~F}_{0,05,1,55}<\mathrm{F}_{07} \mathrm{eF}_{0,05,1,55}<\mathrm{F}_{09}\right)$ sejam falsas; as demais hipóteses devem ser aceitas. Dessa forma, conclui-se que a capacidade de transporte de umidade média dos tecidos 1, 3, 5, 6, 8, 9 e 10 são estatisticamente iguais; os tecidos 2 e 4 também possuem capacidade de transporte de umidade estatisticamente iguais; mas estes oferecem maior transporte de umidade que os primeiros. Os demais tecidos possuem transporte de umidade diferentes, sendo que o tecido 7 apresenta capacidade de transporte de umidade nula, e o tecido 10 a maior capacidade de transporte de umidade dentre todos os tecidos.

\subsubsection{Resistência ao vapor de água (Ret)}

A partir dos resultados obtidos no ensaio de transporte de umidade, foram selecionados quatro tecidos, sendo dois tecidos com piores resultados (tecido $460 \%$ modacrilico, $35 \%$ algodão, $4,5 \%$ poliamida, $0,5 \%$ fibra de carbono; e tecido $7,50 \%$ aramida e $50 \%$ viscose), e dois tecidos com melhores resultados (tecido $254 \%$ modacrilico $44 \%$ algodão $2 \%$ fibra de carbono; e tecido $3,54 \%$ modacrilico $44 \%$ algodão $2 \%$ fibra de carbono).

A Tabela 11 mostra os valores individuais de resistência ao vapor de água para os tecidos: tecido 2, (54\% modacrilico $44 \%$ algodão $2 \%$ fibra de carbono); tecido 3, (54\% modacrilico $44 \%$ algodão $2 \%$ fibra de carbono); tecido 4, (60\% modacrilico, 35\% algodão, $4,5 \%$ poliamida, $0,5 \%$ fibra de carbono); tecido 7 (50\% aramida e 50\% viscose). 
Tabela 11 - Resultados dos ensaios de resistência ao vapor de água $\left(\mathrm{m}^{2} \mathrm{~Pa} / \mathrm{W}\right)-\mathrm{EN}$ 31092

\begin{tabular}{|c|c|c|c|c|}
\hline Amostras & Tecido 2 & Tecido 3 & Tecido 4 & Tecido 7 \\
\hline 1 & 3,86 & 3,31 & 3,87 & 3,90 \\
\hline 2 & 4,10 & 3,45 & 3,88 & 4,06 \\
\hline 3 & 4,24 & 3,45 & 3,84 & 3,93 \\
\hline Média & 4,07 & 3,40 & 3,86 & 3,96 \\
\hline Desv. Padrão & 0,19 & 0,08 & 0,02 & 0,09 \\
\hline
\end{tabular}

Fonte: Cristina Salete Valentin, 2014

\subsubsection{Box plot}

A Figura 17 mostra informações sobre a média, a dispersão e a simetria dos valores de resistência ao vapor de água dos tecidos analisados.

Figura 17 - Box plot da resistência ao vapor de água dos tecidos

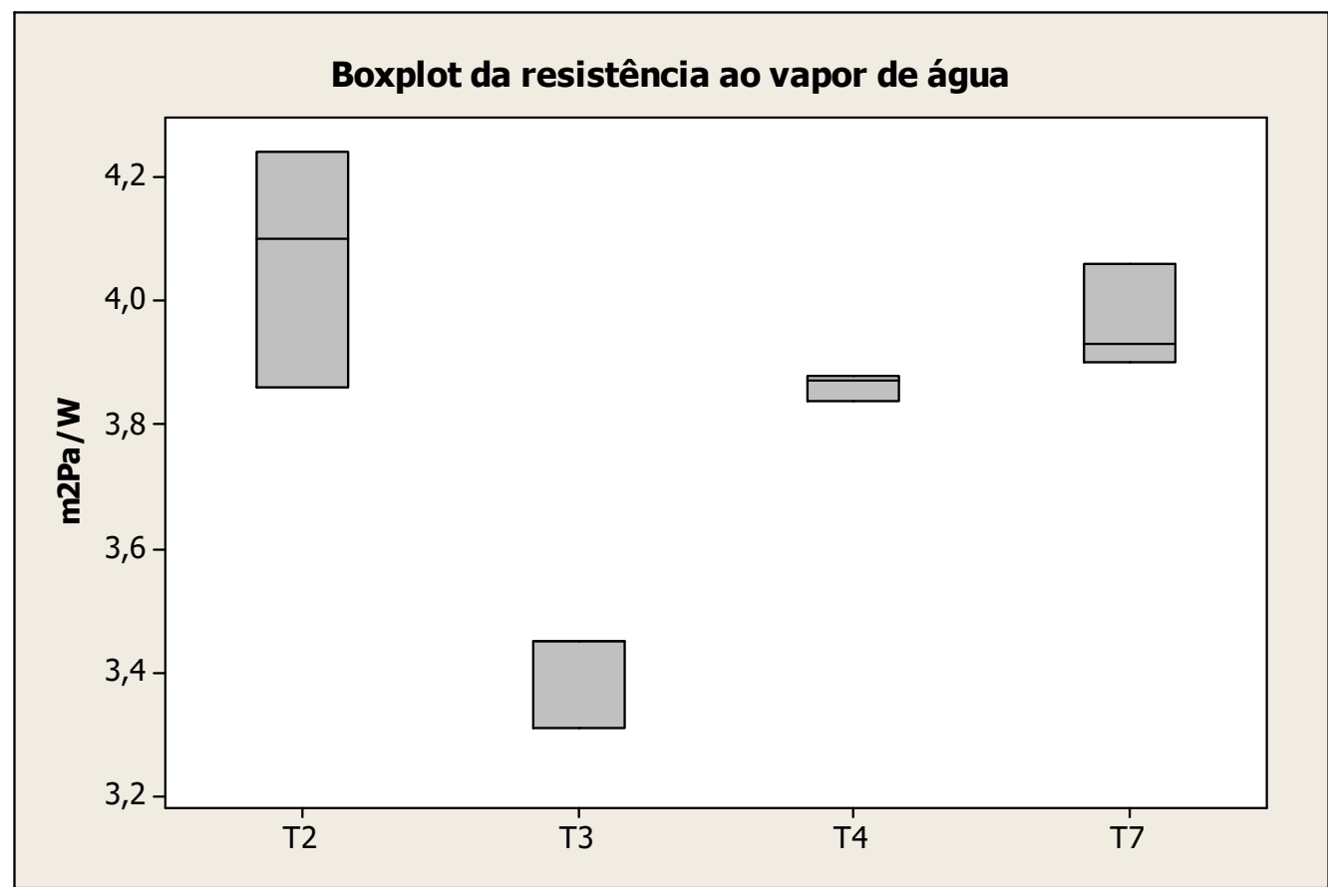

Fonte: Cristina Salete Valentin, 2014

A figura mostra que existe maior probabilidade da resistência ao vapor de água de os tecidos 2 , 4, e 7 serem estatisticamente iguais. 


\subsubsection{Planejamento aleatorizado por níveis}

Foi utilizada a análise de variância (ANOVA) para verificar se os valores de resistência ao vapor de água dos tecidos são estatisticamente iguais. Para a análise dos resultados foi utilizado um intervalo de confiança de $95 \%(\mathrm{p}=0,05)$.

a) Teste de hipóteses

$\mathrm{H}_{0}: \mu_{2}=\mu_{3}=\mu_{4}=\mu_{7}$

$\mathrm{H}_{1}: \mu_{\mathrm{i}} \neq \mu_{\mathrm{j}}$, para qualquer par $\mathrm{i}, \mathrm{j}$

b) Análise de variância (ANOVA)

Tabela 12 - Resumo da tabela ANOVA para testar a hipótese $\mathrm{H}_{0}$ dos valores de resistência ao vapor de água dos tecidos

\begin{tabular}{|l|c|c|c|c|}
\hline \multicolumn{1}{|c|}{$\begin{array}{c}\text { Fonte } \\
\text { variação }\end{array}$} & $\begin{array}{c}\text { Soma } \\
\text { Quadrados }\end{array}$ & $\begin{array}{c}\text { Graus de } \\
\text { Liberdade }\end{array}$ & $\begin{array}{c}\text { Quadrados } \\
\text { Médios }\end{array}$ & F0 \\
\hline $\begin{array}{l}\text { Entre } \\
\text { tratamento }\end{array}$ & 0,77 & 3 & 0,26 & 20,09 \\
\hline $\begin{array}{l}\text { Erro (dentro } \\
\text { tratamento) }\end{array}$ & 0,10 & 8 & 0,01 & \\
\hline Total & 0,87 & 11 & & \\
\hline
\end{tabular}

Fonte: Cristina Salete Valentin, 2014

c) Análise dos resultados

Da distribuição $F$ Snedecor tem-se que $F_{0,05,3,8}$ é igual a 4,07. Como $F_{0}>F_{0,05,3,8}$, podese dizer que há uma evidência muito forte de que $\mathrm{H}_{0}$ seja falsa e que pelo menos dois tecidos possuem resistência ao vapor de água diferentes. O método do modelo de efeitos fixos permite verificar se as médias de diversos tratamentos são diferentes ou não. Portanto, nesse caso, há necessidade de realizar uma comparação individual das médias para determinar quais delas divergem.

d) Comparação das médias individuais dos tratamentos

Para comparar os valores médios de resistência ao vapor de água foram verificadas as seguintes hipóteses nulas:

1) $\mathrm{H} 0: \mu 2=\mu 4 \Rightarrow \mathrm{C} 1=1 . \mathrm{y} 2 .+0 . \mathrm{y3} .-1 . \mathrm{y} 4 .+0 . \mathrm{y} 7$.

2) $\mathrm{H} 0: \mu 3=\mu 4 \Rightarrow \mathrm{C} 2=0 . \mathrm{y} 2 .+1 . \mathrm{y} 3 .-1 . \mathrm{y} 4 .+0 . \mathrm{y} 7$.

3) $\mathrm{H} 0: \mu 4=\mu 7 \Rightarrow \mathrm{C} 3=0 . \mathrm{y} 2 .+0 . \mathrm{y} 3 .+1 . y 4 .-1 . \mathrm{y} 7$. 
e) Verificação da restrição (experimentos com o mesmo número de amostras)

C1, tem-se: $1+0-1+0=0$

C2, tem-se: $0+1-1+0=0$

C3, tem-se: $0+0+1-1=0$

Por conseguinte, todos os contrastes propostos satisfazem o critério.

f) Teste de hipótese

$1^{\mathrm{a}}$ hipótese $-\mathrm{H} 0: \mu 2=\mu 4$, tem-se que SSc1 = 0,06 e F01 = 6,20

$2^{\mathrm{a}}$ hipótese $-\mathrm{H} 0: \mu 3=\mu 4$, tem-se que SSc2 $=0,32$ e F02 = 31,74

$3^{\mathrm{a}}$ hipótese $-\mathrm{H} 0: \mu 4=\mu 7$, tem-se que SSc3 = 0,02 e F03 = 2,00

g) Análise dos resultados

Da distribuição F Snedecor tem-se que $\mathrm{F}_{0,05,1,3}$ é igual a 10,13. Assim sendo, há uma evidência muito forte de que a hipótese $2\left(\mathrm{~F}_{0,05,1,3}<\mathrm{F}_{02}\right)$ seja falsa, as demais hipóteses devem ser aceitas. Dessa forma, conclui-se que a resistência ao vapor de água dos tecidos 2, 4 e 7 são estatisticamente iguais.

\subsection{Ensaios de conforto físico e ergonômico}

\subsubsection{Kawabata Evaluation System (KES), para conforto tátil}

A Tabela 13 mostra os resultados dos ensaios de tração, de flexão, de tensão de corte, de compressão e de superfície realizados nos tecidos. 
Tabela 13 - Resultados experimentais para análise do conforto tátil

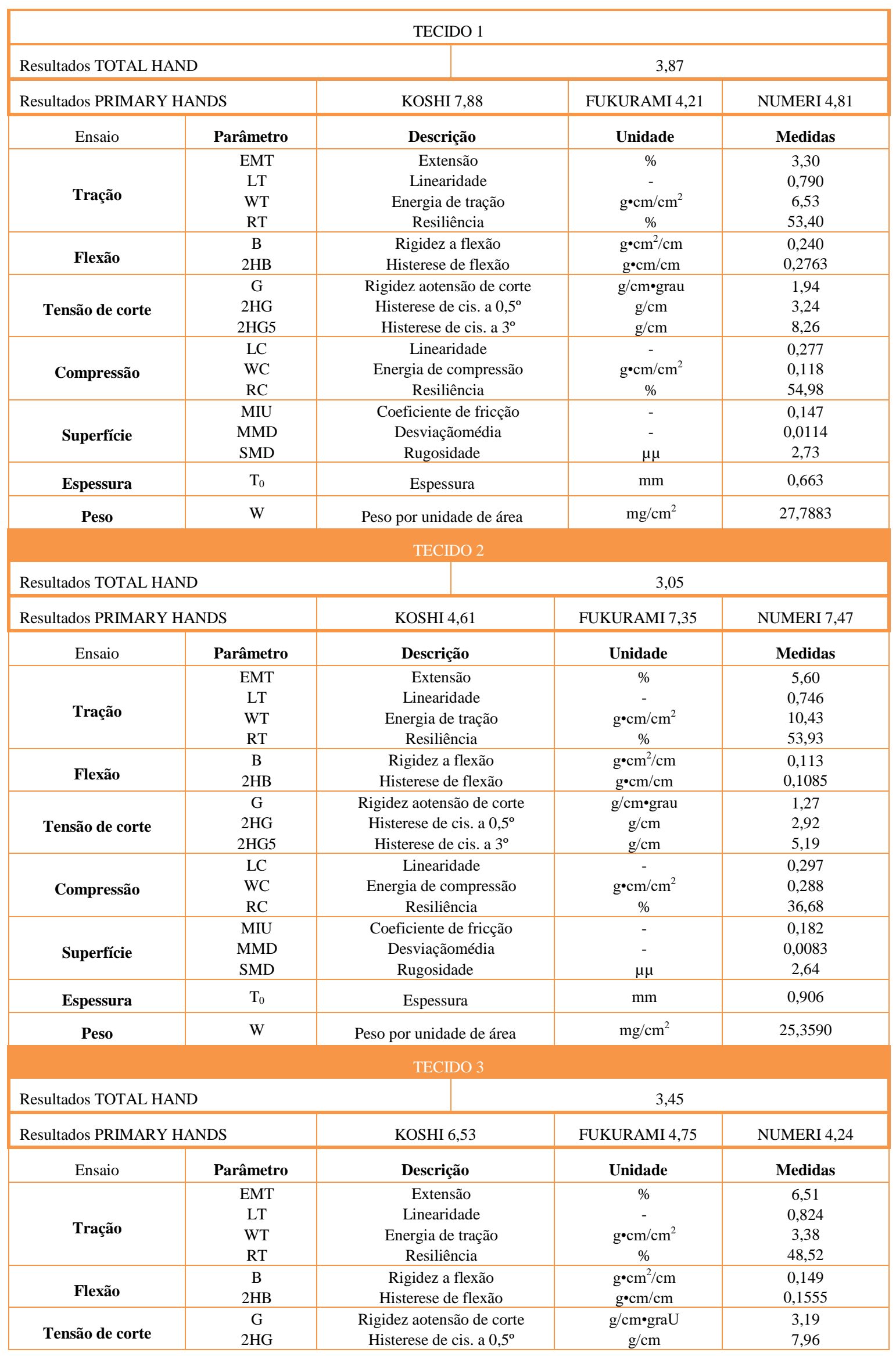




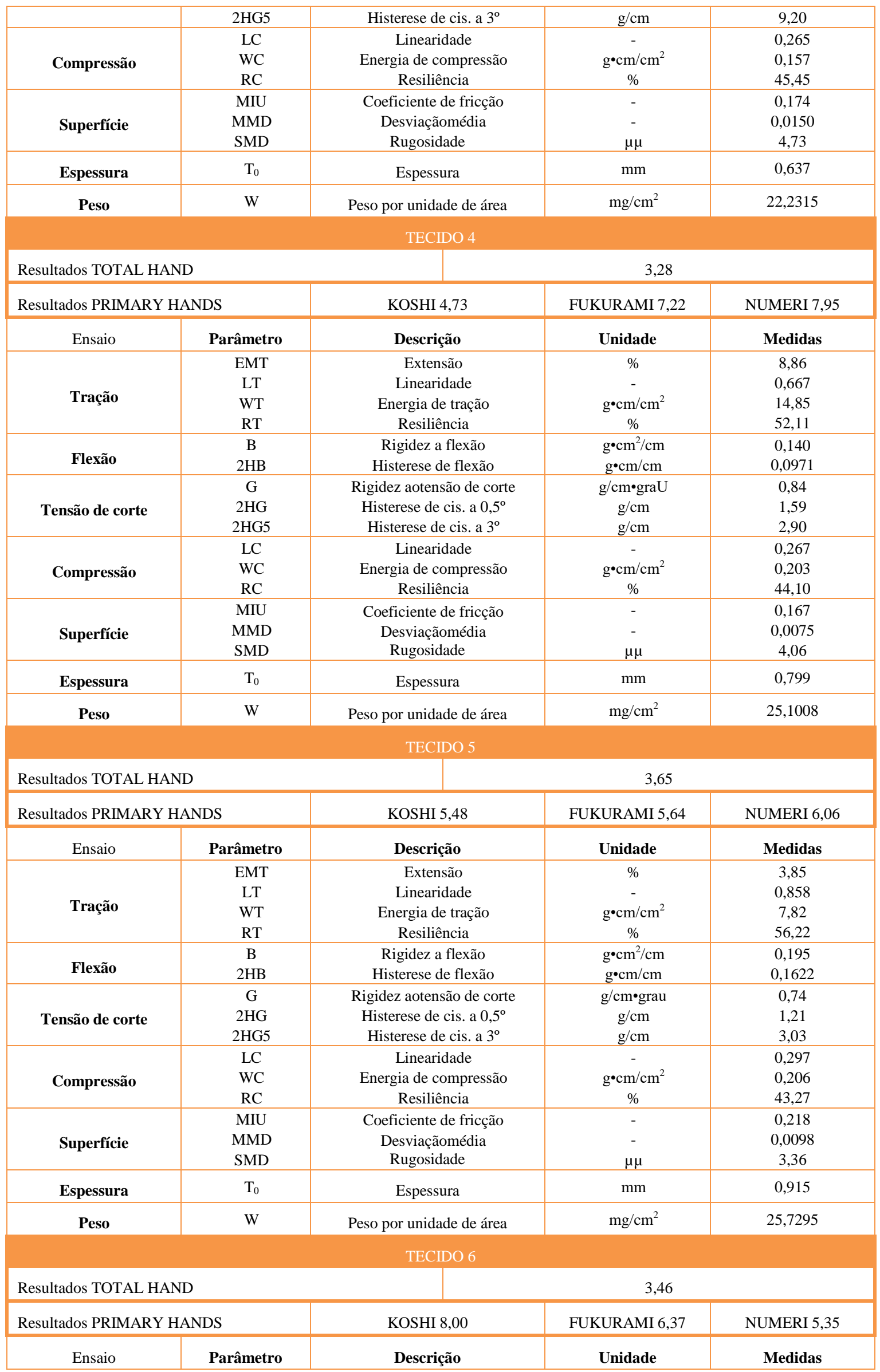




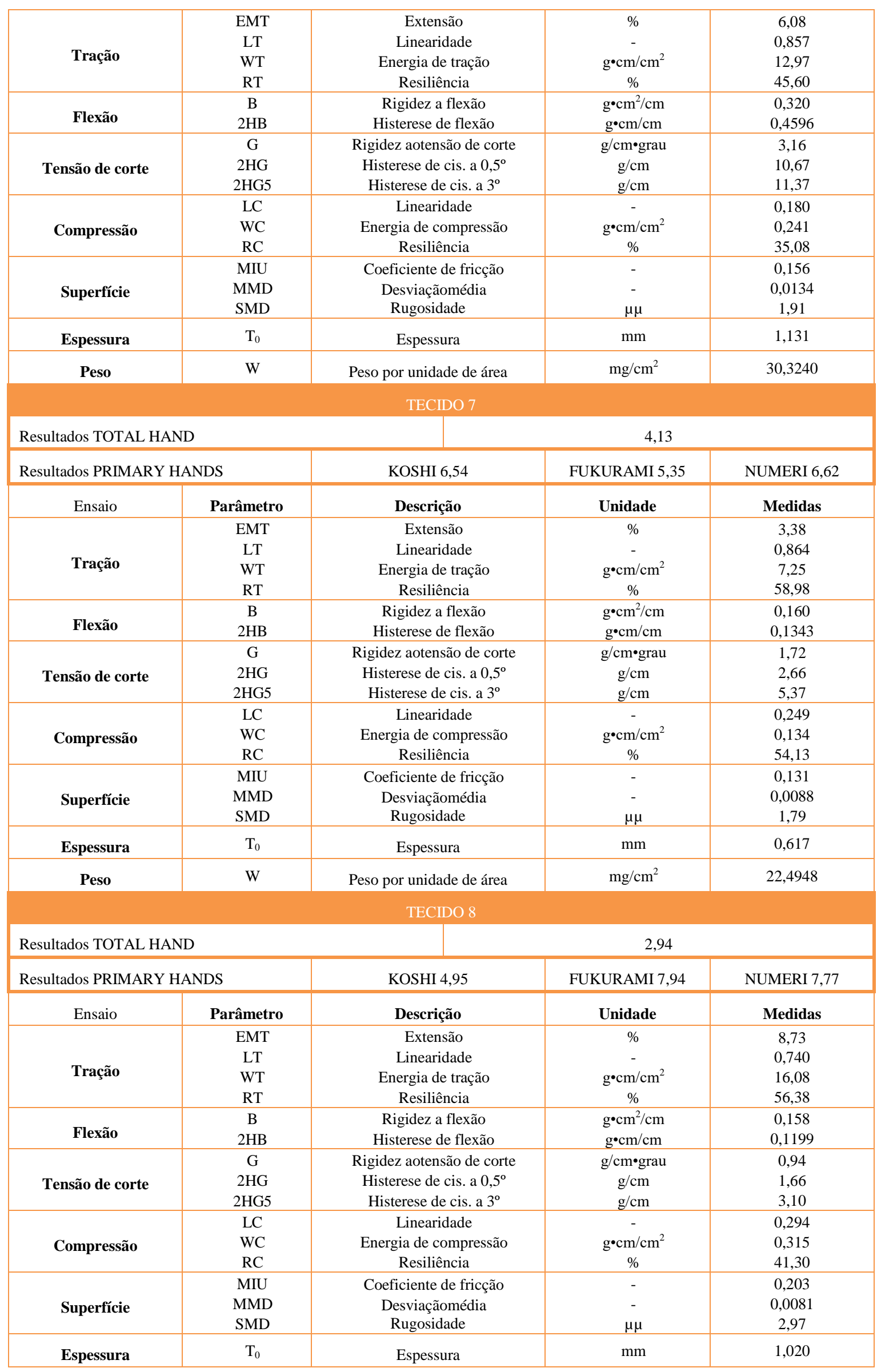




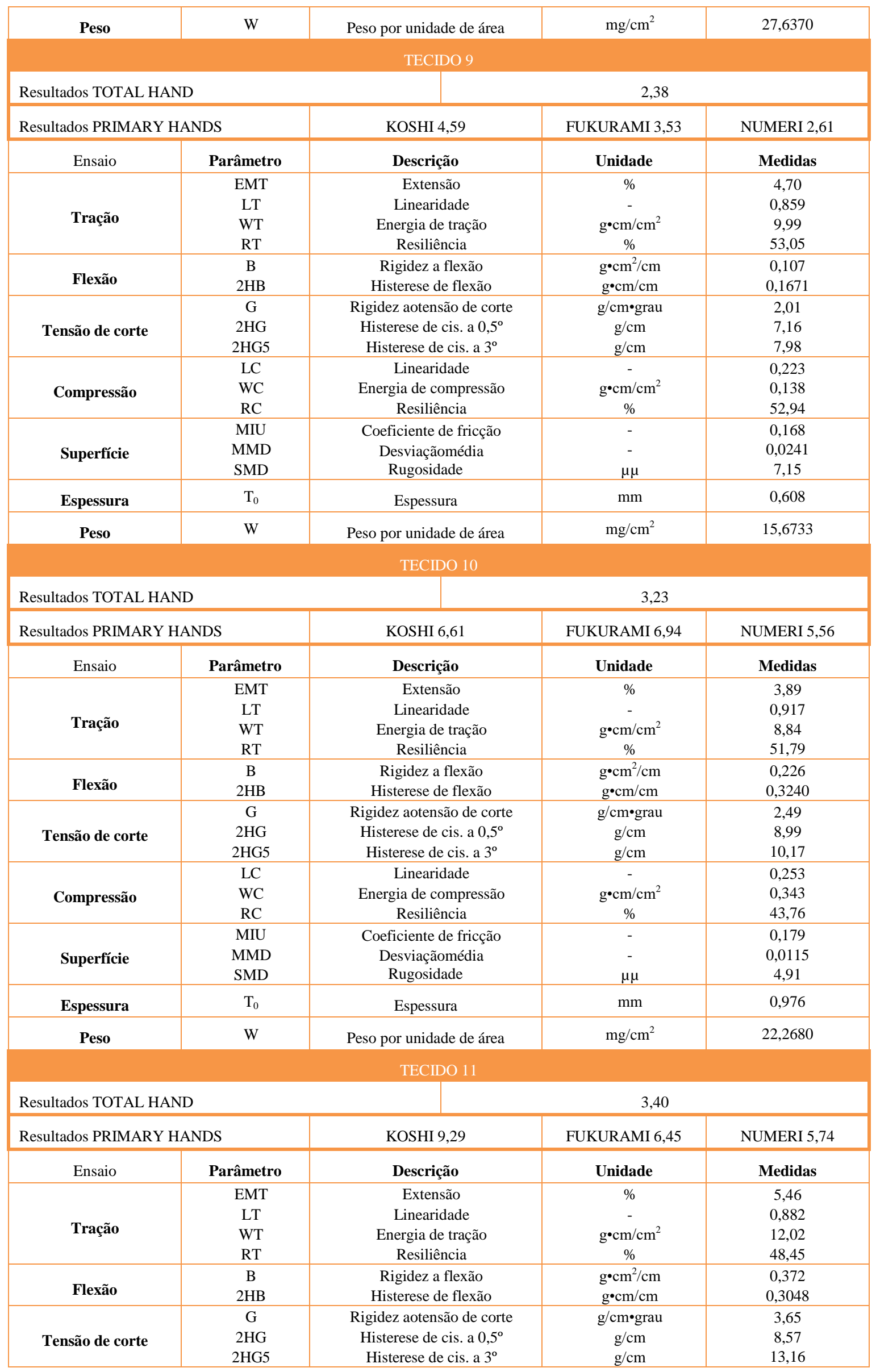




\begin{tabular}{|c|c|c|c|c|}
\hline & LC & Linearidade & - & 0,289 \\
Compressão & WC & Energia de compressão & $\mathrm{g} \cdot \mathrm{cm}^{2} \mathrm{~cm}^{2}$ & $\%$ \\
& RC & Resiliência & - & 0,233 \\
& MIU & Coeficiente de fricção & - & 0,173 \\
Superfície & MMD & Desviaçãomédia & $\mu, 76$ & 2,55 \\
& SMD & Rugosidade & $\mathrm{mm}$ & 0,980 \\
\hline Espessura & To & Espessura & $\mathrm{mg} / \mathrm{cm}^{2}$ & 34,5032 \\
\hline
\end{tabular}

Fonte: Cristina Salete Valentin, 2014

\subsubsection{Definição das medidas realizadas pelo sistema de medição KES}

A seguir, serão definidas graficamente todas as variáveis físicas quantitativas obtidas nas medidas realizadas pelos distintos módulos que formam o sistema de medição KES.

1) Módulo de ensaio automatizado de tensão e tensão de corte (KES-FB1)

Esse módulo foi desenvolvido para medir as propriedades de tensão e tensão de corte dos tecidos; pode medir energia de tensão, força de tensão e rigidez e histerese de tensão de corte.

a) Ensaio de tensão/tração

A amostra é esticada unidirecionalmente (Figura 18) até o limite de força superior (Fm), uma vez que chega a esse limite, se recupera. A velocidade de extensão e de recuperação é constante.

Figura 18 - Características do ensaio de tensão

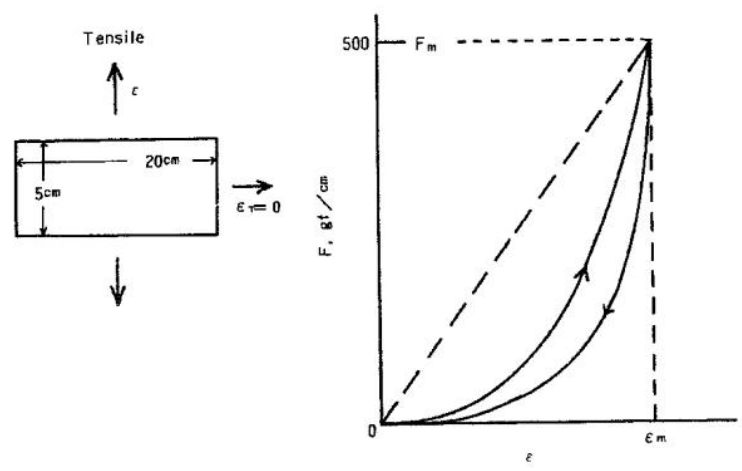

Fonte: Kawabata,1980

A partir desse ensaio, são obtidas as seguintes variáveis físicas:

- LT: representa a linearidade da curva de extensão.

- WT: energia de tensão por unidade de área. 
- RT: porcentagem de recuperação.

- EMT: parâmetro que indica a extensão da carga, como porcentagem máxima de tensão ante a maior força aplicada. É por isto que um valor $100 \%$ significa um tecido completamente elástico, e um $0 \%$ um tecido completamente inelástico.

Os Gráficos 3, 4, 5 e 6 apresentam os valores experimentais obtidos.

Gráfico 3 - Representação da porcentagem máxima de tensão

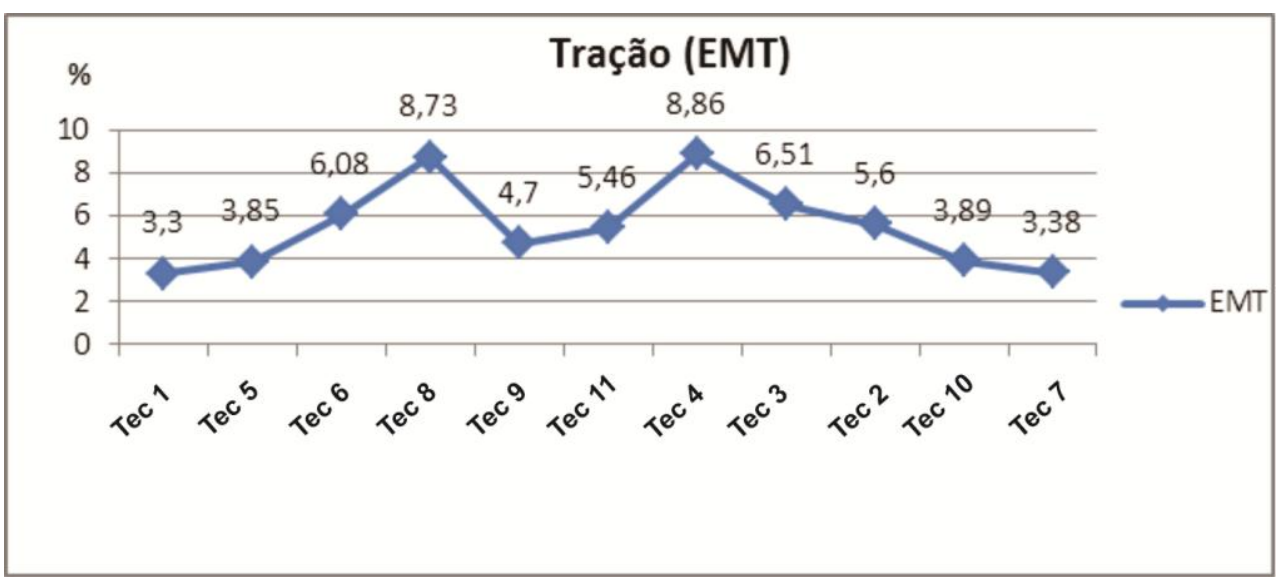

Fonte: Cristina Salete Valentin, 2014

Gráfico 4 - Representação da linearidade da curva de extensão

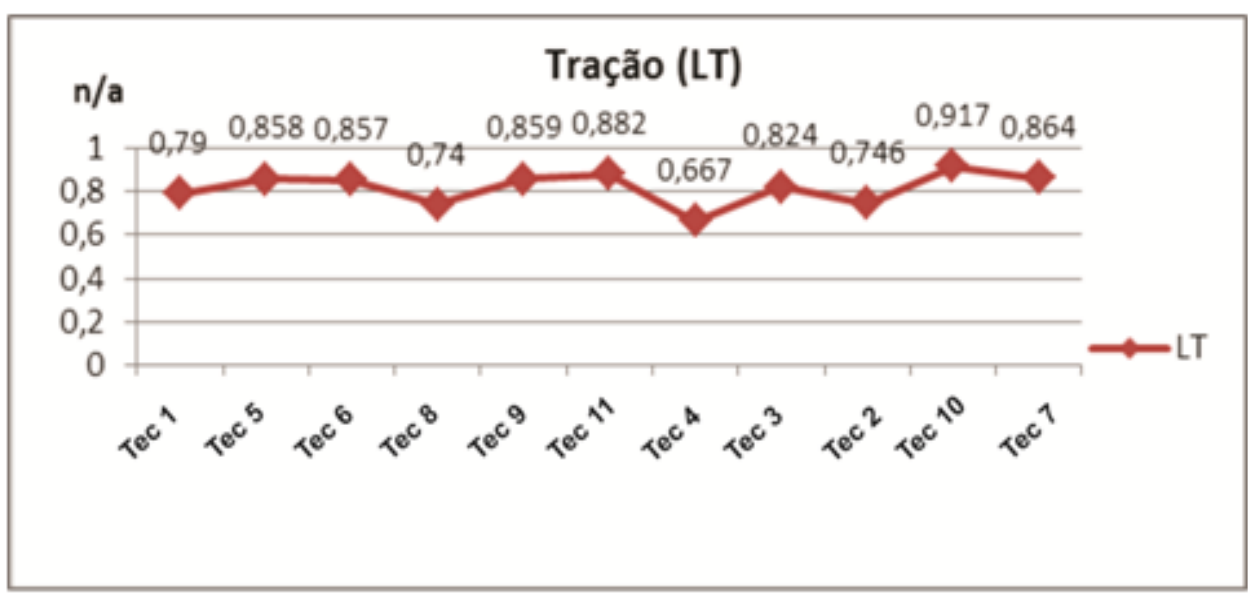

Fonte: Cristina Salete Valentin, 2014 
Gráfico 5 - Representação da energia de tensão por unidade de área

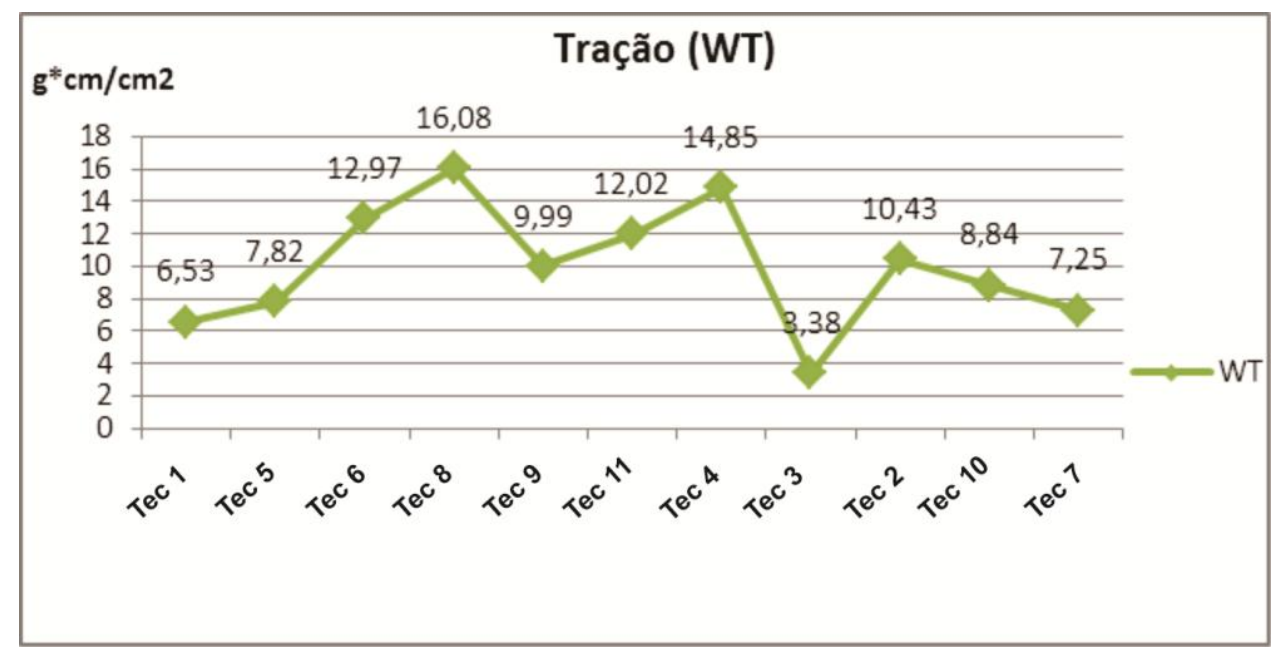

Fonte: Cristina Salete Valentin, 2014

Gráfico 6 - Representação da porcentagem de recuperação

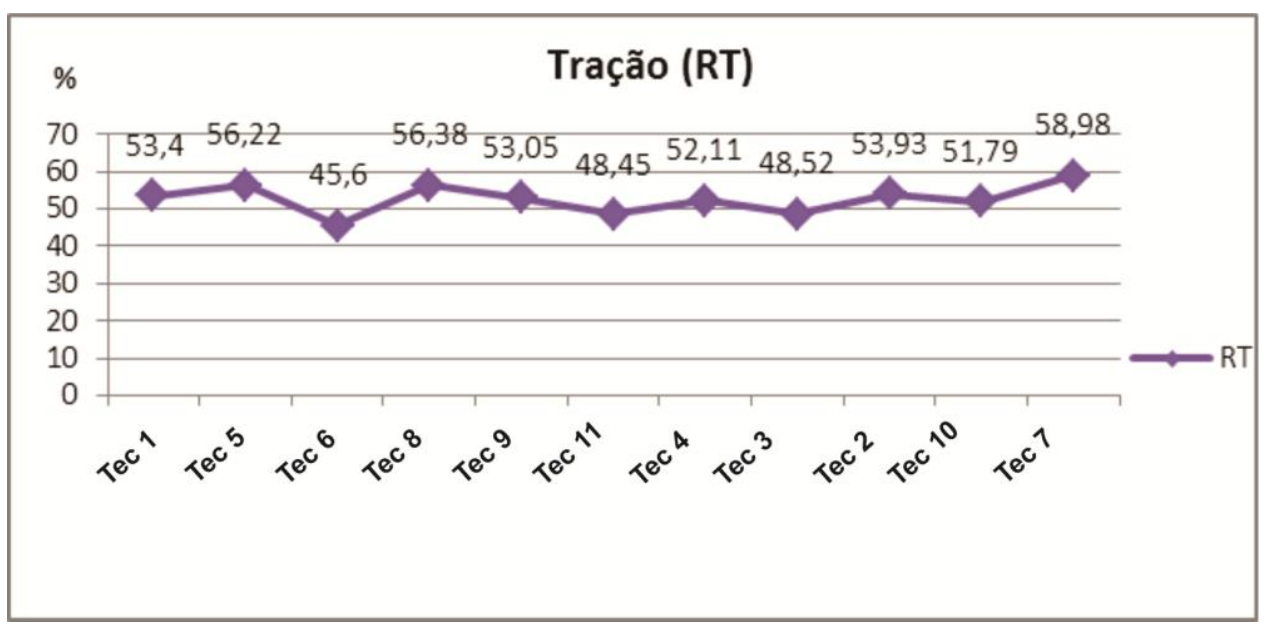

Fonte: Cristina Salete Valentin, 2014

O Gráfico 3 mostra que o tecido 4 (60\% modacrilico, 35\% algodão, 4,5\% poliamida, 0,5\% fibra de carbono) e o tecido 8 ( $88 \%$ algodão FR, $12 \%$ poliamida de alta tenacidade) possuem maior elasticidade frente aos tecidos 1 (93\% meta aramida 5\% para aramida $2 \%$ fibra de carbono) e 7 (50\% aramida, 50\% viscose) que são tecidos praticamente sem elasticidade. Para que um tecido tenha maior conforto, precisa ter características mais elásticas, proporcionando maior comodidade ao usuário, garantindo que o tecido não irá rasgar ou que as costuras se romperão.

b) Ensaio de tensão de corte

Nesse ensaio se aplica uma tensão constante (W), ao largo da direção ortogonal da força de tensão de corte (Figura 19). Esta deformação é uma superposição da tensão da faixa 
biaxial e da deformação de tensão de corte. Nesse ensaio se aplica a força até alcançar um ângulo máximo de 8 graus.

Figura 19 - Características do ensaio de tensão de corte
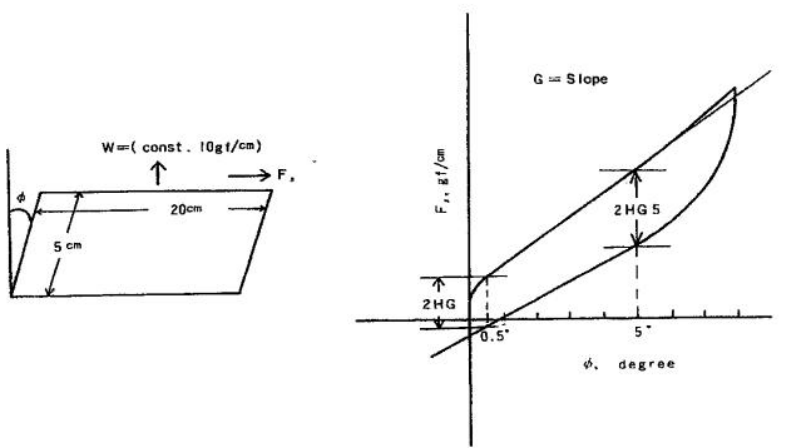

Fonte: Kawabata, 1980

A partir desse ensaio são determinadas as seguintes variáveis físicas:

- G: representa a rigidez ao tensão de corte, ou seja, a facilidade com a que as fibras deslizam umas contra as outras, causando estruturas que vão desde suaves ou flexíveis a duras ou rígidas. $\mathrm{O}$ parâmetro $\mathrm{G}$ é definido como força de tensão de corte por unidade de longitude/ângulo de tensão de corte. No Gráfico 7, G se apresenta como a pendente da curva medida entre $0,5^{\circ}$ e $5^{\circ}$ de tensão de corte. Valores baixos desta variável indicam menor resistência frente a este movimento.

- 2HG: Histereses de tensão de corte a um ângulo de $0,5^{\circ}$.

- 2HG5: Histereses de tensão de corte a um ângulo de $0,5^{\circ}$.

Estas duas últimas variáveis representam a recuperação a distintos ângulos (Gráfico 8). No ensaio de deformação por tensão de corte das amostras que têm a estrutura do tecido não simétrica, a curva de força frente a ângulo de tensão de corte pode ser diferente entre a região positiva e negativa; por isso se requer a obtenção dos valores médios das variáveis G, 2HG e 2HG5. 
Gráfico 7 - Representação da rigidez ao tensão de corte

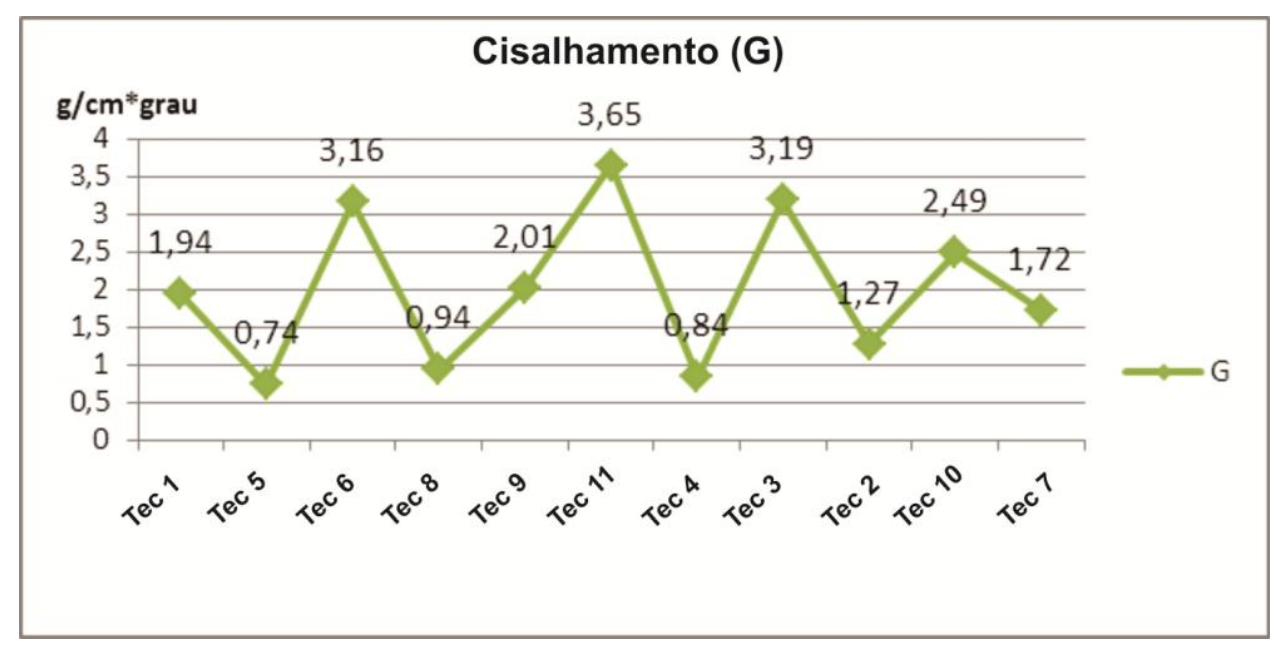

Fonte: Cristina Salete Valentin, 2014

Gráfico 8 - Representação da histerese de tensão de corte em diferentes ângulos

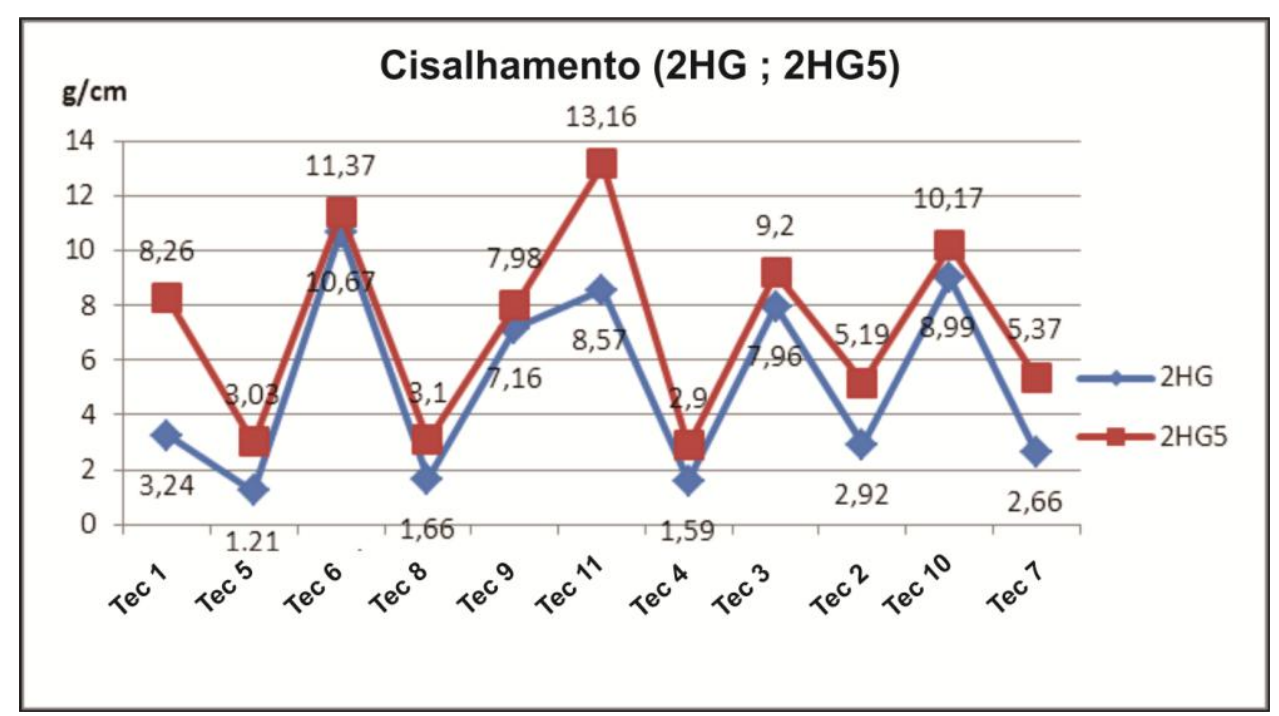

Fonte: Cristina Salete Valentin, 2014

O Gráfico 7 mostra que o tecido 6 (100\% algodão FR), o tecido 11 (54\% modacrilico $44 \%$ algodão $2 \%$ fibra de carbono) e o tecido 3 (54\% modacrilico $44 \%$ algodão $2 \%$ fibra de carbono) são os que maior resistência apresentam frente a esse movimento. Pelo contrário, o tecido 4 (60\% modacrilico, $35 \%$ algodão, 4,5\% poliamida, $0,5 \%$ fibra de carbono), o tecido 5 (48\% modacrilico, 37\% liocel, $15 \%$ para aramida), e o tecido 8 (88\% algodão FR, 12\% poliamida de alta tenacidade) são tecidos com valores mais baixos que indicam menor resistência frente a esse movimento. Ao ter menor resistência, permite melhor adaptabilidade e comodidade ao usuário.

2) Módulo de ensaio automatizado de dobra (KES-FB2) 
Esse módulo é utilizado para medir a flexão de um tecido ou de um nãotecido. $\mathrm{O}$ equipamento mede a rigidez da flexão e sua histerese no momento da flexão; isto é, mede a relação entre o momento de flexão e sua recuperação. Nesse ensaio, a amostra de tecido é montada sobre uma fenda estreita e, em seguida, é dobrada. A amostra se dobra entre umas faixas de curvatura que vão desde $-2,5$ a $+2,5 \mathrm{~cm}-1$ (Figura 20). Nesse ensaio se obtêm valores precisos da rigidez da flexão e do momento de flexão.

Figura 20 - Características do ensaio de flexão (dobra)

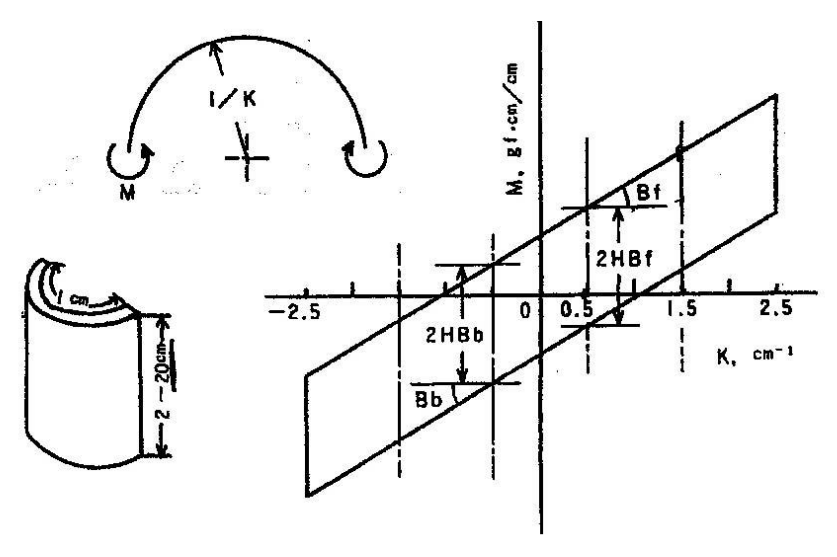

Fonte: Kawabata, 1980

A partir desse ensaio são determinadas as variáveis físicas seguintes:

- B: representa a rigidez de dobra por unidade de longitude; portanto, altos valores de B indicam grande resistência a movimentos de dobra.

- 2HB: histerese a dobra.

Os gráficos 9 e 10 mostram os valores experimentais dos parâmetros (B) e (2B). 
Gráfico 9 - Representação da rigidez de dobra

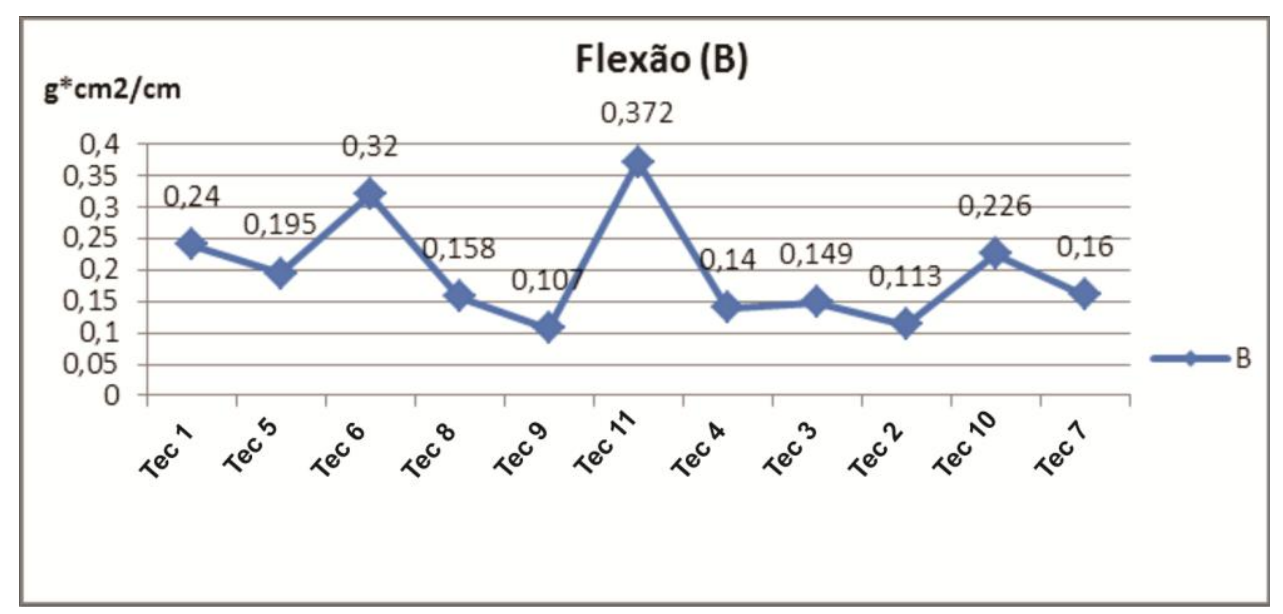

Fonte: Cristina Salete Valentin, 2014

Gráfico 10 - Representação da histerese a dobra

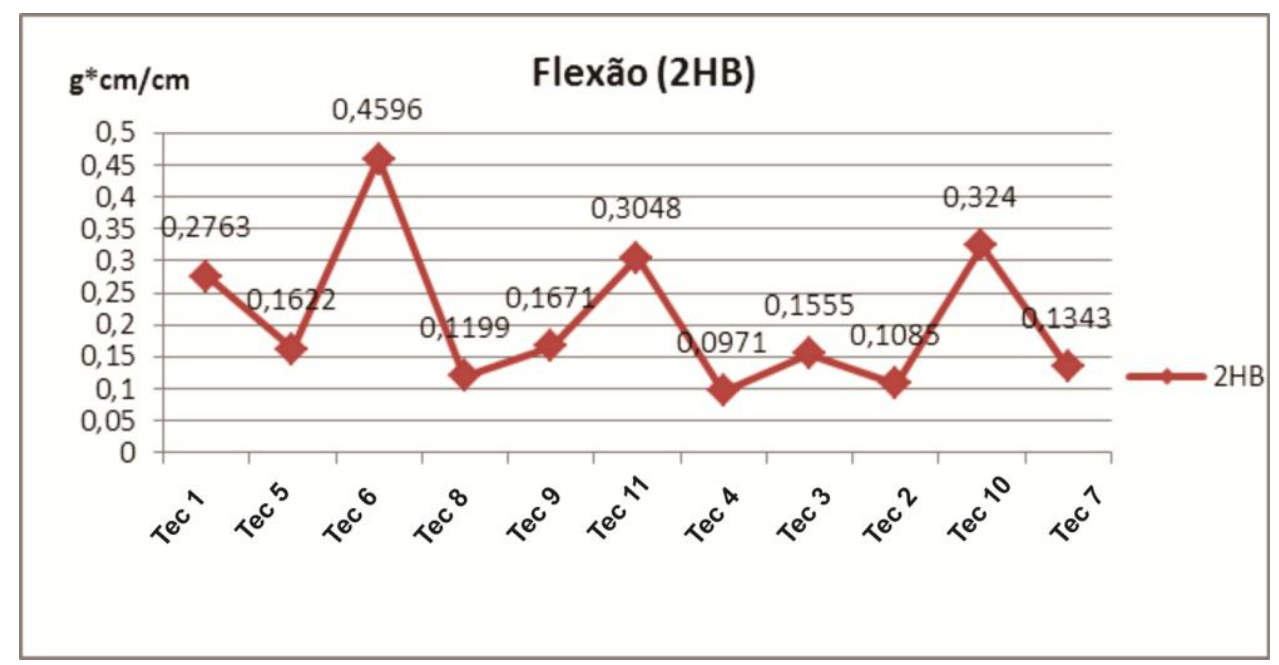

Fonte: Cristina Salete Valentin, 2014

O Gráfico 9 mostra que os tecidos 6 (100\% algodão FR) e tecido 11 (54\% modacrilico $44 \%$ algodão $2 \%$ fibra de carbono) são os que apresentam maiores resistência a movimentos de dobra; e os tecidos 2 (54\% modacrilico 44\% algodão 2\% fibra de carbono) e 9 (93\% meta aramida $5 \%$ para aramida $2 \%$ fibra de carbono) são os que possuem os valores mais baixos, o que indica menor resistência a movimentos de dobra. Os tecidos que apresentam uma menor resistência à dobra apresentarão uma maior comodidade quando o usuário pretenda ou queira realizar algum movimento que implique uma flexão do tecido.

3) Módulo de ensaio automatizado de compressão (KES-FB3) 
Esse dispositivo de medida é utilizado para determinar as propriedades de compressão dos tecidos. O equipamento aplica uma carga de compressão ao tecido $\left(\mathrm{Pm}=50 \mathrm{gf} / \mathrm{cm}^{2} \mathrm{em}\right.$ condições standards) para comprovar o grau de recuperabilidade após aplicar este esforço.

Nesse ensaio, as dimensões da amostra sobre as que se realiza a medida são de $2 \mathrm{~cm}^{2}$, isto é, sobre essa área se realiza a pressão a uma determinada velocidade constante.

A partir desse ensaio de compressão, são estabelecidas as seguintes variáveis físicas:

- LC: linearidade da curva de compressão.

- WC: energia requerida para a compressão.

- RC: porcentagem de resiliência da compressão. Esse valor indica o grau de recuperação quando se tira a força aplicada. Altos valores de RC indicam uma elevada porcentagem de recuperação do estado original.

- EMC: porcentagem de compressibilidade. Esse valor se obtém pela comparação de valores de grossura iniciais com valores de grossura quando é aplicada a força máxima.

A Figura 21 mostra que espessura da amostra pode ser obtida quando se exerce uma pressão de 0,5 y $50 \mathrm{gf} / \mathrm{cm}^{2}$ (em condições standards). Esses valores representam respectivamente as variáveis $\mathrm{T} 0 \mathrm{y} \mathrm{Tm}$.

Figura 21 - Características do ensaio de compressão

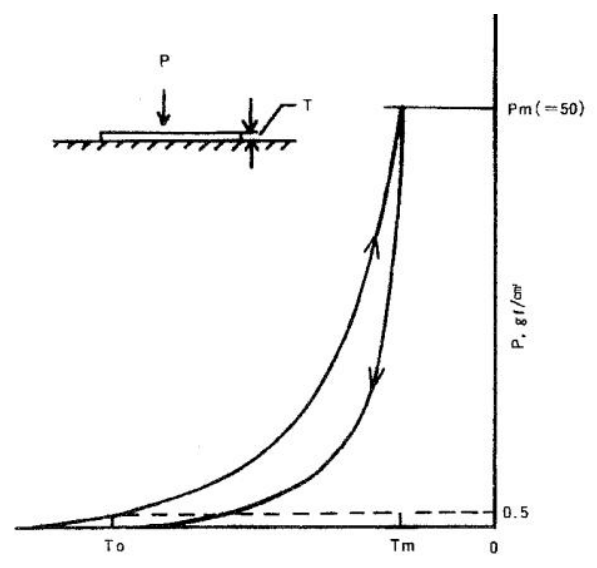

Fonte: Kawabata, 1980

Os Gráficos 11, 12 e 13 apresentam os valores experimentais dos parâmetros (LC), (WC) e (RC). 
Gráfico 11 - Representação da linearidade da curva de compressão

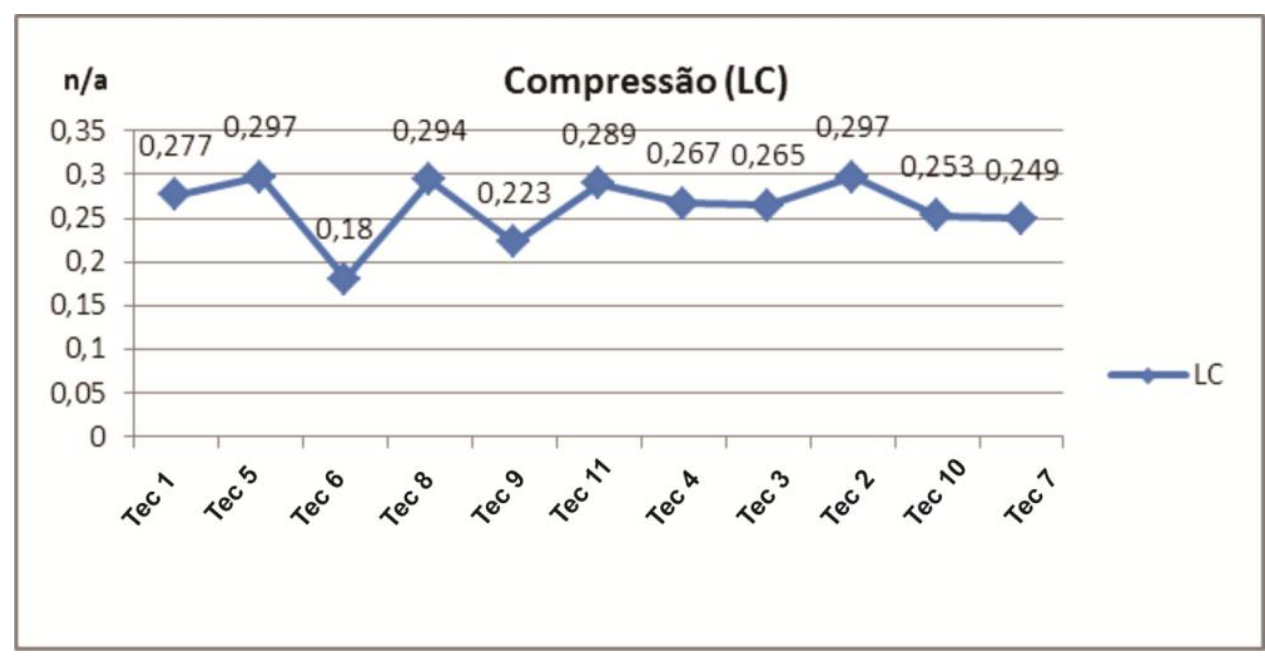

Fonte: Cristina Salete Valentin, 2014

Gráfico 12 - Representação de energia requerida para a compressão

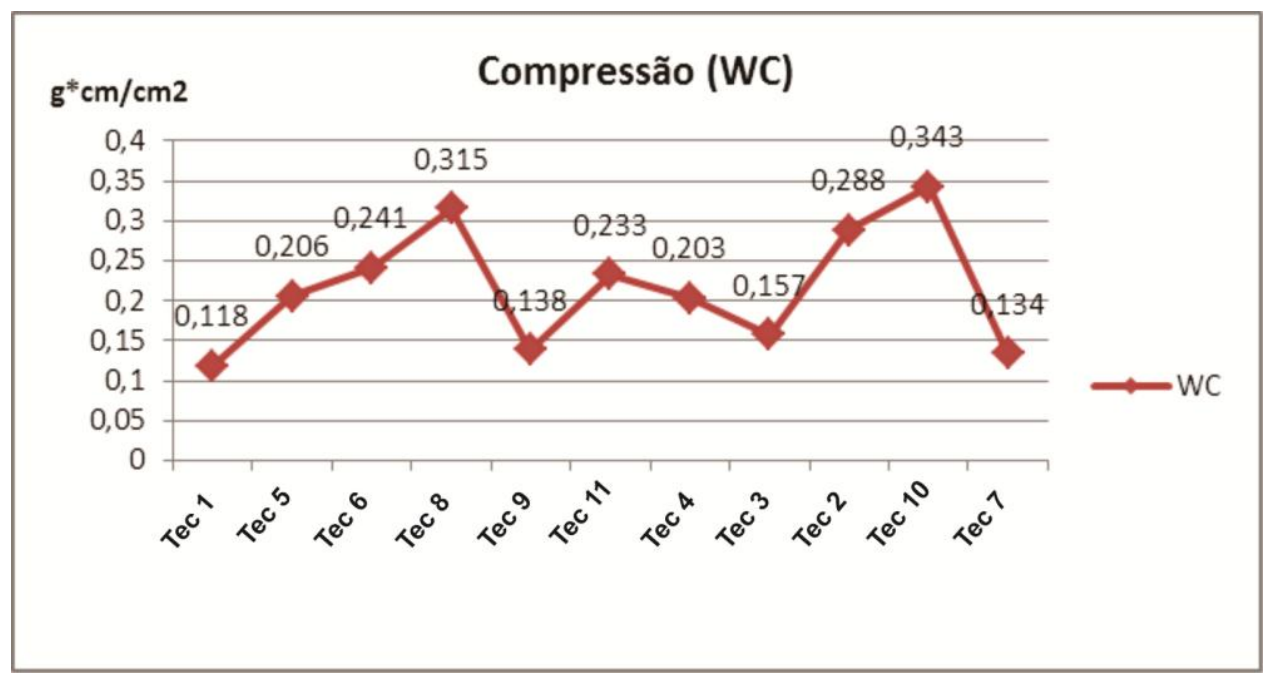

Fonte: Cristina Salete Valentin, 2014 
Gráfico 13 - Representação da porcentagem de resiliência da compressão

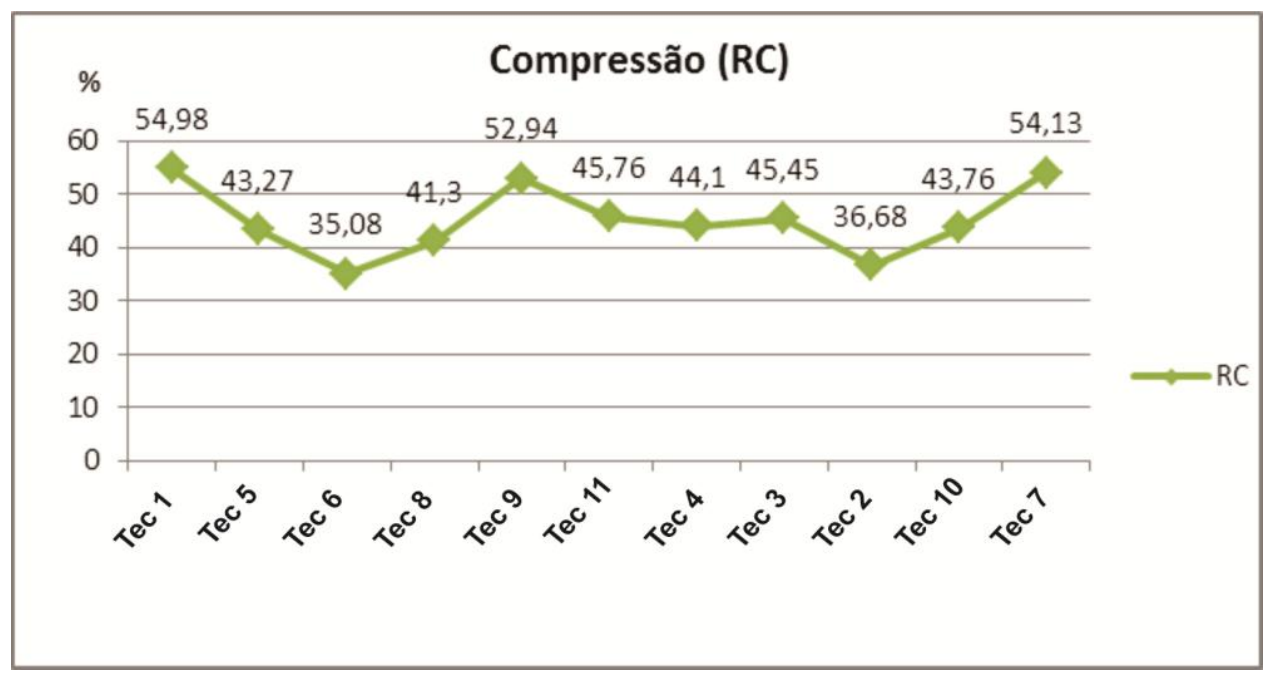

Fonte: Cristina Salete Valentin, 2014

O Gráfico 13 mostra que todos os tecidos oferecem uma porcentagem entre 33\%-55\% de recuperação do estado original. Os tecidos 8 (88\% algodão FR, $12 \%$ poliamida de alta tenacidade) e 10 (93\% meta aramida 5\% para aramida $2 \%$ fibra de carbono) requerem maior energia para obter uma compressão entre $45 \%$ e $40 \%$, que indica maior amortecimento e maior comodidade.

O Gráfico 14 apresenta os valores experimentais de espessura dos tecidos.

Gráfico 14 - Representação da espessura de cada amostra

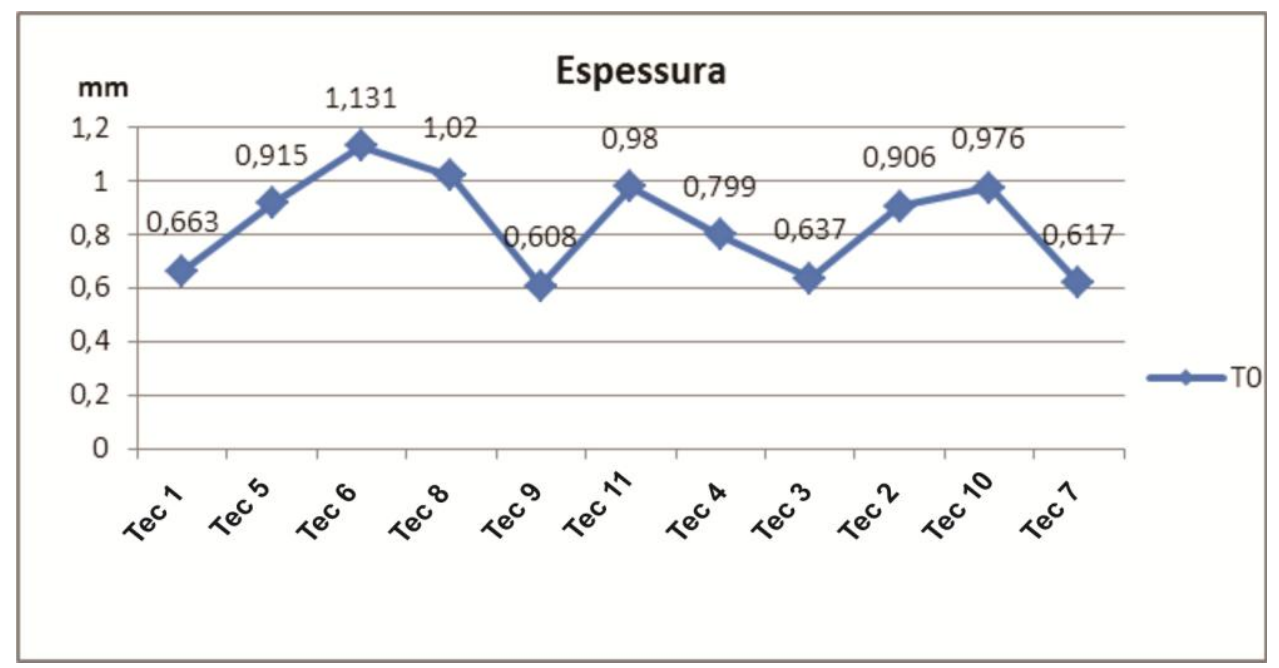

Fonte: Cristina Salete Valentin, 2014

4) Módulo de ensaio automatizado de superfície (KES-FB4) 
Esse módulo é utilizado para medir a superfície dos tecidos: determinação do coeficiente de fricção e da rugosidade geométrica.

Para a medida do coeficiente de fricção se utiliza um contato formado por uma série de fios de metal empilhados. Esses fios de metal têm um diâmetro de 0,5 mm cada um, e dado que o contato está formado por dez fios, a superfície de contato é de $5 \mathrm{~mm}$. Esse contato desliza sobre a superfície exercendo uma força ou pressão de 50 gf. No caso da rugosidade, o contato está formado por um único fio de $0,5 \mathrm{~mm}$ de diâmetro. Nesse caso se exerce uma força de contato de $10 \mathrm{gf}$. Ambos os tipos de contato podem ser observados nas duas figuras abaixo.

Figura 22 - Fricção da superfície (esquerda) e rugosidade da superfície (direita).
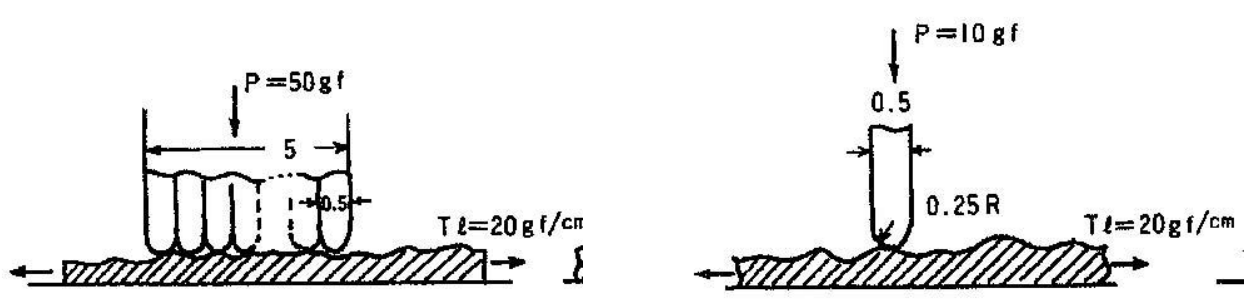

Fonte: Kawabata, 1980

Cabe destacar que, em ambos os casos, o tecido está submetido a uma tensão inicial de $20 \mathrm{gf} / \mathrm{cm}$ e velocidade de deslocamento dos contatos constante $(0,1 \mathrm{~cm} / \mathrm{s})$.

A partir do ensaio de superfície, são determinados os seguintes parâmetros:

- MIU: valor médio do coeficiente de fricção. Esse valor pode oscilar entre 0 a 1. Portanto, quanto maior for o valor de MIU, maior será a fricção do tecido. O valor de MIU está relacionado com o caráter escorregadio e não escorregadio, que pode ser sentido quando se esfregam os objetos. O maior valor de MIU faz referência ao menos escorregadio.

- MMD: esse valor é o desvio médio do coeficiente de fricção; ou seja, indica as variações mostradas no coeficiente de fricção (MIU), como se pode observar na Figura 23. O valor de MMD está correlacionado com a suavidade e a rugosidade que podem ser sentidas quando se esfregam os objetos. $\mathrm{O}$ valor maior de MMD significa maior aspereza.

- SMD: esse parâmetro representa a rugosidade geométrica do tecido. Ele é calculado pela diferença entre a espessura média e as espessuras medidas nos 
pontos indicados na Figura 24. Portanto, quanto maior for o valor de SMD, maior será a rugosidade da amostra.

Figura 23 - Determinação do coeficiente de fricção

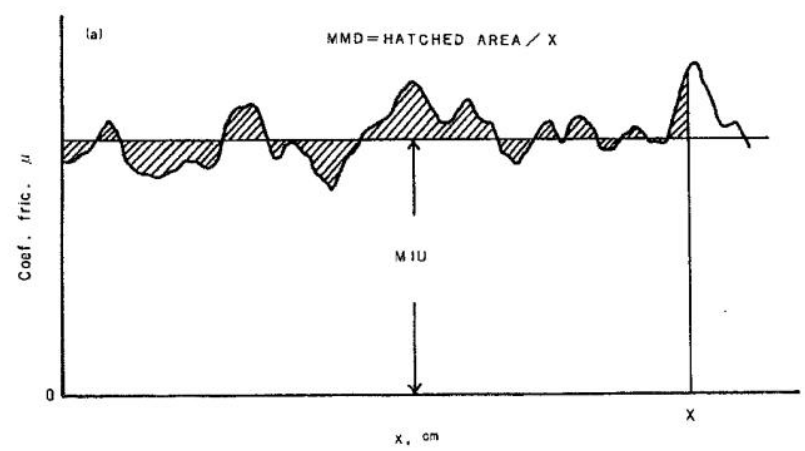

Fonte: Kawabata, 1980

Figura 24 - Determinação da rugosidade da superfície

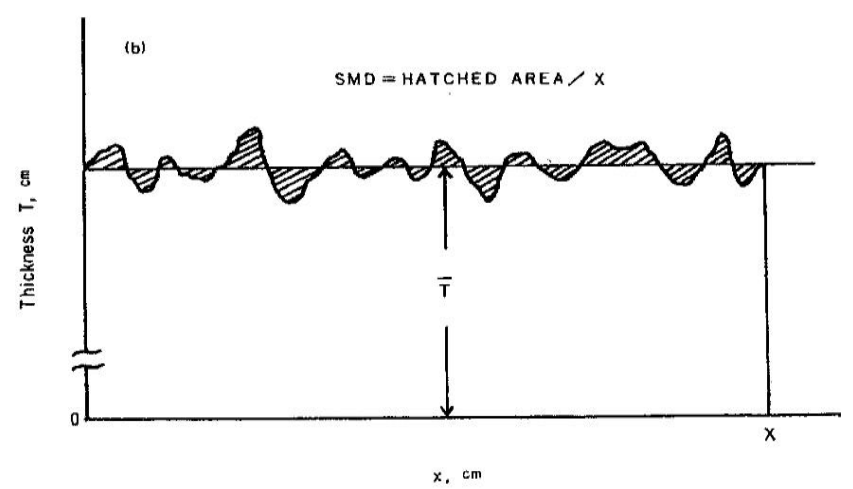

Fonte: Kawabata, 1980

Os Gráficos 15, 16, e 17 mostram os valores experimentais dos parâmetros (MIL), (MMD) e (SMD). 
Gráfico 15 - Representação do valor médio do coeficiente de fricção

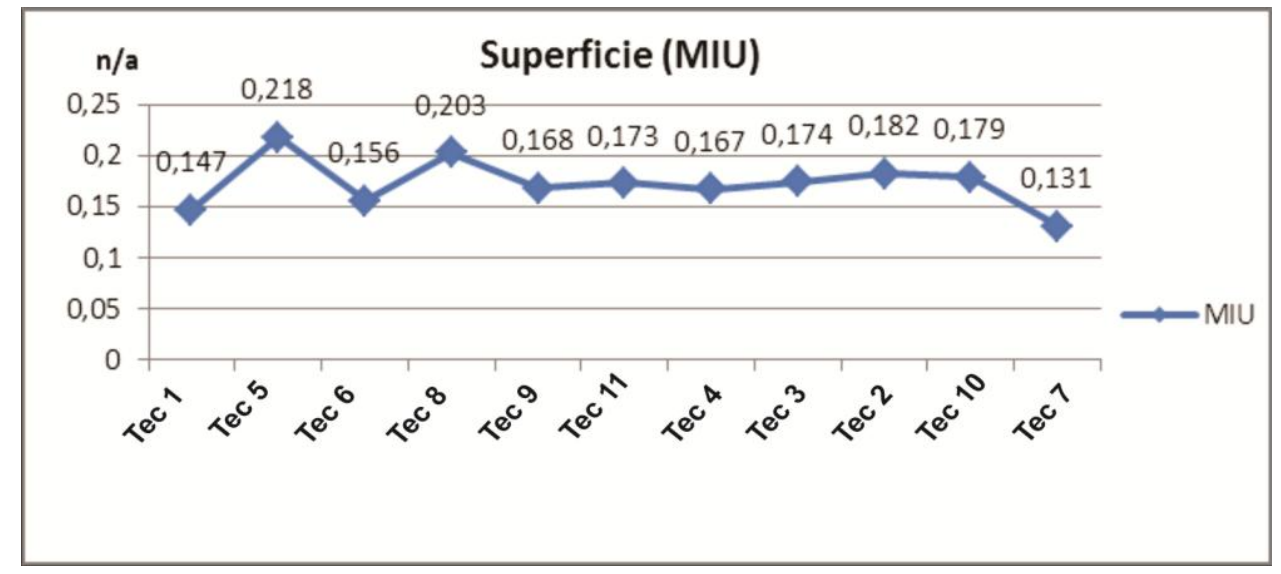

Fonte: Cristina Salete Valentin, 2014

Gráfico 16 - Representação do valor do desvio médio do coeficiente de fricção

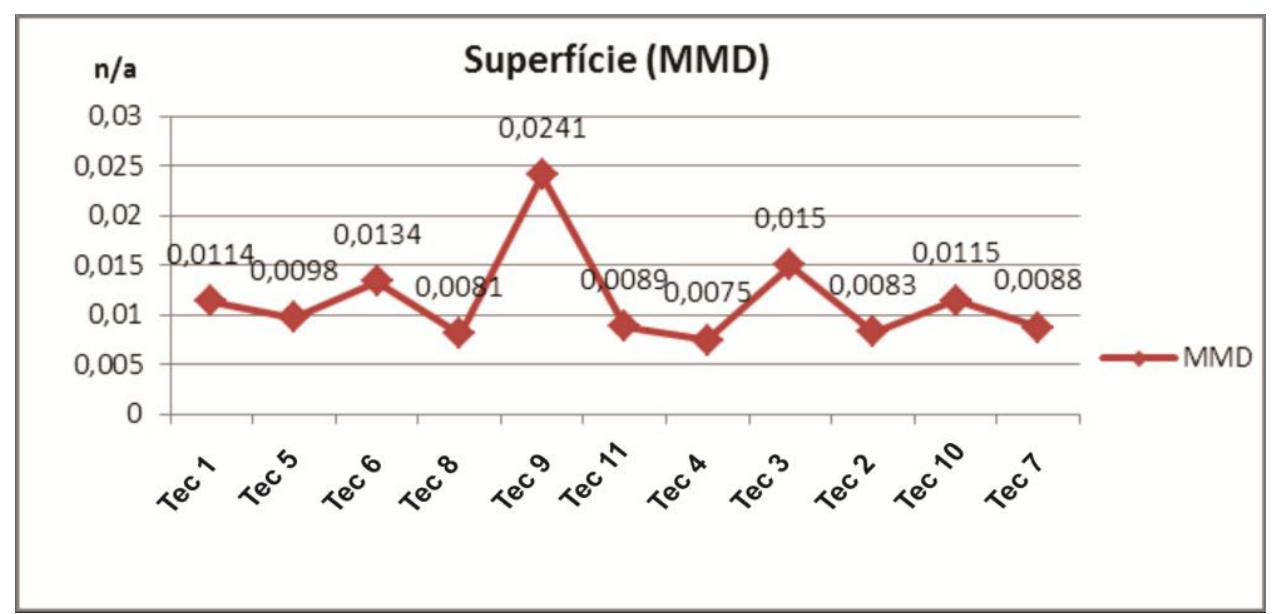

Fonte: Cristina Salete Valentin, 2014

Gráfico 17 - Representação da rugosidade geométrica do tecido

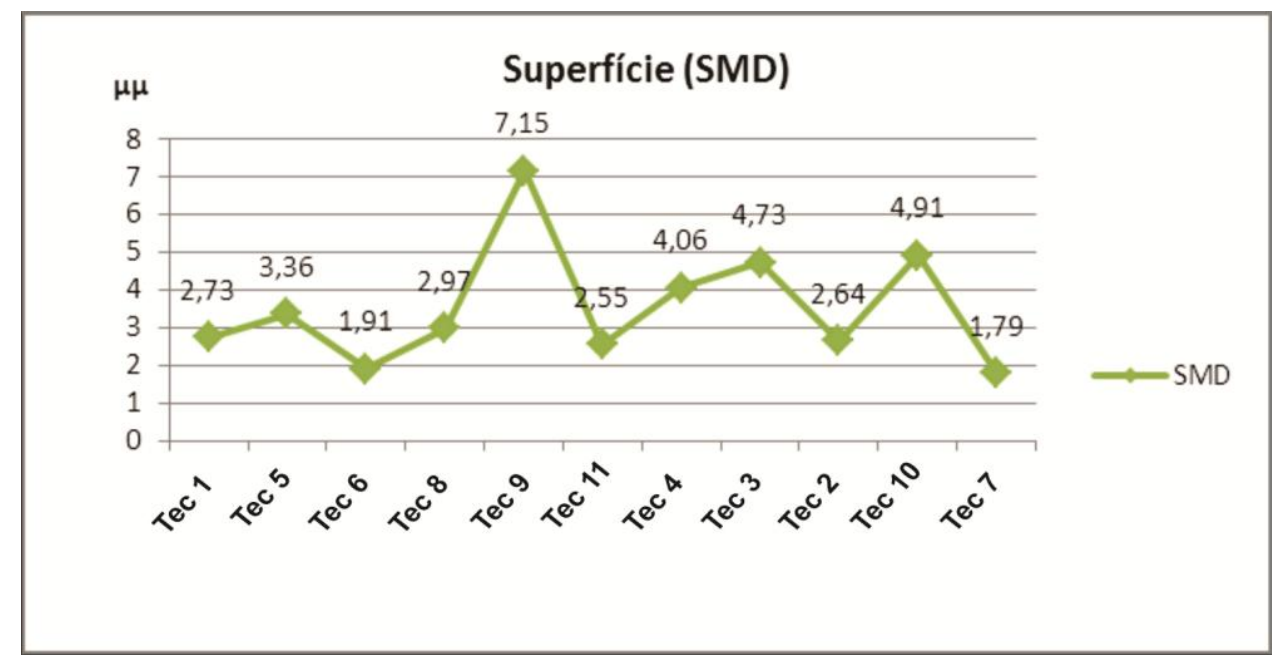

Fonte: Cristina Salete Valentin, 2014 
Os valores experimentais do coeficiente de fricção estão entre 0,130 - 0,220. Esses valores são suficientemente altos para evitar que os tecidos sejam escorregadios se comparados, por exemplo, ao caso de um lençol de cama que apresenta um valor de coeficiente de fricção em torno a 0,100. O Gráfico 15 mostra os tecidos menos escorregadios: o tecido 5 (48\% modacrilico, 37\% liocel, $15 \%$ para aramida), e 8 ( $88 \%$ algodão FR, 12\% poliamida de alta tenacidade).

As amostras que apresentaram maiores valores de MIU possuem valores menores de MMD. O valor de MMD está relacionado com a suavidade dos tecidos; quanto maior for o valor de MMD mais áspero será o tecido; e quanto menor for esse valor, o tecido será mais suave. O Gráfico 16 mostra que o tecido mais áspero é o tecido 1 (93\% meta aramida 5\% para aramida 2\% fibra de carbono) e os mais suáveis são: tecido 5 (48\% modacrilico, $37 \%$ liocel, $15 \%$ para aramida), e 8 ( $88 \%$ algodão FR, 12\% poliamida de alta tenacidade). Em seguida aparecem os tecidos: tecido 2 (54\% modacrilico $44 \%$ algodão $2 \%$ fibra de carbono), tecido 4 (60\% modacrilico, 35\% algodão, 4,5\% poliamida, 0,5\% fibra de carbono), tecido 7 (50\% aramida e 50\% viscose) e 11 (54\% modacrilico 44\% algodão 2\% fibra de carbono).

Quanto maior for o valor de SMD, maior será a rugosidade do tecido. O Gráfico 17 indica que o tecido 9 (93\% meta aramida 5\% para aramida $2 \%$ fibra de carbono) apresenta maior rugosidade, e os tecidos 6 (100\% algodão FR) e 7 (50\% aramida e 50\% viscose) são os que apresentam menor rugosidade. Os tecidos com menor rugosidade serão mais confortáveis para os usuários; já que rugosidade menor apresentará valores maiores de suavidade no tecido, implicando maior conforto ao usuário.

\subsubsection{Primary Hand e THV (Total Hand Value)}

As tabelas 14 e 15 mostram a interpretação dos valores: Total Hand Value e Primary Hands.

Tabela 14 - Valores Total Hand
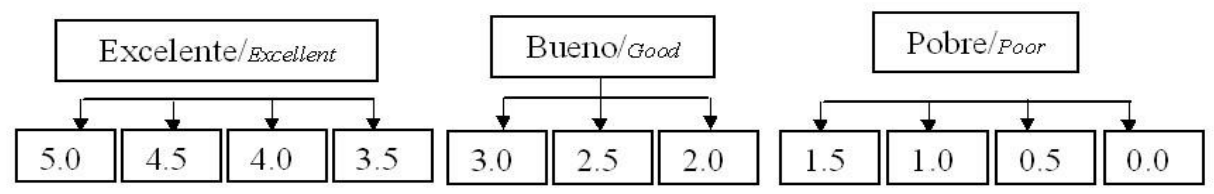

Fonte: Kawabata, 1980 
Tabela 15 - Valores Primary Hands

\begin{tabular}{|c|c|}
\hline$\geq 10$ & MUITO ALTO \\
\hline 9 & ALTO GRAU \\
8 & \\
7 & GRAU MÉDIO \\
\hline 6 & BAIXO \\
\hline 3 & \\
\hline 2 & MUITO BAIXO \\
\hline$\leq 0$ & \\
\hline
\end{tabular}

Fonte: Kawabata, 1980

Definição dos parâmetros:

KOSHI: rigidez (sensação relacionada com a rigidez/elasticidade ao dobrar).

NUMERI: suavidade (sensação relacionada com um toque liso, plano e suave).

FUKURAMI: densidade e suavidade (corpo, sensação de voluminosidade e riqueza).

SHARI: rugosidade, aspereza, crespo.

HARI: caimento (tecido que se estende com facilidade).

SOFUTOSA: sensação de suavidade, voluminosidade, flexibilidade.

KISHIMI: som que faz o tecido ao tocá-lo.

SHINAYAKASA: flexibilidade.

A variável W representa o peso da amostra. Apesar dessa variável não ser medida pelo sistema de medida KES, ela é utilizada nos cálculos dos parâmetros: Primary Hand e THV. O peso dos tecidos foi determinado por uma balança analítica. O Gráfico 18 mostra os valores experimentais obtidos.

Gráfico 18 - Representação do peso dos tecidos

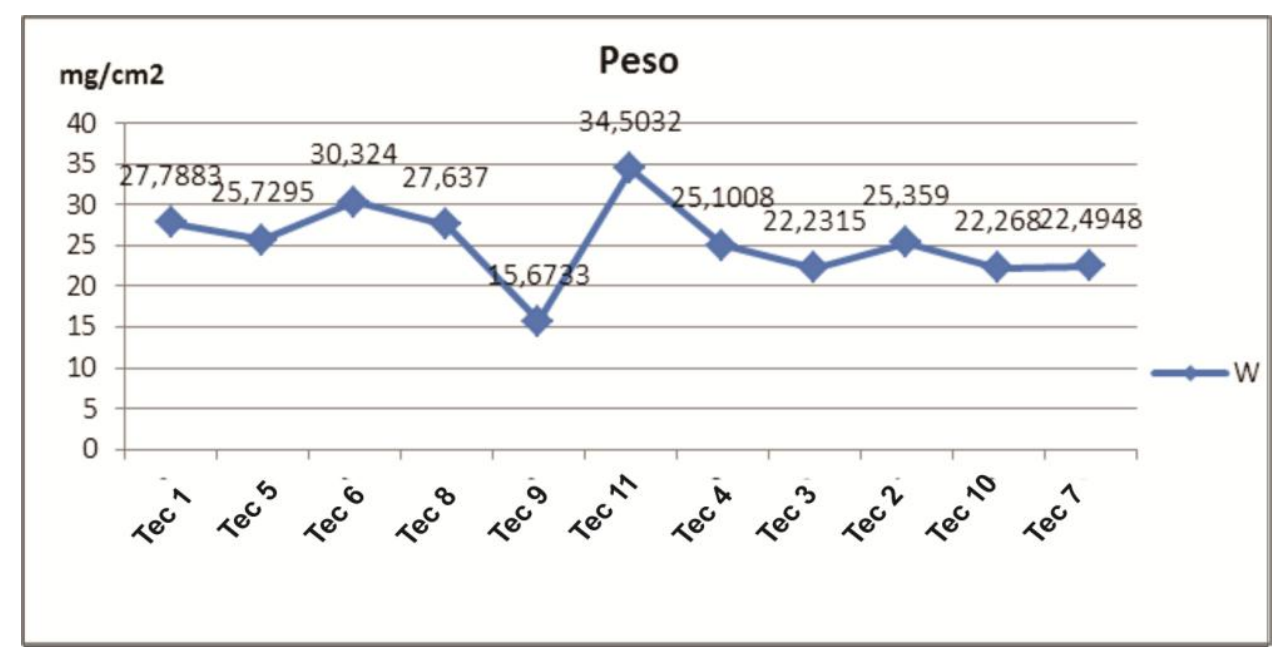

Fonte: Cristina Salete Valentin, 2014 
Este Gráfico 18 mostra que o tecido 11 (54\% modacrilico $44 \%$ algodão $2 \%$ fibra de carbono) é o que apresenta o maior peso por centímetro quadrado; e o tecido 9 (93\% meta aramida $5 \%$ para aramida $2 \%$ fibra de carbono) apresenta o menor peso por centímetro quadrado. Os tecidos que possuem menor peso por centímetro quadrado serão mais leves e, portanto, mais confortáveis.

A partir do peso dos tecidos, foi possível calcular os valores numéricos para os Primary Hand correspondentes, conforme o modelo pré-estabelecido que foi determinado para cada tecido. O THV é o indicador objetivo da adequação ou não, - em termos de sensação ao toque, - de um material têxtil a uma determinada aplicação.

Os Gráficos 19 e 20 mostram os resultados dos Primary Hand, o valor final de THV.

Gráfico 19 - Representação dos valores Primary Hands

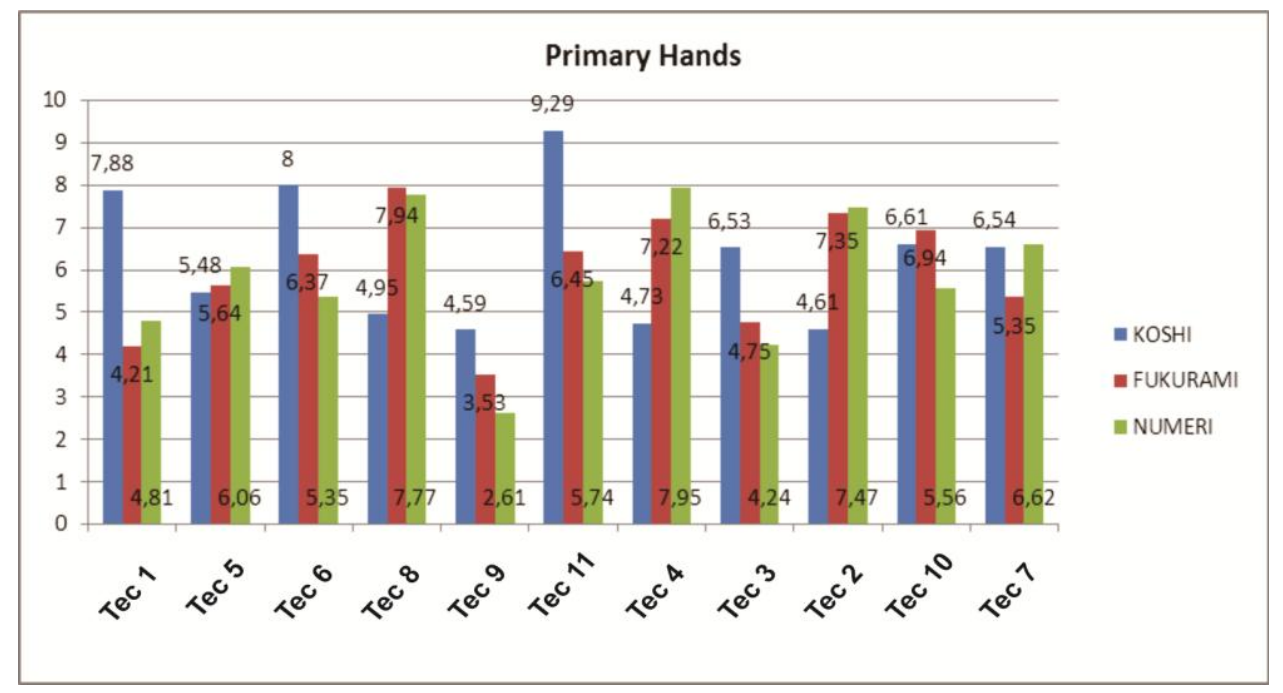

Fonte: Cristina Salete Valentin, 2014 
Gráfico 20 - Representação dos valores Total Hand Value

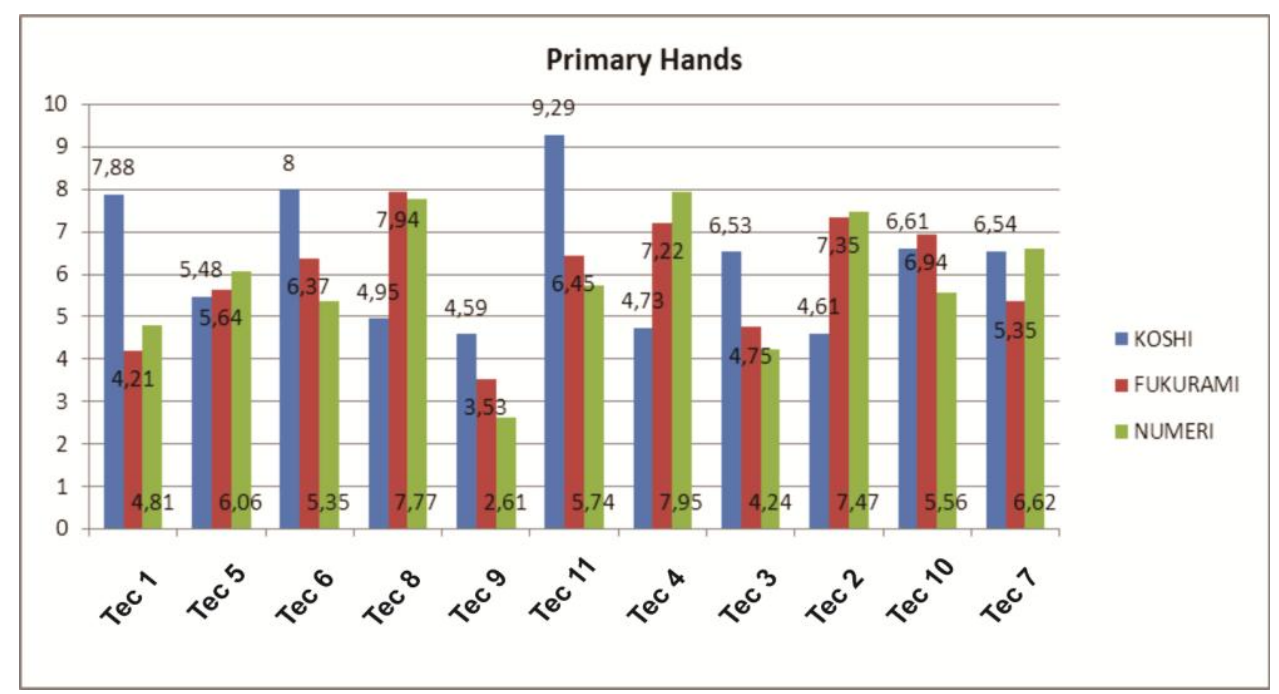

Fonte: Cristina Salete Valentin, 2014

a) Análise dos resultados

a.1) Tecido 1: $93 \%$ meta aramida 5\% para aramida $2 \%$ fibra de carbono

O THV mostra que o tecido 1 se adapta perfeitamente à categoria selecionada, o que significa ser um tecido apto para esta aplicação: calças masculinas - Inverno. Além disso, segundo o sistema de medição KES, cataloga-se como “excelente” para esta categoria.

Observando os valores de PRIMARY HAND, destaca-se a alta rigidez (KOSHI) apresentada por esse tecido. Os demais valores, de densidade (FUKURAMI) e suavidade (NUMERI), se apresentaram em um nível intermediário.

a.2) Tecido 5: $48 \%$ modacrilico, $37 \%$ liocel, $15 \%$ para aramida

O THV indica que o tecido 5 se adapta perfeitamente à categoria selecionada, o que significa ser um tecido apto para esta aplicação: calças masculinas - Inverno. Além do mais, segundo o sistema de medição KES, cataloga-se como “excelente” para esta categoria.

a.3) Tecido 6: 100\% algodão FR 
O THV mostra que o tecido 6 se adapta perfeitamente à categoria selecionada, o que significa ser um tecido apto para esta aplicação: calças masculinas - Inverno. Além disso, segundo o sistema de medição KES, cataloga-se como "bom” para esta categoria.

Observando os valores de PRIMARY HAND, destaca-se a alta rigidez (KOSHI) apresentada por esse tecido. Os demais valores de densidade (FUKURAMI) e suavidade (NUMERI), se apresentaram em um nível intermediário.

a.4) Tecido 8: $88 \%$ algodão FR, $12 \%$ poliamida de alta tenacidade

O THV indica que o tecido 8 se adapta perfeitamente à categoria selecionada, o que significa ser um tecido apto para esta aplicação: calças masculinas - Inverno. Além disso, segundo o sistema de medição KES, cataloga-se como "bom” para esta categoria.

Observando os valores de PRIMARY HAND, destacam-se a suavidade (NUMERI) e a densidade ou sensação de voluminosidade (FUKURAMI) que esse tecido apresenta.

a.5) Tecido 9: $93 \%$ meta aramida 5\% para aramida 2\% fibra de carbono

Ainda que no tecido 9 é onde se obtém o valor de THV mais baixo, continua considerando-se que se adapta à categoria selecionada, o que significa ser um tecido apto para esta aplicação: calças masculinas - Inverno. Além disso, segundo o sistema de medição KES, cataloga-se como "bom" para esta categoria.

a.6) Tecido 11: $54 \%$ modacrilico $44 \%$ algodão $2 \%$ fibra de carbono

O THV mostra que o tecido 11 se adapta perfeitamente à categoria selecionada, o que significa ser um tecido apto para esta aplicação: calças masculinas - Inverno. Além disso, segundo o sistema de medição KES, cataloga-se como "bom” para esta categoria.

Observando os valores de PRIMARY HAND, destaca-se a alta rigidez (KOSHI) apresentada por esse tecido, inclusive em comparação com todos os demais tecidos. Os outros valores de densidade (FUKURAMI) e suavidade (NUMERI) se apresentaram em um nível intermediário. 
a.7) Tecido 4: 60\% modacrilico, 35\% algodão, 4,5\% poliamida, 0,5\% fibra de carbono

O THV indica que o tecido F200 se adapta perfeitamente à categoria selecionada, o que significa ser um tecido apto para esta aplicação: calças masculinas - Inverno. Além disso, segundo o sistema de medição KES, cataloga-se como "bom” para esta categoria.

Observando os valores de PRIMARY HAND, cabe destacar o alto valor de suavidade (NUMERI) que apresenta o tecido, superando todos os demais tecidos. Os outros valores de densidade (FUKURAMI) e rigidez (KOSHI) se apresentaram em um nível intermediário.

a.8) Tecido 3: $54 \%$ modacrilico $44 \%$ algodão $2 \%$ fibra de carbono

O THV mostra que o tecido 3 se adapta perfeitamente à categoria selecionada, o que significa ser um tecido apto para esta aplicação: calças masculinas. Além disso, segundo o sistema de medição KES, cataloga-se como "bom” para esta categoria.

a.9) Tecido 2: $54 \%$ modacrilico $44 \%$ algodão $2 \%$ fibra de carbono

O THV mostra que o tecido 2 se adapta perfeitamente à categoria selecionada, o que significa ser um tecido apto para esta aplicação: calças masculinas - Inverno. Além disso, segundo o sistema de medição KES, cataloga-se como "bom” para esta categoria.

Observando os valores dos PRIMARY HAND neste caso também cabem ressaltar a alta suavidade (NUMERI), bem como a densidade ou a sensação de voluminosidade com um alto valor de FUKURAMI que esse tecido apresenta.

a.10) Tecido 10: $93 \%$ meta aramida $5 \%$ para aramida $2 \%$ fibra de carbono

O THV indica que o tecido 10 se adapta perfeitamente à categoria selecionada, o que significa ser um tecido apto para esta aplicação: calças masculinas - Inverno. Além disso, segundo o sistema de medição KES, cataloga-se como "bom” para esta categoria.

a.11) Tecido 7: 50\% aramida e 50\% viscose 
O THV mostra que o tecido 7 se adapta perfeitamente à categoria selecionada, ao obter-se o maior valor de THV entre todos os tecidos valorados, o que significa que é um tecido apto para esta aplicação: calças masculinas - Inverno. Além do mais, segundo o sistema de medição KES, cataloga-se como "excelente” para esta categoria.

\subsubsection{Ensaio térmico}

A Tabela 16 mostra os valores de sensação de frio/calor, condutividade térmica e isolamento térmico dos tecidos: tecido 2 (54\% modacrilico $44 \%$ algodão $2 \%$ fibra de carbono), tecido 3 (54\% modacrilico $44 \%$ algodão $2 \%$ fibra de carbono), tecido 4 (60\% modacrilico, $35 \%$ algodão, 4,5\% poliamida, $0,5 \%$ fibra de carbono), tecido 7 (50\% aramida e $50 \%$ viscose).

Tabela 16 - Resultados experimentais para análise térmica

Referência: Tecido 3

\begin{tabular}{|c|c|c|c|c|}
\hline \multirow{2}{*}{ Ensaio } & Parâmetro & Descrição & Unidade & Médias \\
\hline \multirow{3}{*}{ Térmico } & qmax & Sensação de frio & $\mathrm{W} / \mathrm{m}^{2}$ & 0.207 \\
\cline { 2 - 5 } & $\mathrm{K}$ & Condutividade Térmica & $\mathrm{W} / \mathrm{m}^{2} * \mathrm{~K}$ & 6.003 \\
\cline { 2 - 5 } & $\alpha \mathrm{d}$ & Isolamento Térmico & $\%$ & 13.14 \\
\hline
\end{tabular}

Referência: Tecido 2

\begin{tabular}{|c|c|c|c|c|}
\hline Ensaio & Parâmetro & Descrição & Unidade & Médias \\
\hline \multirow{3}{*}{ Térmico } & $\mathrm{qmax}$ & Sensação de frio & $\mathrm{W} / \mathrm{m}^{2}$ & 0.177 \\
\cline { 2 - 5 } & $\mathrm{K}$ & Condutividade Térmica & $\mathrm{W} / \mathrm{m}^{2} * \mathrm{~K}$ & 6.613 \\
\cline { 2 - 5 } & $\alpha \mathrm{d}$ & Isolamento Térmico & $\%$ & 11.54 \\
\hline
\end{tabular}

Referência: Tecido 4

\begin{tabular}{|c|c|c|c|c|}
\hline \multirow{2}{*}{ Ensaio } & Parâmetro & Descrição & Unidade & Médias \\
\hline \multirow{3}{*}{ Térmico } & qmax & Sensação de frio & $\mathrm{W} / \mathrm{m}^{2}$ & 0.199 \\
\cline { 2 - 5 } & $\mathrm{K}$ & Condutividade Térmica & $\mathrm{W} / \mathrm{m}^{2} * \mathrm{~K}$ & 6.272 \\
\cline { 2 - 5 } & $\alpha \mathrm{d}$ & Isolamento Térmico & $\%$ & 13.14 \\
\hline
\end{tabular}

Referência: Tecido 7

\begin{tabular}{|c|c|c|c|c|}
\hline \multirow{2}{*}{ Ensaio } & Parâmetro & Descrição & Unidade & Médias \\
\hline \multirow{3}{*}{ Térmico } & qmax & Sensação de frio & $\mathrm{W} / \mathrm{m}^{2}$ & 0.192 \\
\cline { 2 - 5 } & $\mathrm{K}$ & Condutividade Térmica & $\mathrm{W} / \mathrm{m}^{2} * \mathrm{~K}$ & 5.148 \\
\cline { 2 - 5 } & $\alpha \mathrm{d}$ & Isolamento Térmico & $\%$ & 6.35 \\
\hline
\end{tabular}

Fonte: Cristina Salete Valentin, 2014 


\section{1) Sensação frio/calor (qmáx)}

O parâmetro térmico denominado "qmáx" mede a sensação de frio/calor. Quando uma peça de tecido entra em contato com a pele, ocorre um fluxo térmico, uma vez que a temperatura da pele é maior que a do tecido. Essa diferença de temperatura causará um fluxo térmico que variará em função do tempo que pode ser representado graficamente, conforme mostra a Figura 25.

Figura 25 - Variação do fluxo de calor com o tempo

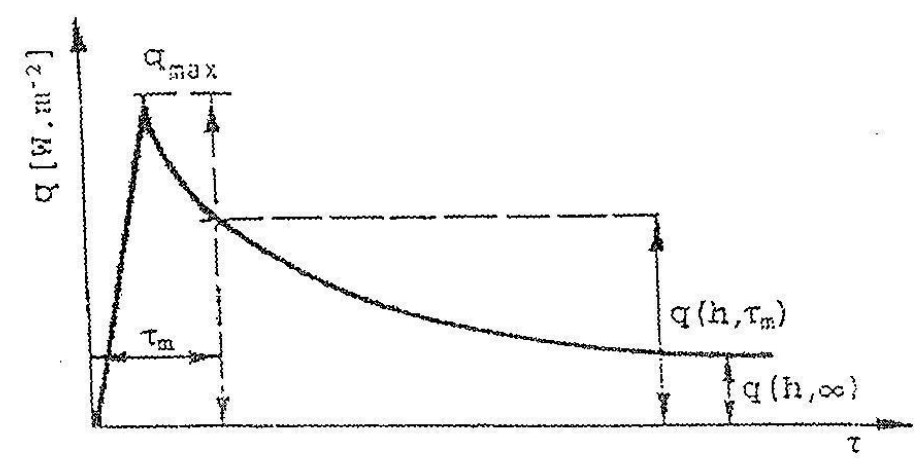

Fonte: Kawabata, 1980

Os valores mais altos de "qmáx" indicam sensação de frio, e os mais baixos indicam sensação de calor. Isso pode-se comprovar quando não há tecido e o valor de "qmáx" é máximo (0.633); o fluxo necessário para manter o T-Box, que simboliza a pele, a $30^{\circ} \mathrm{C}$ é máximo sem tecido, mas diminui ao colocar um tecido.

Dele se pode observar como, dos tecidos estudados, os tecidos que apresentam maior sensação de calor ao serem tocados são o tecido 2 (54\% modacrilico $44 \%$ algodão $2 \%$ fibra de carbono), o tecido 7 (50\% aramida e 50\% viscose) e o tecido 4 (60\% modacrilico, 35\% algodão, 4,5\% poliamida, $0,5 \%$ fibra de carbono), respectivamente, frente ao tecido 3 (54\% modacrilico $44 \%$ algodão $2 \%$ fibra de carbono), o qual apresenta maior sensação de frio ao ser tocado.

2) Condutividade térmica $(\mathrm{K})$ (por contato)

Os resultados experimentais mostram que o tecido 2 (54\% modacrilico $44 \%$ algodão $2 \%$ fibra de carbono) possui maior condutividade térmica; em seguida aparecem os tecidos: tecido 4 (60\% modacrilico, $35 \%$ algodão, $4,5 \%$ poliamida, $0,5 \%$ fibra de carbono) e 3 (54\% modacrilico $44 \%$ algodão $2 \%$ fibra de carbono).

3) Isolamento térmico ou retenção de calor em seco ( $\alpha$ d) (por convecção ou transmissão pelo ar) 
A partir da perda de calor, pode-se calcular a porcentagem de retenção de calor dos diferentes tecidos. Os tecidos 4 (60\% modacrilico, $35 \%$ algodão, $4,5 \%$ poliamida, $0,5 \%$ fibra de carbono) e 3 (54\% modacrilico $44 \%$ algodão $2 \%$ fibra de carbono) são os que oferecem maior isolamento térmico ou retenção de calor, - propriedade que resulta muito interessante para os tecidos usados no inverno, - seguidos do tecido 2 (54\% modacrilico $44 \%$ algodão $2 \%$ fibra de carbono); o tecido 7 (50\% aramida e 50\% viscose) é o que apresenta menor isolamento térmico ou retenção de calor pelo ar. 


\section{Conclusão}

Conclui-se que este trabalho alcançou seu objetivo que era fornecer dados e informações de tecidos para vestimentas de trabalho para proteção térmica e subsídio para a real avaliação do conforto térmico em ambientes de trabalho no Brasil. Do mesmo modo, analisou e estabeleceu comparativamente as características técnicas relacionadas com conforto desses tecidos, determinando aquele com maior capacidade de proporcionar conforto térmico.

Especificamente nos ensaios de conforto térmico, o ensaio de transporte de umidade apresentou resultados similares entre os diferentes tecidos: foi possível deduzir que aqueles que apresentaram pior resultado possuíam algum tipo de tratamento superficial, afetando, assim, os resultados, e fazendo com que estes tecidos se comportassem como impermeáveis. A classificação dos tecidos por tipo pode ser observada no Gráfico 21.

Gráfico 21 - Representação da classificação do tipo de tecido

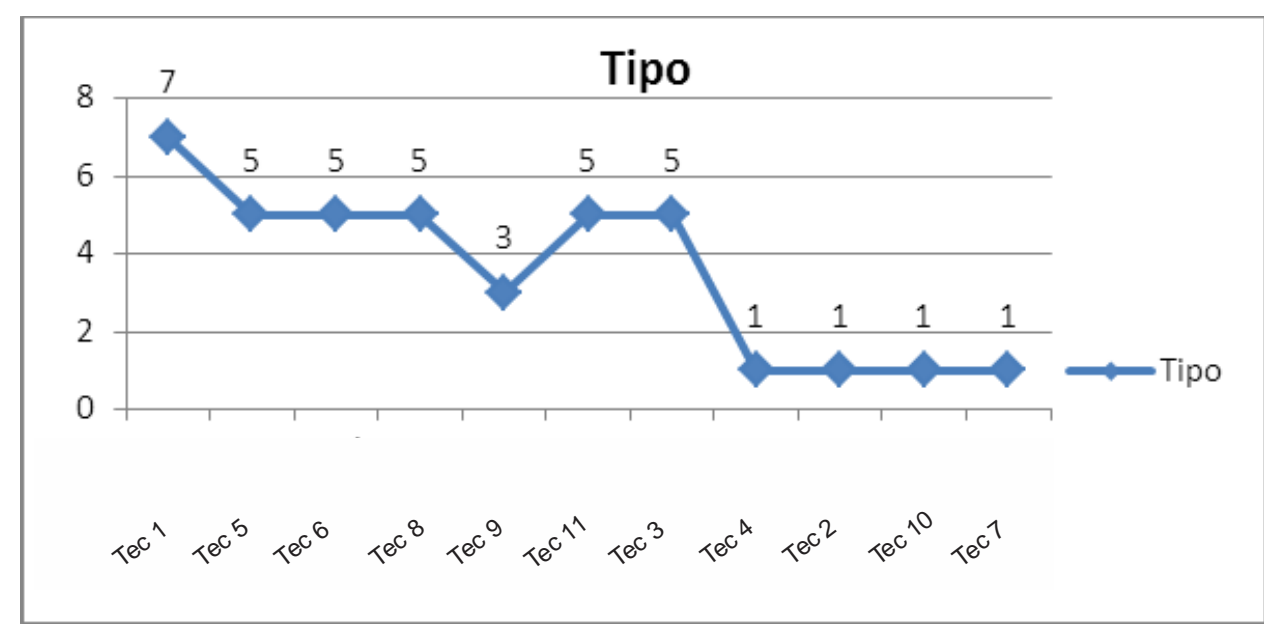

Fonte: Cristina Salete Valentin, 2014

A partir dos resultados obtidos, pôde-se ainda deduzir que alguns dos tecidos analisados possuíam algum tipo de tratamento superficial, que afetaram os resultados, e fez com que estes se comportassem como tecidos impermeáveis, como é o caso dos tecidos: tecido 2 (54\% modacrilico $44 \%$ algodão $2 \%$ fibra de carbono), tecido 4 (60\% modacrilico, $35 \%$ algodão), tecido 7 (50\% aramida 50\% viscose) e tecido 10 (93\% meta-aramida 5\% para aramida $2 \%$ fibra de carbono). 
Dessa forma, de acordo com os resultados de capacidade de transporte de umidade (OMMC) obtidos, pôde-se separar os tecidos estudados em dois grupos: os que apresentaram nula capacidade de transporte de umidade, por possuírem algum tratamento superficial (Gráfico 22), e os que ofereceram capacidade de transporte de umidade, por não possuírem tratamento superficial (Gráfico 23).

Gráfico 22 - Representação da capacidade de transporte de umidade dos tecidos com tratamento superficial

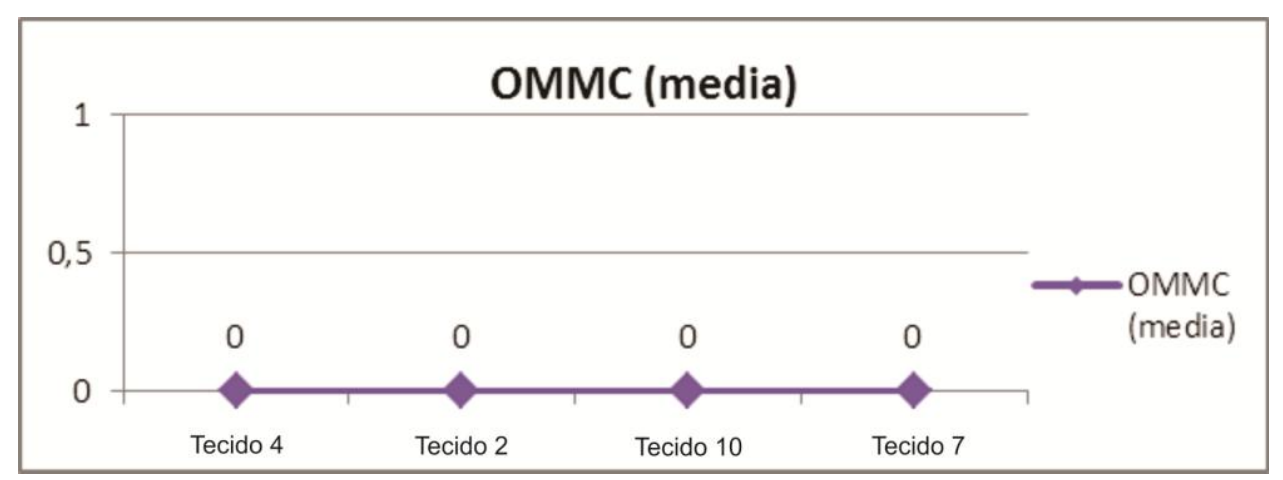

Fonte: Cristina Salete Valentin, 2014

Gráfico 23 - Representação da capacidade de transporte de umidade dos tecidos sem tratamento superficial

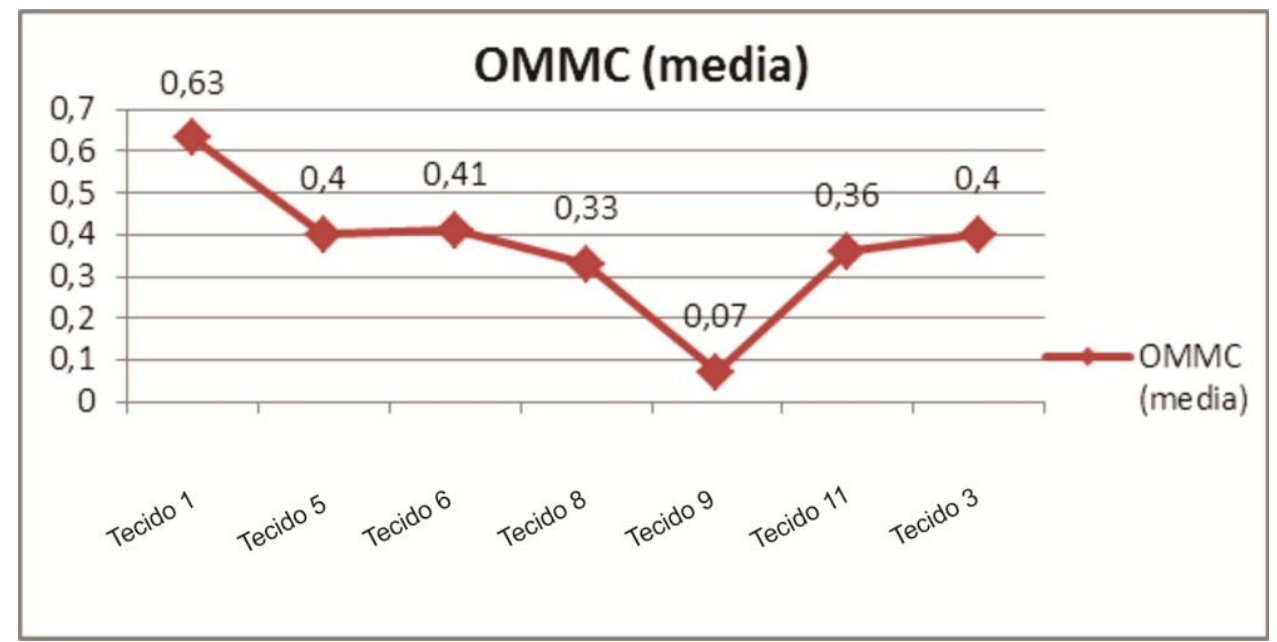

Fonte: Cristina Salete Valentin, 2014

O Gráfico 23 mostra que o tecido 1 (93\% meta-aramida 5\% para aramida 2\% fibra de carbono) é o que oferece maior capacidade de transporte de umidade, enquanto que, por outro lado, o tecido 9 (93\% meta-aramida 5\% para aramida $2 \%$ fibra de carbono) é o que apresenta menor capacidade de transporte de umidade. 
Os resultados apresentados no Gráfico 20 e 21 do ensaio de transporte de umidade e características, - isto é, a distinção entre um grupo de tecidos com nula capacidade de transporte de umidade devido a um tratamento superficial, e um grupo de tecidos com capacidade de transporte de umidade, - também foram evidenciados através da análise estatística, porém, de forma oposta: conforme a análise estatística, os tecidos 2 e 4 possuem capacidade de transporte de umidade, bem como o tecido 10 (93\% meta aramida 5\% para aramida $2 \%$ fibra de carbono), que apresenta a maior capacidade de transporte de umidade dentre todos os tecidos. Entretanto, e em detrimento da análise estatística, de acordo com a norma AATCC 195:2011, Determinação das propriedades de transmissão de umidade de tecidos, os tecidos são classificados conforme o diagrama de fluxo de critérios abaixo (Figura 26):

Figura 26 - Fluxograma do método de classificação

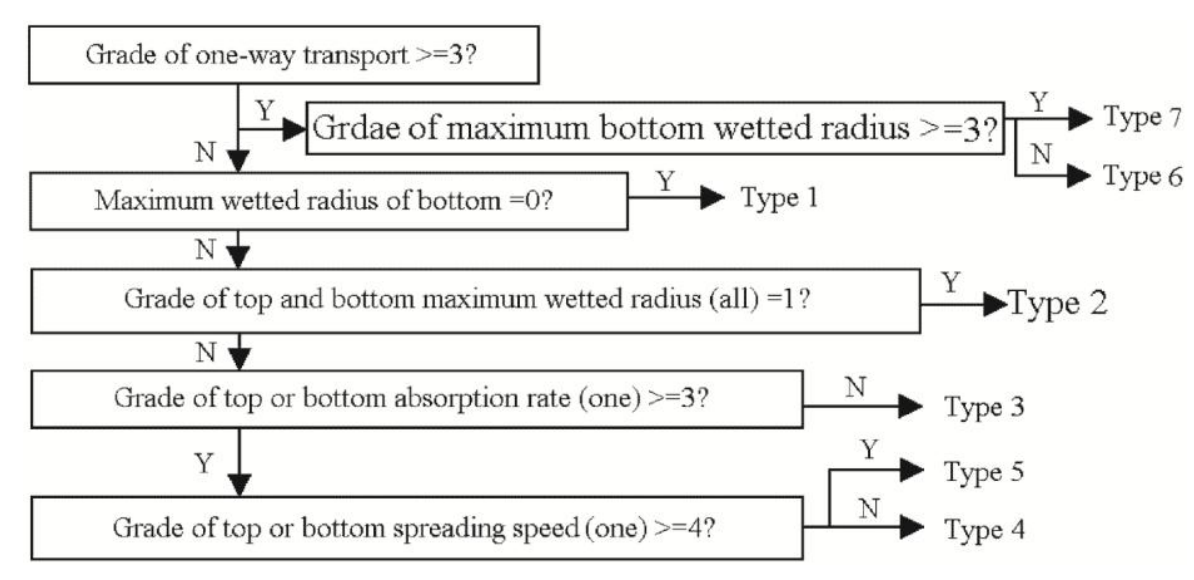

Fonte: Li, 2006

Do ensaio de resistência ao vapor de água, à vista dos resultados obtidos, pode-se dizer que os tecidos ensaiados são todos transpiráveis ao vapor de água. Para tecidos do gênero de malha ou tecido plano, se pode afirmar que valores entre 3-5 se consideram que têm boa transpirabilidade, e há valores menores de 3 , que se considera de muito boa transpirabilidade.

No caso dos dois tecidos que piores resultados davam no ensaio de transporte de umidade (tecido $460 \%$ modacrilico, $35 \%$ algodão, $4,5 \%$ poliamida, $0,5 \%$ fibra de carbono, e tecido $750 \%$ aramida e 50\% viscose), - onde se concluiu que a amostra ensaiada se tratava de tecido impermeável, - pode-se dizer que são transpiráveis ao vapor de água, mas impermeáveis à água. 
No caso dos dois tecidos que melhores resultados davam no ensaio de transporte de umidade (tecido $254 \%$ modacrilico $44 \%$ algodão $2 \%$ fibra de carbono e tecido $354 \%$ modacrilico $44 \%$ algodão $2 \%$ fibra de carbono), - onde se concluiu que as amostras ensaiadas apresentavam uma rápida absorção de umidade e uma rápida secagem, - no ensaio de Ret além do mais disseram que são também transpiráveis.

Quanto mais grosso um tecido, mais isolamento apresentará, mas também maior resistência ao vapor de água (menor transpirabilidade). O caso ideal seria aquele que, apresentando o maior isolamento possível, apresenta ainda a resistência ao vapor de água mais baixo possível.

Nos ensaios para avaliar o conforto físico e ergonômico, especificamente os ensaios realizados através do sistema Kawabata, os resultados também se apresentaram muito similares entre si: todos os produtos se mostraram aptos para a aplicação a que se destinam. Além disso, segundo o sistema de medição KES, o tecido 1 , o tecido 5 , e o tecido 7 se catalogaram como excelente para a categoria. Os demais, todos se catalogaram como bom para a categoria a que se destinam.

No ensaio realizado com o equipamento Thermo Labo II que, entre outros parâmetros avalia o isolamento térmico de materiais, foram testados aqueles mesmos tecidos com os quais se realizou o ensaio de resistência ao vapor de água; o tecido 7 foi aquele que apresentou menor isolamento térmico ou retenção de calor pelo ar, enquanto que o tecido 4 e o tecido 3 apresentaram maior isolamento térmico ou maior retenção de calor, propriedade que resulta interessante para aqueles tecidos para o inverno.

\subsection{Sugestões de trabalhos futuros}

Este trabalho não pretendeu esgotar o assunto, muito ao contrário, sua intenção foi ser um ponto de partida para o progresso no desenvolvimento de vestimentas de proteção com conforto, propiciando desta forma, maior segurança e proteção para os trabalhadores, melhores condições de trabalho e qualidade de vida. Sem por outro lado deixar de considerar a redução de despesas decorrentes de possíveis acidentes de trabalho.

À partir da realização deste trabalho, podem ser desenvolvidas novas experimentações e estudos. Um primeiro estudo pode ser a avaliação de vestimentas confeccionadas, com tecidos que foram objeto do presente estudo, através de manequim térmico. 
Seria interessante ainda, uma avaliação destas vestimentas confeccionadas através de uma prova de campo com usuários. 


\section{Referências}

ALBUQUERQUE, Sandra Monteiro de. Estudo comparativo do comportamento da costura em tecido que retarda a chama, submetida ao calor e à chama. 2013. Dissertação (Mestrado em Têxtil e Moda) - Escola de Artes e Humanidades da Universidade de São Paulo. São Paulo, 2013.

ASSOCIAÇÃO BRASILEIRA DE NORMAS TÉCNICAS. NBR 10588: tecidos planos determinação da densidade de fios. São Paulo, 2008.

. NBR 12546: materiais têxteis - ligamentos fundamentais de tecidos planos terminologia. São Paulo, 1991.

AMERICAN SOCIETY FOR TESTING AND MATERIALS. ASTM D3776 - 96 Standard Test Methods for Mass Per Unit Area (Weight) of Fabric, 2002.

ASSOCIAÇÃO NACIONAL DA INDÚSTRIA DE MATERIAL DE SEGURANÇA E PROTEÇÃO AO TRABALHO. Indicadores do Mercado Brasileiro de Equipamentos de Proteção Individual, 2014.

AMERICAN SOCIETY OF HEATING, REFRIGERATING AND AIR-CONDITIONING ASHRAE. Handbook-Fundamentals, Capítulo 9 - ThermalComfort. 2013.

ANIMASEG - Associação Nacional da Indústria de Material de Segurança e Proteção ao Trabalho. Indicadores do Mercado Brasileiro de Equipamentos de proteção Individual, 2014.

ARAUJO, Mário; CASTRO, Ernesto. Manual de Engenharia Têxtil. Vol. 1. Lisboa: Fundação CalousteGulbenkian, 2000.

ARAUJO, Mário; FANGUEIRO, Raúl; HONG, Hu. Têxteis Técnicos - Materiais do Novo Milênio. Lisboa: Williams, 2000.

BALTAR, Marta Garcia. Redução da demanda de energia elétrica utilizando parâmetros construtivos visando ao conforto térmico. 2006. Dissertação (Mestrado em Engenharia Elétrica) - Universidade Católica do Rio Grande do Sul. Porto Alegre, 2006.

BRASIL. Manual de orientação para especificação das vestimentas de proteção contra os efeitos térmicos do arco elétrico e do fogo repentino. Secretária de Inspeção do Trabalho SIT, Departamento de Segurança e Saúde no Trabalho - DSST do Ministério do Trabalho e Emprego. Disponível em:

http://portal.mte.gov.br/data/files/8A7C816A31F92E6501321734945907BD/manual_vestime ntas.pdfAcesso em 13/7/2013.

. NR 6 - Equipamento de Proteção Individual - EPI. Disponível em:

http://portal.mte.gov.br/data/files/8A7C812D36A2800001388130953C1EFB/NR06\%20(atualizada)\%202011.pdf. Acesso em 13/7/2013. 
. NR 15 - Atividades e Operações Insalubres. Disponível em:

http://portal.mte.gov.br/data/files/8A7C816A47594D040147D14EAE840951/NR-

15\%20(atualizada\%202014).pdf. Acesso em 20/9/2014.

. NR 17 - Ergonomia. Disponível em:

http://portal.mte.gov.br/data/files/FF8080812BE914E6012BEFBAD7064803/nr_17.pdf.

Acesso em 20/9/2014.

CERVO, Amado L.; BERVIAN, Pedro A. Metodologia Científica. $4^{\text {a }}$ edição. São Paulo: Makron Books, 1996.

CHANDE, AdniloFaizal Abdul Remane. Riscos de stress térmico em ambiente fabril. 2009. Dissertação (Mestrado em Dinâmicas Sociais, Riscos Naturais e Tecnológicos) - Faculdade de Ciências e Tecnologia da Universidade de Coimbra. Coimbra, 2009.

CHARLES, Kate E. Fanger's Thermal Comfort and Draught Models. Institute for Research in Construction. Canadá, Ottawa, 2003.

CORREIA, Ermelinda de Lurdes Salgado. L. S. Modelo térmico aplicado à caracterização do conforto térmico proporcionado pelo vestuário. 2005. Dissertação (Mestrado em Engenharia Humana) - Universidade do Minho. Braga, 2005.

COSTA, Emília Quelhasda; BAPTISTA J. dos Santos; DIOGO, M. Tato; MAGALHÃES, A. Barbedo. Ambiente Térmico Quente e o seu impacto na produtividade e sinistralidade.

Simpósio Internacional de Segurança e Higiene ocupacionais, 2011.

COSTA, Silgia Aparecida da.Tecnologia e vestuário esportivo. II Simpósio Temático da PróReitoria de Graduação. Universidade de São Paulo EACH - USP, 2014.

COUTO, Hudson de Araújo. Ergonomia aplicada ao trabalho: o manual técnico da máquina humana. Vol. 1. Belo Horizonte: Ergo, 1995.

FABRIS, Jonas Pedro. Conforto térmico na indústria têxtil: um estudo de caso em MondaiSC. 2013. Dissertação (Mestrado em Engenharia Civil) - Universidade Federal de Santa Catarina. Florianópolis, 2003.

FREUND, John E. Estatística aplicada: economia, administração e contabilidade. Porto Alegre: Ed. Bookman, 2006.

FROTA, Anésia Barros; SCHIFFER, Sueli Ramos. Manual de conforto térmico: arquitetura, urbanismo. $3^{\text {a }}$ ed. São Paulo: Studio Nobel, 1999.

GASI, Fernando; BITTENCOURT, Edison. Estudo das propriedades de conforto em tecidos de malha das fibras sintéticas de poliéster e poliamida 6.6: permeabilidade ao vapor transporte de umidade e proteção ultravioleta. REDIGE, Senai, Cetiqt, 2010.

GIL, Antonio Carlos. Como elaborar projetos de pesquisa. $4^{\mathrm{a}}$ edição. São Paulo: Editora Atlas, 2002. 
GRANDI, MarieleStefani. Avaliação da percepção da sensação térmica em uma sala de controle. 2006. Dissertação (Mestrado em Engenharia de Produção) - Universidade Federal do Rio Grande do Sul, 2006.

HOLMES, David A. Textile for survival. In Horrocks, A. R.; Anand, S.C. Handbook of technical textiles. Cambridge: Woodhead Publishing, 2000.

IIDA, Itiro; WIERZBICKI, Henri A. J. Ergonomia.2a ed. São Paulo: C.U.C - Comunicação Universidade - Cultura Editora, 1973

KAWABATA, Sueo. The Standardization and Analysis of Hand Evaluation 2nd Edition.2 ${ }^{\text {nd }}$ Edition.Japão: Hand Evalution Standardization Committee, 1980.

LAMBERTS, Roberto. Conforto e Stress térmico.Laboratório de Eficiência Energética em Edificações - Universidade Federal de Santa Catarina, 2011.

LI, Yi; YAO, Bao-guo; HU, Jun-yan; KWOK, Yi-lin; YEUNG, Kwok-wing. An improved test method for characterizing the dynamic liquid moisture transfer in porous polymeric materials. Institute of Textiles and Clothing, The Hong Kong Polytechnic University. Hong Kong, 2006.

MCCULLOUGH, Elizabeth A.; LARRY KENNEY, W. Thermal Insulation and Evaporative Resistance of Football Uniforms. Medicine \& Science in Sports \& Exercise: May 2003 Volume 35 - Issue 5 - pp 832-837

MONTGOMERY, Douglas.C.;Introduction to statistical quality control. New Jersey: John Wiley\& Sons, Inc., 2009.

MOURA, Louisi Francis. Verificação da existência de imprecisões nos valores do índice de isolamento térmico de vestimenta da norma ISO 9920:2007. 2012. Dissertação (Mestrado em Engenharia de Produção) - Universidade Tecnológica Federal do Paraná. Ponta Grossa, 2012.

NAZIA, Nawaz; TROYNIKOV, Olga; WATSON, Chris.Evaluation of Surface Characteristics of Fabrics Suitable for Skin Layer of Firefighters' Protective Clothing.International conference on Physics Science and Technology 2011.School of Fashion and Textiles, RMIT University, Melborne, 2011.

OGLAKCIOGLU, Nida; MARMARALI, Arzu.Thermal Comfort properties of cotton knitted fabrics in dry and wet states. EgeUniversity. Turquia, 2010.

PEREIRA, Maria Adelina. Manual de Têxteis TécnicosClassificação, Identificação e Aplicações. 2a Edição. São Paulo, 2005.

PINTO, Norma de Melo. Condições e parâmetros para a determinação de conforto térmico em ambientes industriais do ramo metal mecânico. 2011. Dissertação (Mestrado em Engenharia de Produção) - Universidade Tecnológica Federal do Paraná. Ponta Grossa, 2011. 
RAVANDI, S. A. Hosseini; VALIZADEH, M. Properties of fibers and fabrics that contribute to human comfort. In: Guowen, S. Improving Comfort in Clothing. Cambridge: Woodhead Publishing, 2011.

RODRIGUES, Maria Isabel; A. F. IEMMA. Planejamento de Experimentos e Otimização de Processos. 2a Edição. São Paulo: Editora Cárita, 2009

RUAS, Álvaro César. Conforto Térmico nos Ambientes de Trabalho. FUNDACENTRO: São Paulo, 1999.

Avaliação de conforto térmico, contribuição à aplicação prática das normas internacionais. 2001. Dissertação (Mestrado em Engenharia Civil) - Faculdade de Engenharia Civil, Universidade Estadual de Campinas. São Paulo, 2001.

SANCHES, Regina Aparecida. Procedimento para o desenvolvimento de Tecidos de Malha a partir de Planejamento de Experimentos. 2006. Tese (Doutorado em Engenharia mecânica). Faculdade de Engenharia Mecânica, Universidade Estadual de Campinas. São Paulo, 2006.

SHAKIR, Abdul Khaliq. Thermal Comfort Modelling of an Open Space.Thesis (MSc Energy Sistems\& the Environment) - Faculty of Engineering, University of Strathclyde Glasgow, UK, 2001.

SILVA, Robert Guimarães; FALQUETTO, Fernando; JÚNIOR, Antonio da Silva M.; CUNHA, Carlos Elpídio Lago; Identificação de riscos do posto de trabalho do forneiro em uma indústria cerâmica de Imperatriz/MA. Revista Ingepro, vol 02, $\mathrm{n}^{\circ} 02$.

TASHKANDI, Salwa; FERGUSSON, Stanley. M.; WANG, Lijing; KANESALINGAM, Sinnappoo. Thermal Comfort Properties of Wool and Polyester/Wool Woven Fabrics Dyed in Black.Journal of Fiber Bioengineering and Informatics, vol. 6, no. 3, pp. 265-275. RMIT University, Melborne, 2013.

TRIOLA, Mario F.; Introdução à estatística. 10ª Edição. Rio de Janeiro: Editora LTC, 2008.

TROYNIKOV, Olga; ASHAYERI Elnaz.Thermoregulatory evalution of triathlon suits in regards to their physiological comfort properties. 5th Asia-Pacific Congress on Sports Technology (APCST).School of Fashion and Textiles, RMIT University, Melborne, 2011.

UNE-EN 12127:1998. Textêis. Tecidos. Determinação da massa por unidade de superfície de pequenas amostras.

VALENTIN, Cristina S.; CARVALHO, Adriana T.; ALBUQUERQUE, Sandra M. Têxteis técnicos na proteção pessoal contra o fogo. São Paulo, Escola de Artes, Ciência e Humanidades da USP, 2011.

XAVIER, Antonio Augusto de Paula. Predição de conforto térmico em ambientes internos com atividades sedentárias - teoria física aliada a estudos de campo. 2000. Tese (Doutorado em Engenharia de Produção) - Universidade Federal de Santa Catarina, Florianópolis, 2000. 
WARDININGSIH, Wiah; TROYNIKOV, Olga; NAWAZ, Nazia; WATSON, Chris. Influence of wearing impact protective garment on thermophysiological comfort of the wearer. The 2014 conference of the International Sports Engineering Association.RMIT University, Melborne.

\section{SITES INSTITUCIONAIS}

ASHARE. Standard 55. Disponível em https://www.ashrae.org/resources-publications/bookstore/standard-55. Acesso em 20/9/2014.

ISO InternationalOrganizationStandardization. Disponível em www.iso.org. Acesso em 20/9/2014

ABNT Associação Brasileira de Normas Técnicas. ABNT Catálogo. Disponível em http://www.abntcatalogo.com.br. Acesso em 20/9/2014

IPT Instituto de Pesquisas Tecnológicas. Disponível em http://www.ipt.br/solucoes/120caracterizacao_e_desempenho_de_texteis_tecnicos.htm. Acesso em 12/4/2015 


\section{ANEXO A - Tipos de tecidos}

1) Tecido impermeável:

- Muito lenta absorção;

- Lenta propagação;

- Sem transporte unidirecional, nem penetração.

2) Tecido repelente à água:

- Sem molhado;

- Sem absorção;

- Sem propagação;

- Pobre transporte unidirecional sem forças externas.

3) Tecido com lenta absorção e lenta secagem:

- Lenta absorção;

- Lenta propagação;

- Pobre transporte unidirecional.

4) Tecido com rápida absorção e lenta secagem:

- De médio a rápido molhado;

- De média a rápida absorção;

- Pequena área de propagação;

- Lenta propagação;

- Pobre transporte unidirecional.

5) Tecido com rápida absorção e rápida secagem:

- De médio a rápido molhado;

- De média a rápida absorção;

- Grande área de propagação;

- Rápida propagação;

- Pobre transporte unidirecional.

6) Tecido com penetração de água:

- Pequena área de propagação;

- Excelente transporte unidirecional.

7) Tecido com transporte de umidade:

- De médio a rápido molhado; 
- De média a rápida absorção;

- Grande área de propagação na face externa do tecido;

- Rápida propagação na face externa do tecido;

- De bom a excelente transporte unidirecional. 